\title{
Predicting the performance characteristics of assembled rollover protective structure designs for tractors
}

James R. Harris

West Virginia University

Follow this and additional works at: https://researchrepository.wvu.edu/etd

\section{Recommended Citation}

Harris, James R., "Predicting the performance characteristics of assembled rollover protective structure designs for tractors" (2008). Graduate Theses, Dissertations, and Problem Reports. 2838.

https://researchrepository.wvu.edu/etd/2838

This Dissertation is protected by copyright and/or related rights. It has been brought to you by the The Research Repository @ WVU with permission from the rights-holder(s). You are free to use this Dissertation in any way that is permitted by the copyright and related rights legislation that applies to your use. For other uses you must obtain permission from the rights-holder(s) directly, unless additional rights are indicated by a Creative Commons license in the record and/ or on the work itself. This Dissertation has been accepted for inclusion in WVU Graduate Theses, Dissertations, and Problem Reports collection by an authorized administrator of The Research Repository @ WVU.

For more information, please contact researchrepository@mail.wvu.edu. 


\title{
PREDICTING THE PERFORMANCE CHARACTERISTICS OF ASSEMBLED ROLLOVER PROTECTIVE STRUCTURE DESIGNS FOR TRACTORS
}

\author{
by \\ James R. Harris, P.E. \\ Dissertation submitted to \\ College of Engineering and Mineral Resources \\ at West Virginia University \\ in partial fulfillment of the requirements \\ for the degree of \\ Doctor of Philosophy \\ In \\ Occupational Safety and Health
}

Committee:

Gary Winn, Ph.D., Committee Chair

Paul Ayers, Ph.D.

Bhaskaran Gopalakrishnan, Ph.D.

Wafik Iskander, Ph.D.

Ken Means, Ph.D.

Department of Industrial and Management Systems Engineering

Morgantown, West Virginia

2008

Keywords: ROPS, rollbar, tractor overturn, tractor rollover 


\title{
Abstract \\ PREDICTING THE PERFORMANCE CHARACTERISTICS OF ASSEMBLED ROLLOVER PROTECTIVE STRUCTURE DESIGNS FOR TRACTORS
}

\author{
James R. Harris, P.E.
}

Tractor overturn fatalities are the single leading cause of agricultural fatalities in the United States. Approximately 100 people die each year as the result of a tractor overturn. Effective engineering controls to mitigate injury and prevent death from tractor overturns are available in the form of rollover protective structures (ROPS) and seatbelts. However, approximately $50 \%$ of all tractors in the United States are without ROPS. Cost of ROPS is frequently cited as a reason why tractor owners do not have ROPS installed. Cost-effective ROPS (CROPS) have been developed with the intent to lower the cost of retro-fitting a tractor with ROPS. Cost reductions were achieved by using common structural components (e.g. fasteners, tubing, plate) and eliminating welding from the CROPS assembly process. A CROPS design was developed and fabricated for a Ford-3000 tractor. Experimental data demonstrates that the Ford-3000 CROPS prototype successfully completed static testing according to consensus standard SAE J2194. A finite element analysis (FEA) model was developed for the Ford-3000 CROPS prototype based upon SAE J2194 experimental data. The model predicted longitudinal load at energy criterion within $10 \%$ and transverse load at energy criterion within 5\%. At the longitudinal loading simulation end point, energy absorbed in the simulation differed from experimental energy absorbed by $2 \%$. For transverse loading this value was $9 \%$. Probabilistic design techniques were utilized with the model to evaluate the effect of expected variation in Ford-3000 CROPS geometric and material properties on standard testing performance. Simulations were conducted for both SAE J2194 and OSHA 1928.52 ROPS test requirements. FEA screening tests were performed to identify statistically significant input variables. A central composite design (CCD) of experiments was used to build response surfaces for output variables of interest. Ten-thousand Monte Carlo simulations were performed using the response surfaces generated. Scenarios were predicted where the CROPS Ford-3000 prototype would fail SAE J2194 static testing. However, no scenarios were predicted where the Ford-3000 CROPS prototype failed OSHA 1928.52 static testing requirements. The techniques presented in this research could facilitate development of future CROPS designs by identifying poor design choices before timely and costly prototype testing is conducted. 
I dedicate this work to my beautiful family--- Aimee, Cassidy, Alexa, and Dylan. Thank you for your unconditional love and dedication. You make it all worthwhile... 


\section{Acknowledgments}

I would like to start by thanking my family for their encouragement, support, patience, and understanding during my Ph.D. program. A special thank you is extended to my wife who assumed more than her fair share of the family work load during my training. Without her, this would not have been possible. I also want to thank my mother, Ellen, who long ago taught me the value of hard work, sacrifice, and perseverance.

Next, I would like to thank the Centers for Disease Control and Prevention (CDC) and the National Institute for Occupational Safety and Health (NIOSH) for their generous support of my training program. I would also like to especially acknowledge Captain Jim Spahr, Dr. Al Amendola, Dr. Hongwei Hsiao, Mr. Tim Pizatella, and Dr. Nancy Stout for help and support in preparation of my training proposal. I am truly grateful for their continued backing throughout my training program.

I wish to thank the unsung heroes of the laboratory who helped in experimental preparation or data collection for this research. Mr. Doug Cantis, Dr. Tony McKenzie, and Mr. John Powers were an invaluable part of this research effort. In addition, Mrs. Darlene Weaver assisted in preparation of several figures for this document.

Finally, I am very appreciative of the expertise provided by the committee, Dr. Paul Ayers, Dr. Bhaskaran Gopalakrishnan, Dr. Wafik Iskander, and Dr. Ken Means. A special note of appreciation goes to the chair of this committee, Dr. Gary Winn, for guiding me through the Ph.D. process and for motivating me to pursue graduate work in occupational safety and health. 


\section{Table of Contents}

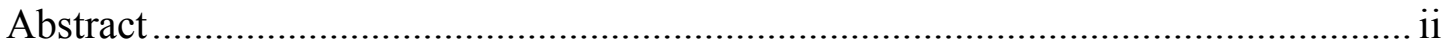

Acknowledgments.......................................................................................... iv

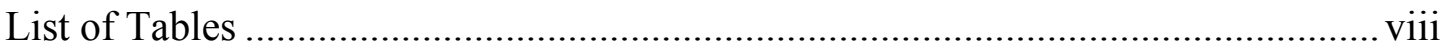

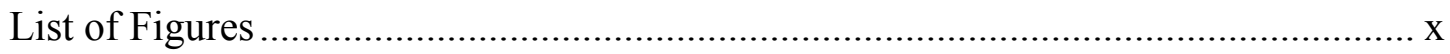

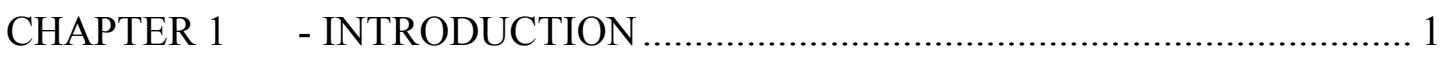

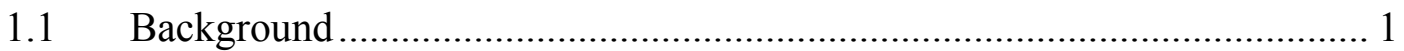

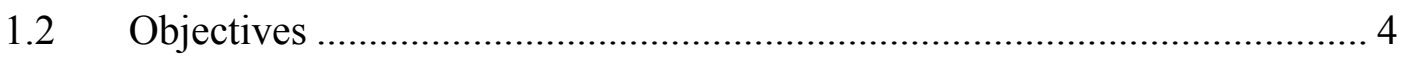

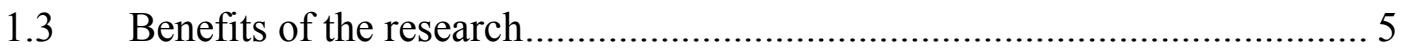

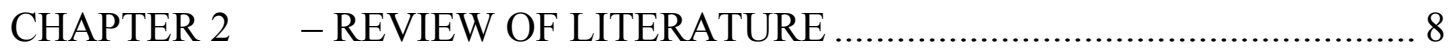

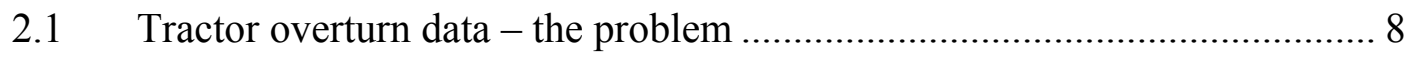

2.2 Rollover protective structure (ROPS) and standards development .............. 9

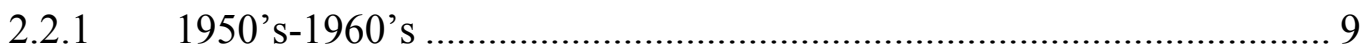

2.2.2 1970's and 1980's

2.2.3 Recent developments .................................................................... 18

2.3 Structural performance of ROPS and simulation techniques ..................... 19

2.4 Probabilistic/statistical design of safety controls....................................... 29

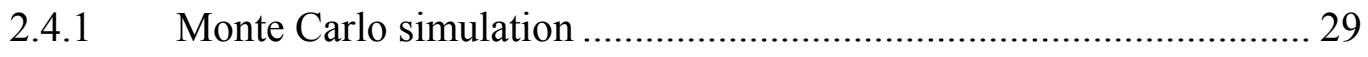

2.4.2 Response Surface Method............................................................. 29

2.4.3 Application of probabilistic methods ……………………………..... 30

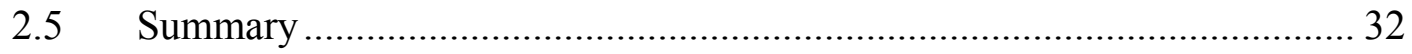

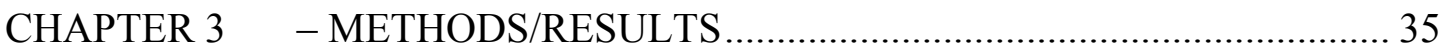




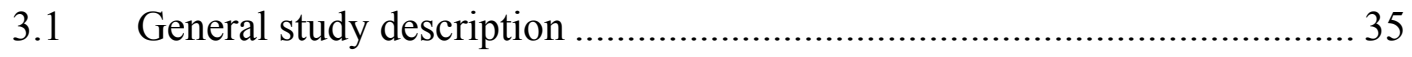

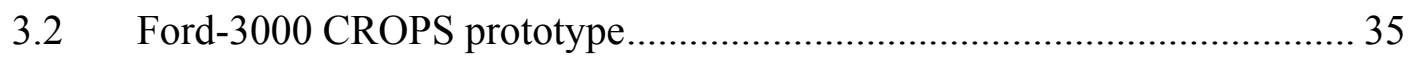

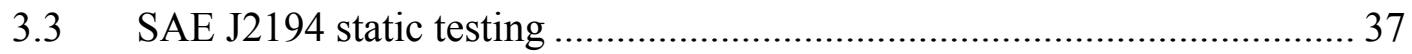

3.3.1 Experimental equipment .................................................................... 37

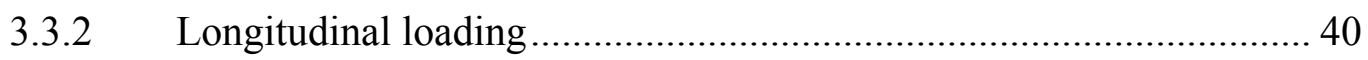

3.3.3 First vertical crush test .................................................................. 42

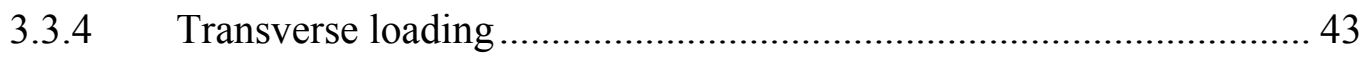

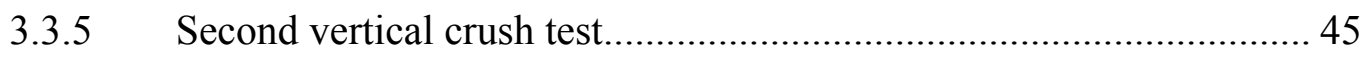

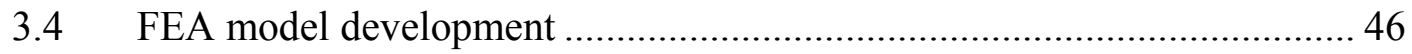

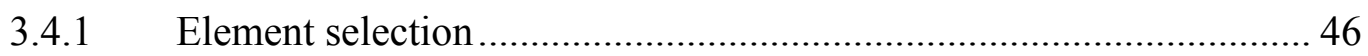

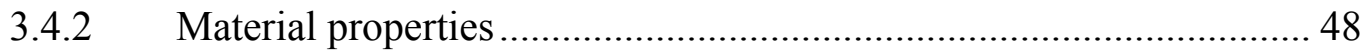

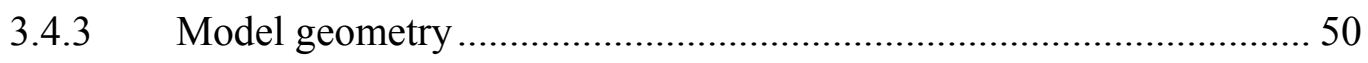

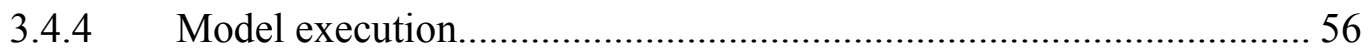

3.4.5 Evaluation of structural failure, exposure, and intrusion .....................5 57

3.5 Comparison of SAE J2194 and FEA simulation results ................................ 64

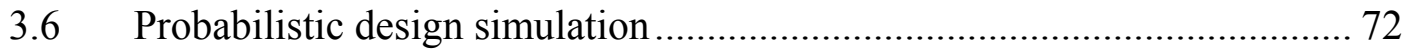

3.6.1 Input variables, response variables, and probabilistic distribution ..... 72

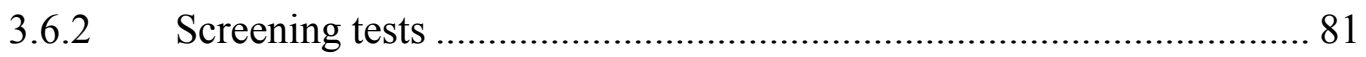

3.6.3 Development and evaluation of response surfaces ............................. 88

3.6.4 Monte Carlo simulations and reliability prediction …………............. 95

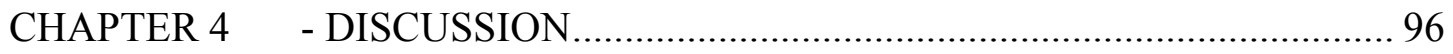

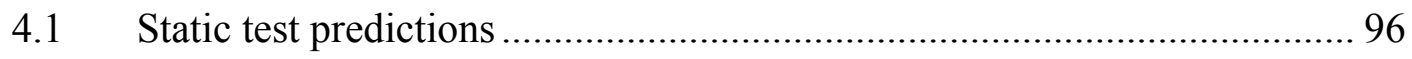

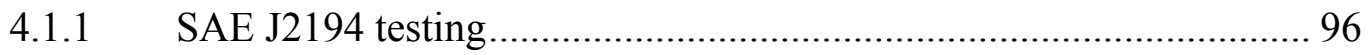




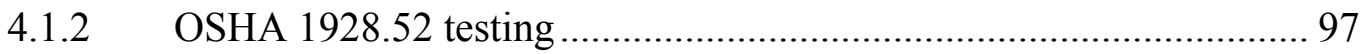

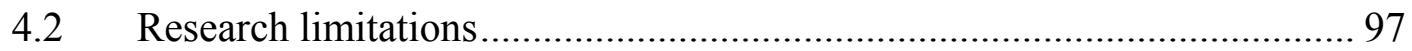

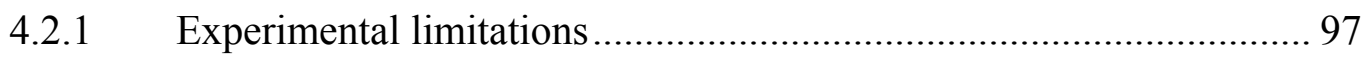

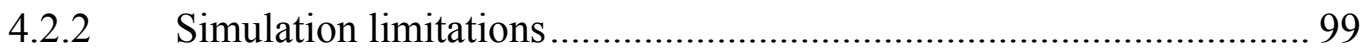

4.3 Implications for SAE and OSHA ROPS testing ................................ 103

CHAPTER 5 - CONCLUSIONS AND RECOMMENDATIONS ................... 105

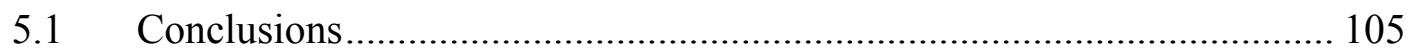

5.2 Recommendations for future work ................................................ 108

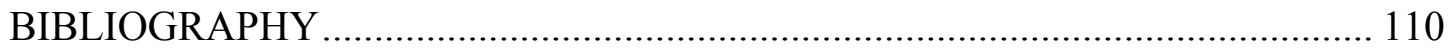

APPENDIX A: Ford-3000 Prototype Drawings............................................. 115

APPENDIX B: Sample FEA (ANSYS) Input Files ........................................... 127

APPENDIX C: Regression Analysis Details for DT Response Surface .................. 147

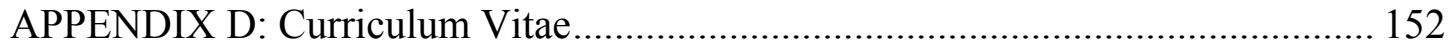




\section{List of Tables}

Table 2-1 Ayers and Liu ROPS design margin data.................................................. 26

Table 3-1 Nebraska Tractor Test \#883 front and rear wheel weight distribution....... 40

Table 3-2 Summary of SAE J2194 test criteria......................................................... 46

Table 3-3 Force vs. deflection data for Ford-3000 longitudinal SAE J2194 test. ...... 66

Table 3-4 Energy vs. deflection data for Ford-3000 longitudinal SAE J2194 test..... 68

Table 3-5 Force vs. deflection data for Ford-3000 transverse SAE J2194 test. ......... 69

Table 3-6 Energy vs. deflection data for Ford-3000 transverse SAE J2194 test........ 70

Table 3-7 COMBIN7 element stiffness values........................................................ 71

Table 3-8 Steel properties of CROPS beam materials............................................... 78

Table 3-9 ASTM A 500 beam steel tangent modulus values. ..................................... 79

Table 3-10 Truncated Gaussian distribution parameters for FEA code. ..................... 80

Table 3-11 CROPS parameter values for simulation failure..................................... 81

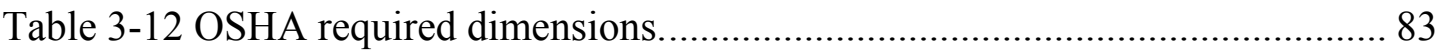

Table 3-13 Sensitivity for random input variables with respect to transverse load.... 85

Table 3-14 Sensitivity of random input variables with respect to DT......................... 86

Table 3-15 Sensitivity of random input variables with respect to ET. ........................ 86

Table 3-16 Sensitivity of random input variables with respect to RFZ...................... 87

Table 3-17 Sensitivity of random input variables with respect to M........................... 87

Table 3-18 Sensitivity of random input variables with respect to F............................ 87

Table 3-19 Sensitivity of random input variables with respect to E........................... 88

Table 3-20 Regression coefficients for response surface to predict variable DT....... 92

Table 3-21 Response surface predictions for DT variable at CCD sample points. .... 92 
Table 3-22 Regression coefficients for response surface to predict variable ET. ...... 94

Table 3-23 Response surface predictions for ET variable at CCD sample points...... 94

Table 4-1 CROPS parameter values for failed SAE J2194 simulation loop. ............. 96

Table 4-2 Actuator calibration data for force transducer..................................... 98

Table 4-3 Actuator calibration data for LVDT. .................................................. 98

Table 4-4 Minimum V-notch impact strengths (see ASTM A 370) ........................ 101

Table 4-5 Charpy test results for sample ASTM A 500 CROPS material................ 101 


\section{List of Figures}

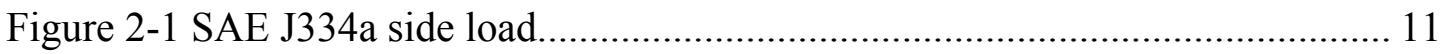

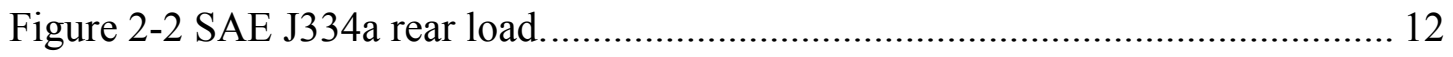

Figure 2-3 Modified load-deflection curve for SAE J334a.................................. 12

Figure 2-4 SAE J1194 clearance zone (side view).............................................. 16

Figure 2-5 SAE J1194 clearance zone (front view) ............................................ 16

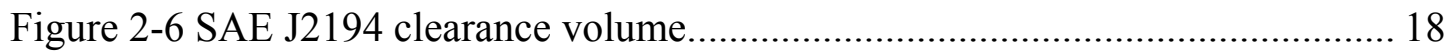

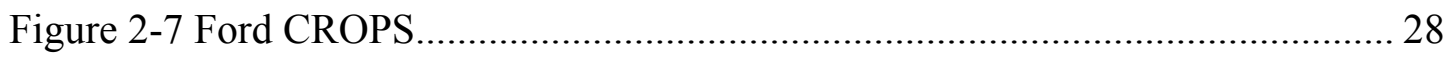

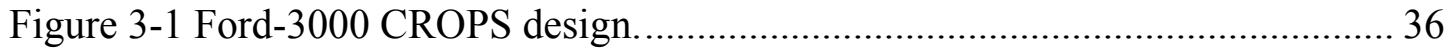

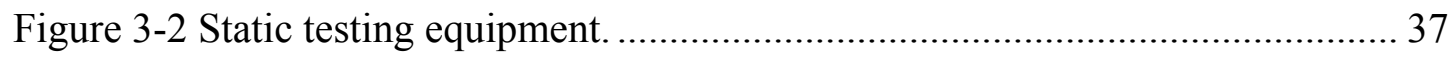

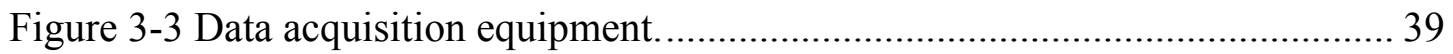

Figure 3-4 SAE J2194 longitudinal loading of Ford-3000 CROPS. ......................... 42

Figure 3-5 SAE J2194 vertical crush loading of Ford-3000 CROPS. ....................... 43

Figure 3-6 SAE J2194 transverse loading of Ford-3000 CROPS.............................. 44

Figure 3-7 Assessing exposure criterion during transverse loading........................ 45

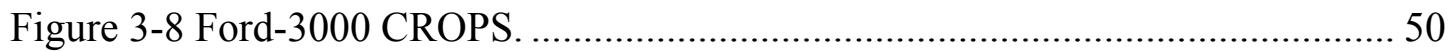

Figure 3-9 Ford-3000 FEA model. .................................................................. 51

Figure 3-10 Bolted connection for upright to axle housing bracket during testing.... 52

Figure 3-11 Cantilever beam under two point loads........................................... 54

Figure 3-12 Intrusion planes for simulation of SAE J2194 longitudinal load............ 58

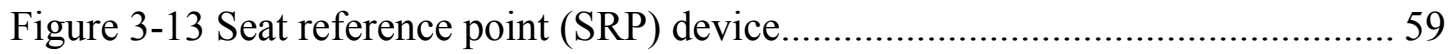

Figure 3-14 Mathematical determination of longitudinal load ground plane............ 60

Figure 3-15 Mathematical determination of transverse load ground plane. .............. 62 


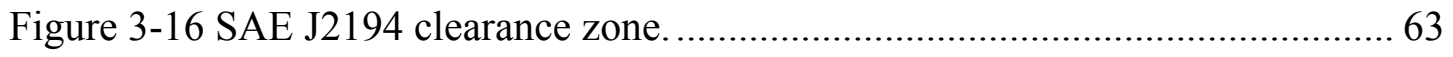

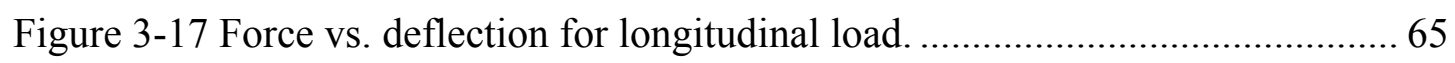

Figure 3-18 Energy vs. deflection for longitudinal load.................................... 67

Figure 3-19 Force vs. deflection for transverse load. .......................................... 69

Figure 3-20 Energy vs. deflection for transverse load...................................... 70

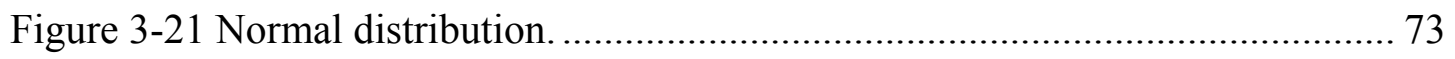

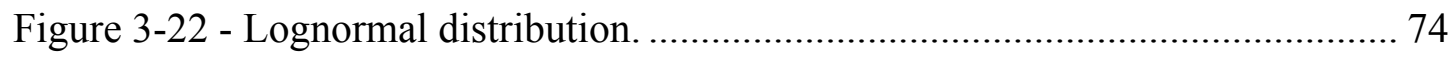

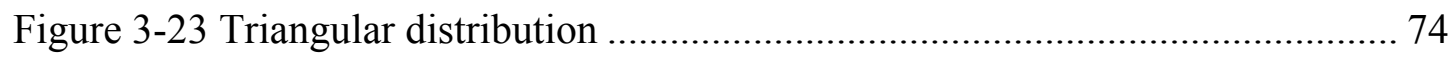

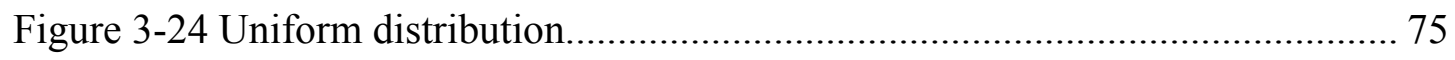

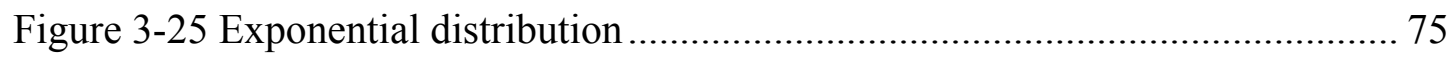

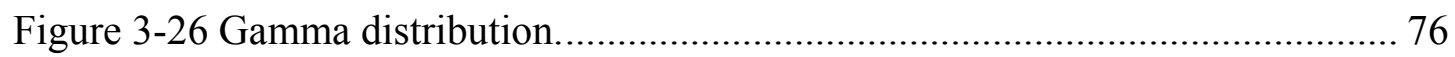

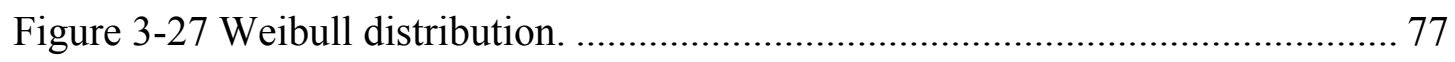

Figure 3-28 Critical dimensions for OSHA 1928.52 transverse load....................... 83

Figure 3-29 Critical dimensions for OSHA 1928.52 longitudinal load..................... 83

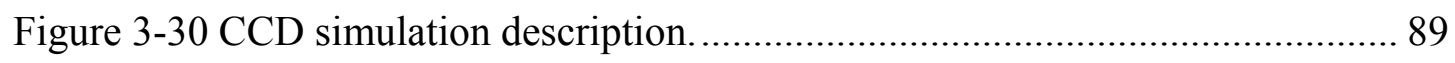

Figure 3-31 Distance from longitudinal centerline (DT) when meeting transverse energy criterion during 10,000 Monte Carlo simulations..................................... 95 


\section{CHAPTER 1 - INTRODUCTION}

\subsection{Background}

The agriculture/forestry/fishing/hunting $(\mathrm{A} / \mathrm{F} / \mathrm{F} / \mathrm{H})$ industry sector continues to be one of riskiest industries based upon fatality rates. In 2003, the $\mathrm{A} / \mathrm{F} / \mathrm{F} / \mathrm{H}$ industry sector had the highest rate of fatal occupational injuries in the United States (US Department of Labor, 2003). Many of the deaths within the $\mathrm{A} / \mathrm{F} / \mathrm{F} / \mathrm{H}$ sector are specifically tied to agriculture; many agriculture occupational fatalities involve tractors and tractor overturns. Data for agricultural production from 1992-1998 show the largest source of identifiable fatal injury was the tractor (Hard, Myers, and Gerberich, 2002). When these same data are evaluated by injury event, over $1 / 4$ of all agricultural production deaths $(1,051)$ were attributed to "overturning vehicle/machine" for the time period 1992-1998.

A highly effective engineering control already exits to prevent almost all fatalities due to tractor overturn, the rollover protective structure (ROPS) and a seatbelt. In fact it has been cited that ROPS, when properly used with a seatbelt, typically prevent fatal injury in $99 \%$ of overturns (Hallman, 2005). ROPS systems have been commercially available for several decades now in the U.S., but this intervention has not saturated the tractor fleet. In 2001, ROPS usage in the United States was estimated at 50\% (Myers, 2003). This implies that an estimated 2.32 million tractors were without ROPS in 2001 (Myers). Attempts to understand why this safety control has not been 
universally applied within the U.S. have followed the 3 E's of safety engineering and loss control: (1) engineering, (2) enforcement, and (3) education.

Engineering efforts to prevent deaths due to tractor overturns initially concentrated on protecting a volume around the driver through design of rollbars. Much of the initial rollbar work was conducted in Sweden (Springfeldt, Thorson, and Lee, 1998). Once a concept was developed for protecting the tractor operator, research effort shifted to performance standardization through testing of these rollbars or ROPS. Voluntary consensus groups such as the American Society of Agricultural Engineers (ASAE) and the Society of Automotive Engineers (SAE) became involved. Much effort was spent in understanding how ROPS material responds to testing and what the dimensions should be for the protective volume which surrounds the driver.

ROPS enforcement activities in the United States are based upon Occupational Safety and Health Administration (OSHA) regulations. OSHA requirements have largely followed consensus standards and have incorporated ASAE and/or SAE standards by reference. Enforcement activities within the U.S. have been somewhat limited due to appropriations restrictions placed each year by Congress on OSHA enforcement activities. In effect, OSHA is prohibited from spending money to inspect farms with 10 or fewer employees (OSHA, 2006). The vast majority of farms in the U.S. fall into this category. In 1997, only 9\% of farms had 10 or more employees (U.S. Department of Agriculture, 1997). By voluntary agreement of the tractor manufacturing industry, all tractors manufactured since 1986 come equipped with ROPS (with very few 
exceptions) and this has helped increase the percentage of tractors in the U.S. with ROPS (Myers, 2003). Some other countries have established a strict and severe citation scheme for those operating tractors without ROPS. An Australian researcher has cited citations as high as $\$ 50,000$ (Day, 2003).

The safety community and other concerned entities have employed a variety of educational/incentive techniques to increase ROPS usage in the U.S. In 1985, a voluntary agreement among tractor manufacturers provided ROPS and safety belts for nearly all new tractors sold in the U.S (Center for Disease Control and Prevention [CDC], 1993). In 1991, the Surgeon General of the United States convened a conference specifically looking at agricultural safety (NIOSH, 1992). A consequence of the increased attention to agricultural safety and health within NIOSH was the formation of ten agricultural research centers spread throughout the country. A follow-up conference, the Tractor Risk Abatement Conference (TRAC), was held in 1997. Many of the same issues identified at the 1992 conference appeared once more at TRAC (Donham et al., 1997). Some of the NIOSH Agricultural Centers have evaluated incentive plans in an attempt to improve ROPS usage (Kelsey, May, and Jenkins, 1996; Struttmann, Brandt, Morgan, Piercy, and Cole, 2001).

Recently, NIOSH has investigated other engineering means for increasing ROPS usage. Researchers developed an automatically deploying ROPS system, AutoROPS, that remains in a retracted position until an overturn condition is sensed (Powers et al., 2001). When an overturn condition is identified, the ROPS deploys to full 
functional height. The intervention is targeted at new tractor sales as an alternative to passive foldable ROPS. Other NIOSH engineering research has examined the technical feasibility of cost-effective ROPS (CROPS). CROPS are designed as a retro-fit option for tractors already in operation which do not currently have ROPS installed (Harris, McKenzie, Etherton, and Cantis, 2002). The intent behind the CROPS research is to lower ROPS retro-fit costs by developing designs that utilize standard components (e.g. tubing, plating) which can be easily assembled.

In 2004, the NIOSH Agricultural Safety and Health Centers with other interested safety professionals and manufacturers compiled the National Agricultural Tractor Safety Initiative. The effort seeks to mitigate injury and death attributed to tractors and particularly calls attention to the issue of tractor overturns. This document calls for “...effective, acceptable, and low-cost ROPS and ROPS-mounting techniques for older tractors" (Pacific Northwest Agricultural Safety and Health Center, 2004).

\subsection{Objectives}

The agricultural safety and health community is calling for additional CROPS research. No large body of data yet exists from field experience or manufacturer prototype development and/or quality assurance procedures to fully understand the performance characteristics of CROPS designs. Performance characteristics are not well known over the operating ranges of the CROPS components. Materials used in CROPS designs to date have been specified according to applicable ANSI and/or ASTM standards. Many of these designs have been tested also. However, these test 
results often represent a single data point for a single combination of parameters thought to influence CROPS performance such as component tensile strength, modulus of elasticity, percent elongation at failure, and component fastening torque values. This research seeks to evaluate the interaction between these parameters and the influence this has on ROPS performance as measured by consensus or regulatory performance standards.

Specifically finite element analysis (FEA) and statistical treatment of the important parameters mentioned previously will be used to characterize the relative influence of each parameter. As future CROPS designs are developed, the data collected from the FEA modeling tool will assist designers in picking appropriate components and assembly techniques such that ROPS performance is acceptable over the range of parameter specifications. Predicted ROPS performance will be evaluated against the 2005-2006 OSHA 29CFR1928.52 ROPS regulatory revision as well as SAE standards.

\subsection{Benefits of the research}

Occupational tractor overturns continue to kill over 100 people annually in the U.S. ROPS are a proven engineering control, but are only found on approximately $50 \%$ of all U.S. tractors (Myers, 2003). Cost of ROPS is often given as a reason for not having ROPS installed on a tractor. The National Institute for Occupational Safety and Health (NIOSH) has been researching the engineering feasibility of developing CROPS designs based on off-the-shelf components and easy assembly/fastening 
techniques. CROPS prototypes have been tested for several different tractor models, but with limited replication of each experiment due to cost and time involved. Using statistical treatment of FEA techniques, this research will evaluate CROPS prototype performance over a range of possible parameter values.

A thorough examination on the relative influence of each CROPS component will aid designers in determining appropriate component specifications. By replicating standard test sequences on the CROPS designs through FEA, it can be determined whether current specifications are appropriate or whether CROPS design modifications are necessary to ensure satisfactory performance over a range of values. This research is a part of a process that can lead to well-engineered CROPS that could be attractive retro-fit options for the millions of tractors that currently have no ROPS. It is hoped that this research will build confidence in the performance of CROPS options. Proper application of CROPS designs could reduce the high number of annual fatalities due to tractor overturn.

The specific potential benefits of this research include the following:

- $\quad$ This study will develop FEA modeling techniques for effective application of probabilistic design to rollbar design evaluation.

- Experimental techniques for application of standard ROPS performance test sequences will be refined through this study.

- $\quad$ This research will allow comparison of simulated ROPS performance results under the SAE J2194 and OSHA testing schemes. 
- For a given CROPS design, this research will quantify the relative safety of the design with regard to standard test procedures. 


\section{CHAPTER 2 - REVIEW OF LITERATURE}

\subsection{Tractor overturn data - the problem}

The National Safety Council may have been one of the first groups in the United States to trigger the alarm on fatalities due to tractor overturn. As cited by MacCollum (1984), the National Safety Council published a "Resolution on Overturn Protection for Farm Tractor Operators" in 1967. In this resolution they cite that more than 500 lives are lost each year due to tractor overturns. A study examining the 1971-1981 time period in the state of Georgia identified 202 tractor-associated deaths (Centers for Disease Control, 1983). Seventy-six percent of the fatalities (153) occurred due to tractor overturn. In 1983, the National Safety Council reported that tractor overturns accounted for approximately 300 deaths in 1982. Etherton et al. (1991) reported a total of 1523 tractor-related fatalities in the National Traumatic Occupational Fatality database for the time period 1980-1985. Fifty-two percent of these deaths (791) were attributed to overturns. This yields an annual average estimate for deaths due to tractor overturn of 132 . This is likely an underestimate of all tractor overturn deaths in the United States since only work-related cases for individuals 16 years of age or older are included. More recent data from the Bureau of Labor Statistics (//data.bls.gov accessed 2/16/07) shows 92 fatalities in 2004 where the primary source of injury was a tractor and the event was an overturn. 


\subsection{Rollover protective structure (ROPS) and standards development}

\subsubsection{0's-1960’s}

In 1951, overhead canopies on crawlers, tractors, and bulldozers were first seen in California. At almost the same time, work was being conducted on protective structure test sequences in Sweden culminating in 1954 with successful pendulum impact tests (Ross and DiMartino, 1982). In 1956 a "driver safety frame" was developed at the University of California's Agricultural Extension Service at Davis (MacCollum, 1984).

According to MacCollum, the North Pacific Division of the U.S. Army Corps of Engineers led early ROPS standards efforts in the U.S. with a 1958 design requirement for protective tractor canopies used in heavy construction. Requirements applied to all tractors owned by either the government or contractors and used in the Division. The guiding principle of this early standard was that the canopy should resist loadings equivalent to twice the weight of the machine from lateral and vertical impact. To simplify compliance inspection of equipment, the standard included canopy frame fabrication specifications. For example, all equipment of gross weight (including attachment without canopy) $<28,000 \mathrm{lbs}$. was to be constructed of $2 \frac{1}{2} \mathrm{in}$. diameter pipe meeting ASA (American Standards Association) schedule 80; equivalently performing constructions were also allowed.

In the 1960's, committees within the SAE and the American Society of Agricultural Engineers (ASAE) were assigned the task of developing industry ROPS standards. As 
a result, SAE released the standard SAE J334, "Protective Frame Test Procedures and Performance Requirements”, in 1968. ASAE produced two consistent standards, “Operator Protection for Wheeled-Type Agricultural Tractors” (S305) and "Protective Frame for Agricultural Tractors-Test Procedures and Performance Requirements" (S306).

\subsubsection{0's and 1980's}

In the beginning, the Occupational Safety and Health Administration (OSHA) relied upon consensus standards which had already been developed for its regulatory development. In 1974, the Federal Register published the rules and regulations for 29 CFR 1926.1002 "Protective frame (ROPS) test procedures and performance requirements for wheel-type agricultural and industrial tractors used in construction" (U.S. Government Printing Office [G.P.O.], 1974). The source for this standard was SAE J334a (July 1970).

SAE J334a - Protective Frame Test Procedures and Performance Requirements This consensus standard applies to "agricultural tractors" that are defined as "wheeltype vehicle of more than 20 engine horsepower designed to furnish the power to pull, carry, propel, or drive implements that are designed for agricultural usage". Protective frame performance can be measured through either a lab test or field test. If a lab test is conducted, either static or dynamic testing can be performed. If a field test is conducted, then both rearward and sideways overturns are required. Protective frame materials must also meet special low temperature impact strength requirements. 
The tractor weight to be tested must be the greatest weight for which the protective frame is to be used. Vehicle weight includes the protective frame, fuels, and all normal use components. Add ballast if necessary to achieve minimum total weight of 130 lb. (59 kg) per maximum power takeoff (PTO) horsepower at rated engine speed. The front end of the tractor must weigh at least $33 \mathrm{lb}$. (15 kg) per maximum PTO horsepower. If PTO horsepower is not known, then 95\% net engine flywheel horsepower will be used.

For the static testing sequence, the mounting base must include the tractor chassis to which the protective frame is attached. A side load and rear load are performed as indicated in Figures 2-1 and 2-2.

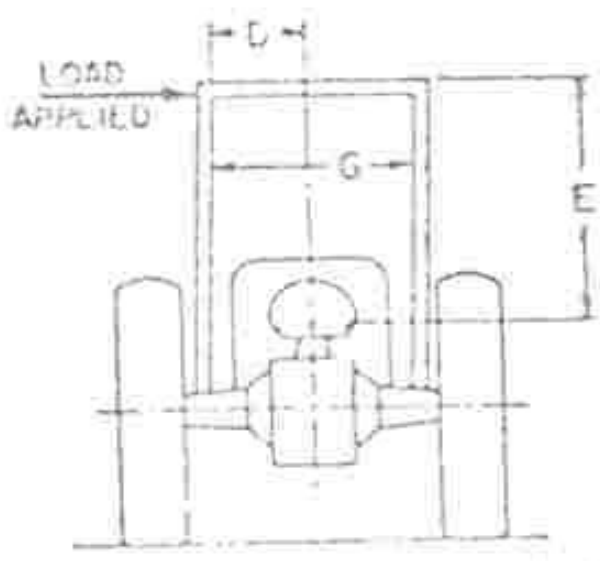

Figure 2-1 SAE J334a side load. 


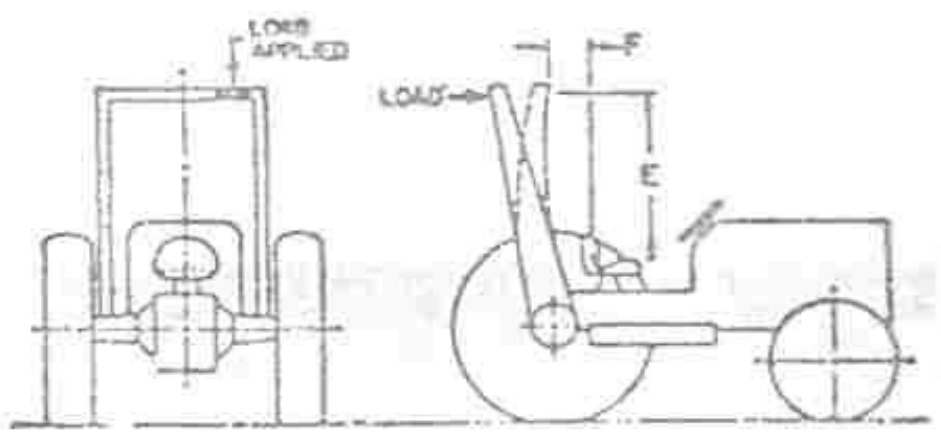

Figure 2-2 SAE J334a rear load.

A load-deflection curve (L-D) and a modified load-deflection curve $\left(\mathrm{L}_{\mathrm{m}}-\mathrm{D}_{\mathrm{m}}\right)$ are constructed as shown in Figure 2-3.

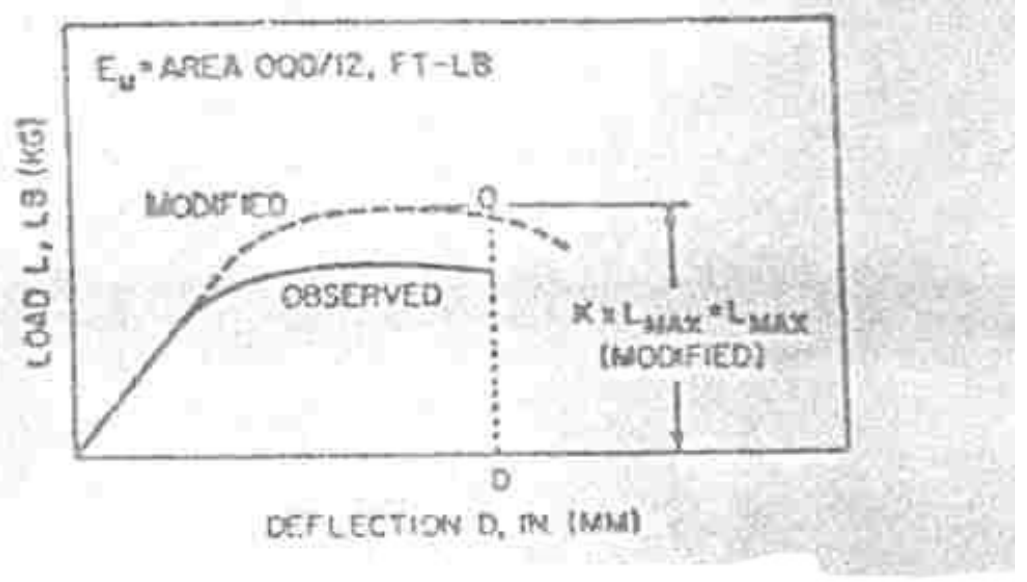

Figure 2-3 Modified load-deflection curve for SAE J334a.

The $\mathrm{L}_{\mathrm{m}}-\mathrm{D}_{\mathrm{m}}$ curve is necessary to account for the increase in strength due to an increase in strain rate. To accomplish this, $\mathrm{L}$ in the plastic range is raised to $\mathrm{L} x \mathrm{~K}$, 
where $\mathrm{K}$ is the increase in yield strength induced by a higher rate of loading. As an example, the standard lists $\mathrm{K}=1.3$ for hot-rolled, low carbon steel (1010-1030).

The side and rear load tests are terminated when any of the following conditions are met: (1) The strain energy absorbed by the frame $\left(E_{a}\right)$ is equal to the required input energy $\left(E_{\text {is }}\right.$ or $\left.E_{\text {ir }}\right),(2)$ Deflection of the frame exceeds the allowable deflection, or (3) The frame load limit occurs before the allowable deflection is reached in the side load. The following definitions apply:

$$
\begin{aligned}
& E_{a}=\text { the area under the } L_{m}-D_{m} \text { curve [ft.-lb. } \\
& W=\text { tractor weight }[1 \mathrm{~b} .] \\
& E_{i s}=\text { energy input to be absorbed during side loading } \\
& E_{\text {is }}=723+(0.4 \mathrm{~W})[\mathrm{ft} .-1 \mathrm{~b} .] \\
& E_{i r}=\text { energy input to be absorbed during rear loading } \\
& E_{\text {ir }}=0.47 \mathrm{~W}[\mathrm{ft} .-1 \mathrm{~b} .]
\end{aligned}
$$

Allowable deflection of the frame is governed by the following definitions which come from Figure 2-1 and Figure 2-2.

$$
\begin{aligned}
& D \geq 2 \text { in. } \\
& E \geq 30 \text { in. } \\
& F=\text { not less than } 0 \text { or more than } 12 \text { in. } \\
& G \geq 24 \text { in. }
\end{aligned}
$$

The load limit is defined as the point on the L-D curve where observed static load is $0.8 \mathrm{~L}_{\max }$ 
Dynamic laboratory testing involves a swinging pendulum striking the protective frame. Details can be found in SAE J334a, but will not be discussed in depth here since ROPS analysis for this research will concentrate on static test procedures.

SAE J394 - Minimum Performance Criteria for Roll-Over Protective Structure for Rubber-Tired Front End Loaders and Rubber-Tired Dozers Early OSHA regulations allowed other options in addition to the SAE J334(a) requirements. ROPS meeting the requirements of 1926.1001 and 1926.1003 for rubber-tired dozers and rubber-tired loaders were acceptable for wheel-type agricultural tractors. This portion of the OSHA regulations pulls from SAE J394, "Minimum Performance Criteria for Roll-Over Protective Structure for Rubber-Tired Front End Loaders and Rubber-Tired Dozers". The required energy absorption during lateral loading is based upon vehicle weight according to the following equation:

$$
\begin{aligned}
U & =42,000\left(\frac{W}{10,000}\right)^{1.25} \\
U & =\text { absorbed energy [in.-lb.] } \\
W & =\text { weight [lb.] }
\end{aligned}
$$

A minimum load requirement is also applied. The minimum load is the vehicle weight multiplied by a factor given according to the following equation:

$$
\begin{aligned}
& M . F .=0.55\left(\frac{W}{10,000}\right)^{0.22} \\
& M . F .=\text { multiplication factor } \\
& W=\text { weight }[1 \mathrm{~b} .]
\end{aligned}
$$


ASAE S306.3-1974 "Protective Frame for Agricultural Tractors - Test Procedures

and Performance Requirements”

ASAE S306.3 corresponds to the requirements of SAE J334.

ASAE S336.1-1974 "Protective Enclosures for Agricultural Tractors - Test

Procedures and Performance Requirements”

ASAE S336.1 agrees with input energy requirements of SAE J334a. However, both a laboratory test (static or dynamic) and a field upset test are required unless energy absorption indicates compliance of $115 \%$ or more. Load application points differ for protective structures that are integral to the cab enclosure and those that are not. If both the rear and side input energy requirements are met, no crush test is required and vertically protection is assumed equivalent to the tractor weight.

SAE J1194 "Rollover Protective Structures (ROPS) for Wheeled Agricultural Tractors"

Many of the concepts in the SAE J1194 standard are derived from the earlier SAE J334a standard. The side and rear loading energy criteria are identical to those specified in SAE J334a. However, the clearance zone specification is different than the deflection limits of SAE J334a as shown in Figures 2-4 and 2-5. 


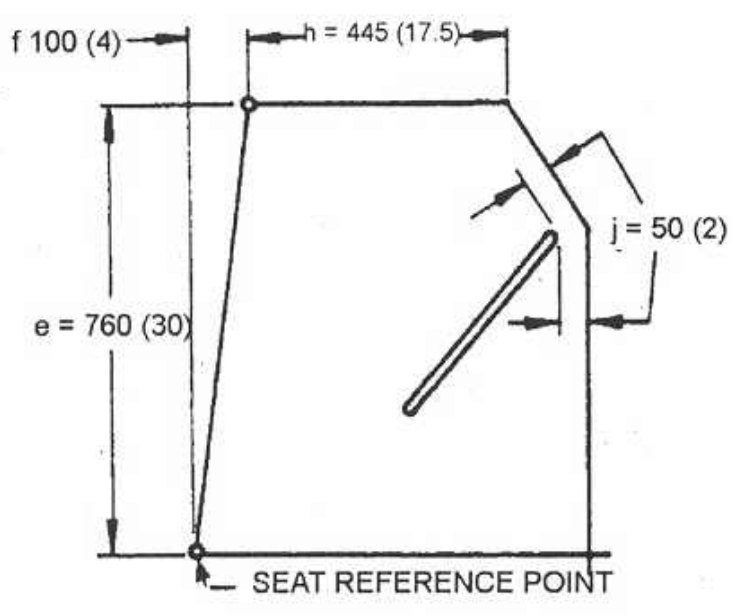

SIDE VIEW OF CLEARANCE ZONE

Figure 2-4 SAE J1194 clearance zone (side view).

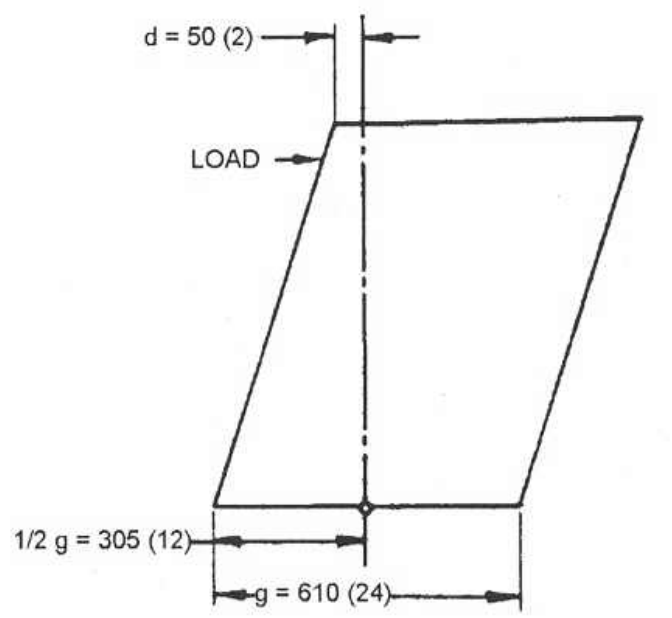

FRONT/REAR VIEW OF CLEARANCE ZONE ALL DIMENSIONS IN mm (in)

Figure 2-5 SAE J1194 clearance zone (front view).

In addition, a vertical crush test is specified. The ROPS must withstand a crush load equivalent to "...1.5 times the gravity force of the tractor mass". No intrusion of the ROPS into the clearance zone is allowed during any of the tests. A field upset test must also be performed unless the rear and side loading tests attain $115 \%$ or more of the energy requirements. 
SAE J2194 "Roll-Over Protective Structures (ROPS) for Wheeled Agricultural Tractors”

Testing performance guidelines are provided for static testing, impact testing, and field upset tests. For ROPS materials meeting certain cold temperature requirements (Charpy impact testing of standard ASTM A 370-76), static testing alone will suffice. Typically, (if $50 \%$ or more of the tractor mass is on the rear axle) the test is conducted as a series of four tests. The same ROPS structure is used throughout the testing sequence. The order is (1) rear longitudinal, (2) rear crush, (3) side transverse, and (4) front crush. The horizontal tests (tests (1) and (3)) have energy criterion to determine when the test is terminated. For the rear longitudinal test, the energy requirement [in Joules] is $1.4 \mathrm{~m}_{\mathrm{t}}$, where $\mathrm{m}_{\mathrm{t}}$ is the tractor mass $[\mathrm{kg}]$. For the side transverse test, the energy requirement [in Joules] is $1.75 \mathrm{~m}_{\mathrm{t}}$. Tests (2) and (4) have load requirements of $20 \mathrm{~m}_{\mathrm{t}}$ [in Newtons]. SAE J2194 differs from earlier consensus standards in the dimensions of the specified clearance volume. The shape of this volume is shown in Figure 2-6. 


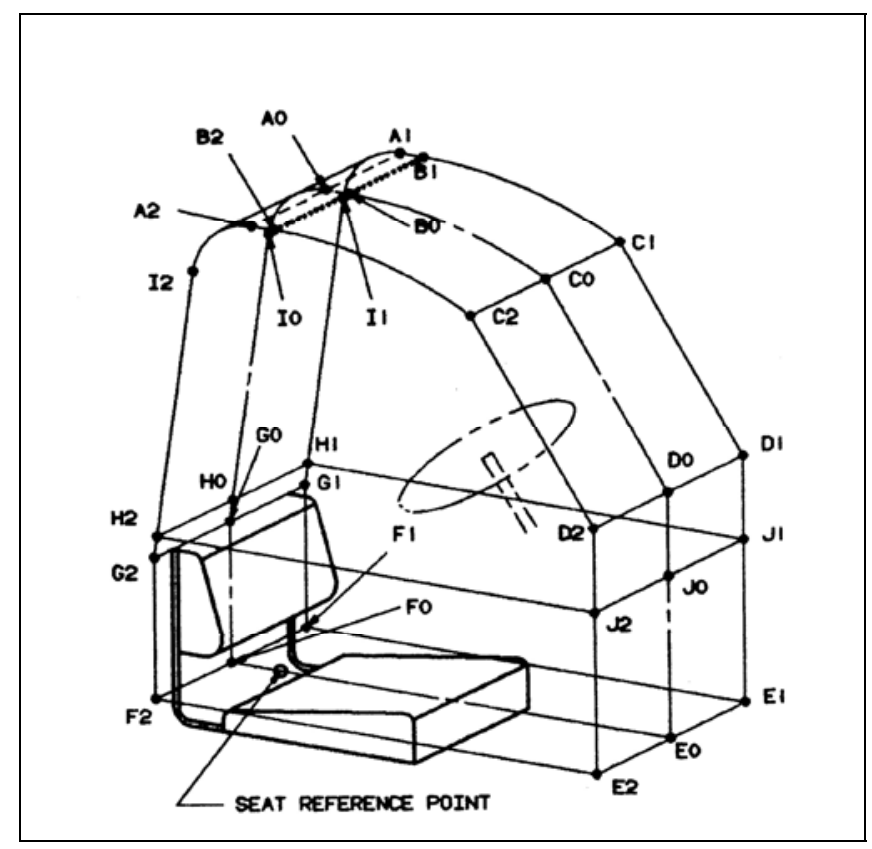

Figure 2-6 SAE J2194 clearance volume.

The concept of the clearance volume is to ensure that the ground plane does not intrude into a protected space around the tractor operator. This imaginary ground plane is constructed assuming that the tractor rolls in the direction from which the test load is applied.

\subsubsection{Recent developments}

For many years prior to 1996, OSHA regulations for agricultural rollbars found in 29CFR1928.51, 29CFR1928.52, and 29CFR1928.53 were taken directly from SAE J334 (ASAE S306.3) and SAE J168 (ASAE S336.1). After 1996 in an effort to "clean up" OSHA standards, the language of the SAE standards was deleted from these regulations, and the consensus standards were simply incorporated by reference. Letters of interpretation issued by OSHA in response to ROPS manufacturer inquiries allowed SAE J2194 to be used as an acceptable test which went beyond OSHA 
regulations (OSHA, 1991). In December 2005, OSHA released a direct final rule to reinstate the previous language of SAE J334 and J168 (U.S. G.P.O., 2005).

\subsection{Structural performance of ROPS and simulation techniques}

Many equipment manufacturing companies began ROPS performance research in earnest in the 1960's as regulations and standards for ROPS were being developed.

Yeh from International Harvester Company outlined crucial elements in ROPS engineering design and simulation (Yeh, 1976). He succinctly captured the essence of ROPS design. "The structure and its mounting adaptors must be strong yet flexible enough to absorb the required energy without intruding into the zone of protection." Yeh and colleagues developed a computer code, the Structural Analysis Program for Roll-Over Protective Structures (SAPROPS), based upon the "plastic hinge" approach. This included a “...piece-wise linearized process with consecutive applications of incremental loads." To fully implement SAPROPS, a yield criterion for the material had to be developed which related beam loads to formation of plastic hinges. To accomplish this and to efficiently utilize computational resources, Yeh made the following assumptions: (1) A simplified form of the Von Mises Criteria applies to the material in that the axial and shear forces are neglected in formulation of the yield function, (2) The stress-strain relationship is assumed to be linear elastic, and perfectly plastic, (3) The section where a plastic hinge develops makes an abrupt change from an elastic to a full plastic state, (4) Plastic yielding is restricted to the cross-section, and does not spread lengthwise, (5) Cross-sections are closed, and have two-way symmetry. 
Results from the side load portion of static testing requirements found in SAE J334 where compared to simulation data. For the point where required energy absorption was met, the simulated peak load was $10 \%$ below the test value, and the simulated deflection exceeded the test value by $4 \%$. In general the ROPS tested was more flexible than the simulated response at the beginning of the test but then became more stiff than the simulation as the energy absorption point was approached.

Yeh also identified the importance of the Nil Ductility Transition (NDT) temperature in ROPS materials. The NDT temperature is defined as “...the highest temperature at which a cleavage fracture can be initiated without appreciable deformation at the notch root in a standard drop-weight test" (Munse, 1990). The concern is that some materials experience a fairly quick transition from ductile to brittle behavior at certain temperatures. Typically, NDT temperature concerns are addressed through impact testing requirements such as the Charpy $\mathrm{V}$ notch requirements of $8 \mathrm{ft}-\mathrm{lbs}$ at $-20^{\circ} \mathrm{F}$.

In 1973 Moberg published a summary of experiences in Sweden at the National Swedish Testing Institute for Agricultural Machinery (NSTIAM). Sweden led the way for development of many of the ROPS testing standards. Moberg cites that “...the first commercial frame expressly designed to provide anticrush protection for the driver was produced in 1954." Development and evaluation of ROPS test methods began soon after at NSTIAM. Initial overturning tests proved impractical due to the fact that reproducing stresses within the ROPS had great variance from one overturn 
to the next. Moberg and colleagues determined that fixing the tractor to the laboratory floor and exposing the ROPS to crushing forces was the best option. Crushing forces could be delivered statically or dynamically. Static loads were delivered via a hydraulic rig and the dynamic loads utilized a swinging pendulum. Comparison between static and dynamic loading of ROPS found static application of a set amount of energy results in a faster rate of deformation when compared to dynamic application of the same amount of energy. They also found that increasing the speed of impact lowers the rate of deformation.

Moberg and colleagues determined that the dynamic pendulum test was the preferred test. Energy levels for the pendulum test were determined so that ROPS deformation would be of the same degree as was witnessed during previous overturning testing. This work became the basis of the test code for the Organization for Economic Cooperation and Development (OECD). A total of three pendulum blows were initially specified: from the back, from the side, and from the front. Energy for these tests was related to the tractor mass in a basically linear fashion. A clearance zone was also included which is very similarly to the present day SAE J2194 clearance zone. As part of this study, Moberg applied strain gages to the lashings which secured the tractor to the laboratory floor and constructed mechanical devices to ascertain the percentage of the total pendulum energy that was absorbed by the ROPS and mounting parts compared to the energy absorbed by the tires and lashing system. The result was that $75-80 \%$ of the energy was absorbed by a ROPS of normal strength. 
Srivastava and Rehkugler (1976) expanded upon the work of others to demonstrate strain rate effects in plastic deformation. In this phenomenon, the effective yield stress is elevated as the rate of strain increases. Srivastava and Rehkugler used dimensional analysis techniques applied to testing of cantilever beams to suggest that for ROPS testing these effects are not large. A 400 percent increase in the strain dependent pi-term caused a $14.9 \%$ and a $19 \%$ change in normalized permanent and maximum deflections, respectively.

In 1980, Woodward and Swan published a report that attempted to answer the question, “Are ROPS providing adequate operator protection?”. Their analysis was based upon over 1,400 rollover incident reports from 1970-1979 and 310 static certification tests. In this study, static testing had been performed according to SAE J1040c. Woodward and Swan estimated that $75 \%$ of ROPS designs in the field exceed the SAE requirements for the machine on which the ROPS is mounted by at least $50 \%$. Further, they estimated that $50 \%$ of the ROPS in the field surpass the SAE requirements by at least $100 \%$.

At the Winter Annual Meeting of the American Society of Agricultural Engineers in 1993, Teaford delivered a paper outlining his experiences and recommendations as a project engineer for John Deere in the areas of ROPS design, development, manufacture, and approval testing. Teaford admonishes design engineers to be cautious in selecting sources for ROPS steel. He recommends running a Charpy energy versus temperature curve from +20 to $-40^{\circ} \mathrm{C}$ with at least three specimens for 
each of the $10^{\circ} \mathrm{C}$ increments as additional testing for supplier qualification. For the steel specification, Teaford recommends either low-carbon, killed, hot-rolled steel or high-strength low-alloy (HSLA) steel. In general, he advises on steels with lower strength but high ductility.

Johnson and Ayers (1994) were among the first researchers to consider ROPS designs for "pre-ROPS" tractors. A pre-ROPS tractor is a tractor design typically developed before circa 1970 when ROPS were options for tractors and tractor axle housings were designed with an intent to support potential ROPS loading. Johnson and Ayers investigated a popular pre-ROPS tractor to evaluate the ability of the axle housing to support a ROPS design. They determined through both static and overturn testing that the particular model investigated (name kept confidential in paper) could indeed support a ROPS for loadings necessary to pass ASAE S519 (equivalent to SAE J2194).

$\mathrm{Li}$ and Ayers (1997) quantified the safety factor involved in placing ROPS designs on pre-ROPS tractors. They determined that longitudinal loading of the ROPS and potential axle housing failures during this mode of loading were more hazardous to the tractor operator than ROPS transverse loading. Longitudinal ROPS loading in ASAE S519 (SAE J2194) is to represent ROPS loading during rear rollover. Axle housing failure during a rear rollover would allow ROPS rotation that would likely crush the operator. Some operator protection is provided during a side overturn by the axle itself despite potential axle housing failures in this mode. Consequently, $\mathrm{Li}$ and 
Ayers applied longitudinal loads to a structural member and calculated a safety factor as the ratio of longitudinal yield torque of the axle housing to the maximum torque subjected during the ASAE S519 (SAE J2194) longitudinal static test. The safety factor calculated for the specific tractor axle housing tested (name not revealed in paper) was 1.99 indicating that the axle housing can successfully support a ROPS.

Ayers (1997) continued work on pre-ROPS tractors by classifying axle housing designs into three major categories. The first major axle housing category was the Ford 8N/800 series tractors. Ayers successfully completed static and field tests for this category. The second major axle housing category included the John Deere A, B, G, 50, 60, 70, 520, 620, 720, 530, 630, and 730 tractors. Ayers estimated that of the 920,000 tractors sold in this axle housing category, approximately 150,000 were still in operation. Successful static and field upset testing was conducted on a John Deere A tractor. The third major axle housing category was selected based upon available tractor databases and discussions with Saf-T-Cab (ROPS manufacturer). The category included the following tractor models: Farmall H, M, Super H, Super M, 300, 400, 350,450 , and 460 . This category represented approximately 278,000 tractors in operation. At the time of the paper, static and field upset testing were in progress.

Liu and Ayers (2000) reported test data for a ROPS designed for a pre-ROPS tractor, the John Deere A. ROPS deflection data were collected during static testing and field upset testing using a Linear Variable Differential Transformer (LVDT). The John Deere A ROPS design successfully passed requirements of SAE J2194. The reference 
mass of the John Deere A was $2467 \mathrm{~kg}$ resulting in a required energy for the first longitudinal loading of $3454 \mathrm{~J}$. Maximum deflection under longitudinal loading was $21 \mathrm{~cm}$. The required energy for the transverse loading was $4318 \mathrm{~J}$, and the maximum deflection was $26 \mathrm{~cm}$. Under field upset conditions, the maximum deflection was 11 $\mathrm{cm}$ for rear overturn and $12 \mathrm{~cm}$ for side overturn. Liu and Ayers note "It seems to be that static test has more absorbed energy requirement. But due to ROPS impact, the maximum impact force may be more than the required static loading, and the impact force can be measured by using a force sensor."

Ayers and Liu (2001) conducted additional testing on pre-ROPS tractors and the strength of pre-ROPS tractors' axle housings. To start, Ayers and Liu added a fourth major category of axle housing designs to the previous three. The fourth category can be represented by the Allis Chalmers D17 and includes the WD, WD45, D10, D12, D14, D17, D19, and D21 tractors. Design margins or safety factors were calculated for several tractors as before by measuring the longitudinal yield torque and the maximum torque applied during ASAE S519 (SAE J2194) longitudinal static testing. The following table is created based upon Table 2 of the Ayers and Liu publication. Note that replicates were performed for some tractor models. Under the "side" column, " $L$ " refers to the left portion of the axle housing and " $R$ " refers to the right portion. Design margin was not calculated for some tractor models if only yield torque data were available. 
Table 2-1 Ayers and Liu ROPS design margin data.

\begin{tabular}{|c|c|c|c|c|c|c|}
\hline Manufacturer & Model & Year (19xx) & Mass [kg] & Side & $\begin{array}{c}\text { Yield torque } \\
{[\mathrm{N}-\mathrm{m}]}\end{array}$ & $\begin{array}{l}\text { Design } \\
\text { margin }\end{array}$ \\
\hline Ford & $2 \mathrm{~N}$ & $42-47$ & N/A & $\mathrm{R}$ & 26,250 & N/A \\
\hline \multirow[t]{4}{*}{ Ford } & $8 \mathrm{~N}$ & $48-52$ & 1232 & $\mathrm{~L}-1$ & 29,000 & 2.23 \\
\hline & & & & $\mathrm{L}-2$ & 29,100 & 2.24 \\
\hline & & & & R-1 & 29,600 & 2.28 \\
\hline & & & & R-2 & 27,700 & 2.13 \\
\hline \multirow[t]{4}{*}{ Farmall } & $M$ & $39-49$ & 2204 & $\mathrm{~L}-1$ & 54,857 & 1.52 \\
\hline & & & & $\mathrm{L}-2$ & 46,520 & 1.29 \\
\hline & & & & L-3 & 51,436 & 1.43 \\
\hline & & & & $\mathrm{R}-1$ & 49,574 & 1.38 \\
\hline \multirow[t]{2}{*}{ Farmall } & 450 & $56-58$ & 3119 & $\mathrm{~L}$ & 43,920 & N/A \\
\hline & & & & $\mathrm{R}$ & 63,027 & N/A \\
\hline \multirow[t]{2}{*}{ Farmall } & $\mathrm{H}$ & $39-49$ & 1676 & $\mathrm{~L}$ & 41,239 & $\mathrm{~N} / \mathrm{A}$ \\
\hline & & & & $\mathrm{R}$ & 43,526 & $\mathrm{~N} / \mathrm{A}$ \\
\hline \multirow[t]{2}{*}{ Farmall } & 460 & $58-62$ & 2747 & $\bar{L}$ & 73,707 & $\mathrm{~N} / \mathrm{A}$ \\
\hline & & & & $\mathrm{R}$ & 71,483 & N/A \\
\hline
\end{tabular}

The importance of axle housing integrity and proper ROPS design are highlighted in a tragic incident captured by the NIOSH Fatality Assessment and Control Evaluation program in Iowa (http://www.cdc.gov/niosh/face/stateface/ia/03ia020.html). In 2003 an Iowa teenager died when the tractor he was operating overturned to the rear. The tractor was equipped with a sturdy "home-made" rollbar that had been welded by the victim's father, a certified welder. The robust rollbar was not correctly fastened to the rear axle housing to appropriately distribute the load of the tractor overturn event. When the tractor overturned to the rear, the axle housing fractured as the rollbar made contact with the ground and the teen was instantly killed as the tractor continued to rotate towards the ground and crushed him.

Tomas, Tran, and Altamore (1996) describe the movement of some state governments in Australia to certify roll-over protection systems for heavy vehicles by computer simulation. In 1995 the Victorian Department of Agriculture, Energy and Minerals 
announced a new initiative to offer $\$ 250$ payment per vehicle to assist with computer simulation of self made or retrofit ROPS. For their work, Tomas and colleagues statically simulated ROPS certification testing of a self made ROPS per Australian Standard AS 2294 using the finite element analysis package ABAQUS. A side rollover was simulated for the same ROPS using MADYMO. They found that for the case simulated, the static test of AS 2294 was sufficient to capture the necessary value of lateral force. This leads Tomas et al. to the conclusion that physical static testing is a good compliance test compared to more expensive physical dynamic tests.

In 2000, Harris, Mucino, Etherton, Snyder, and Means performed finite element modeling of ROPS in static testing and rear overturns. They sought to evaluate the adequacy of SAE J2194 static testing requirements alone to sufficiently and conservatively evaluate ROPS performance in rear overturn situations. Finite element models were developed in the software package ANSYS to simulate the full static testing sequence of SAE J2194. Additionally, models were developed in ANSYS to predict the performance of an identical ROPS design in a rear overturn test as prescribed in the field upset portion of SAE J2194. When comparing the stress induced to the ROPS during each scenario they found that in the worst case the static model underpredicts dynamic model results by approximately $7 \%$. In the best case, the static model overpredicts dynamic results by approximately $32 \%$.

In 2005, Harris, Cantis, McKenzie, Etherton, and Ronaghi presented a paper and results at the annual National Institute for Farm Safety (NIFS) meeting describing 
progress on attempts to design and commercialize cost-effective rollover protective structures (CROPS). The CROPS concept is to increase the percentage of tractors in the United States with ROPS installed by lowering the economic barrier to retrofitting older tractors with ROPS. Harris et al. provided performance data and plans for a prototype CROPS that one ROPS manufacturer estimated could be manufactured and sold for $\$ 290$. The same manufacturer estimated the highest shipping cost for the 48 contiguous states to be $\$ 193$. Typical ROPS costs (including installation) were estimated at $\$ 1000$. Cost savings were realized in the design through a weld-free construction of common structural elements and fasteners. A CROPS design for a Ford tractor is shown in Figure 2-7.

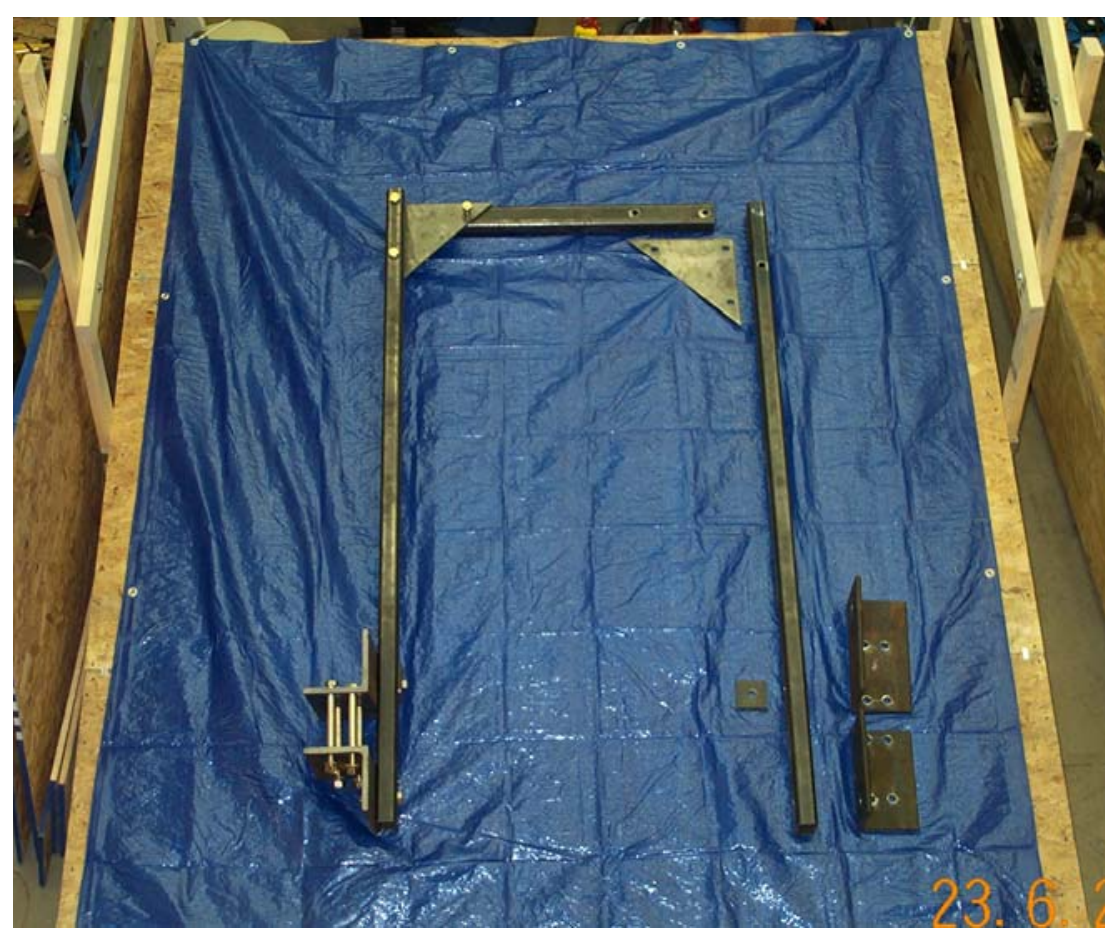

Figure 2-7 Ford CROPS. 


\subsection{Probabilistic/statistical design of safety controls}

Much has been written in the area of statistics and quality control concerning identifying sampling points to estimate product performance. The most prominent techniques, particularly those implemented in engineering analysis software, will be discussed.

\subsubsection{Monte Carlo simulation}

Monte Carlo simulation is a probabilistic technique where sample points are collected for random locations within the design space of the input variables (Hammersley and Handscomb, 1964). Direct (or crude) Monte Carlo simulation involves a random combination (according to some probability distribution) of the input variables with no consideration or memory of previous combinations. It is possible to have multiple combinations of input variables that are similar to one another. Latin Hypercube Simulation helps to prevent clustering. If $n$ sample points are to be collected, each input variable is divided into $n$ intervals of equal probability. Each interval can only be selected once, so a form of "memory" is employed.

\subsubsection{Response Surface Method}

In the response surface method, sampling points are located at pre-determined locations in a systematic manner. The location of these sampling points is dictated by the principals of design of experiments and regression analysis. Design of experiments is concerned with arranging sampling points throughout the design space to obtain the most information from the design space from a minimal number of 
sampling points. An efficient sampling scheme will improve the accuracy of the regression analysis and response surface.

There are two common approaches to implementing response surface methods. One method is the central composite design (CCD). In the central composite design, each input variable can assume one of five levels. The sampling points are distributed among three parts: center point, axis points, and factorial points. Unless there are center point replications, there is one sampling point at the center of the design space. For each input variable, there are two axis points. There are $2^{\mathrm{m}-\mathrm{f}}$ factorial points in a CCD design with $m$ input variables where $f$ represents the fractional portion of a full factorial design.

The second response surface method is the Box-Behnken design (BBD). In BBD, each input variable is assigned to one of three levels. The BBD has two primary parts: center point and midside points.

\subsubsection{Application of probabilistic methods}

Probabilistic methods have found wide application to a variety of problems. A few relatively recent applications occurred in the areas of safety engineering and finite element analysis. Magnusson, Frantzich, and Harada (1996) applied probabilistic techniques to fire safety evaluation of structures. The response variable of interest was available safe egress time (ASET) margin for an assembly room fire. A scenario event tree was developed based upon the functioning/non-functioning status of 
alarms, sprinklers, and emergency doors. Monte Carlo simulations were used to develop confidence intervals on complementary cumulative distribution functions.

Fredriksson and Schramm (2001) utilized explicit finite element modeling with response surface methods and stochastic analysis to evaluate design robustness of nonlinear systems subject to impact loading. They pointed out that finite element simulation models are deterministic by nature; two simulations from the same input files analyzed on the same computing system will yield identical results. When employing Monte Carlo simulations in these situations, two important issues must be addressed. First, each random variable must be assigned a marginal probabilistic distribution. Second, sampling must be chosen such that the limited population of sample sets leads to histograms for each random variable that approximate the marginal probabilistic distributions.

Thiruppukuzhi and Arslanoglu (2004) combined FEA, response surface methodology, and experimental testing to improve cell phone design. The failure mode of concern was screw pull out during a cell phone drop which had a laboratory-based failure probability varying from 0.30 to 0.40 . An explicit FEA model was developed to determine screw tensile force during cell phone drop. A full $2^{2}$ factorial with center point was simulated via FEA as a screening test for the two factors $\mathrm{X}_{1}$ (orientation angle in the side view) and $\mathrm{X}_{2}$ (orientation angle in the front view). The response variable of interest was the tensile force in two screws. The screening test identified $\mathrm{X}_{2}$ as the dominant plane. A Central Composite Design (CCD) was performed to 
characterize tensile force as a function of $\mathrm{X}_{2}$ drop angle. Input factors for the CCD were drop angle $\left(\mathrm{X}_{2}\right)$ and friction $\left(\mathrm{X}_{1}\right)$. Friction was added to the model since drop tests in the laboratory actually occurred on either a vinyl or steel floor. The CCD showed that the only significant factor was the quadratic term for $\mathrm{X}_{2}$ (drop angle). Evaluation of the regression response surface identified the maximum tensile force for the left screw and the drop angle at which this maximum occurred. Laboratory experiments were used to develop probability density functions (p.d.f.) for both drop angle and screw pull out strength. Evaluation of the screw stress p.d.f. and screw strength p.d.f. allowed calculation of system reliability. The system was defined as reliable if screw strength exceeded screw stress. Monte Carlo simulations predicted a failure rate for the flawed design (failure of either screw) of 0.34977 . This compared well with laboratory failure rates which varied from 0.30 to 0.40 . With the simulation methodology validated, simulations were performed on a cell phone with a new insert design for the screws. Probability of failure from either screw was estimated to be 0.02 with the new design.

\subsection{Summary}

Fatalities to tractor operators due to overturn continues to be an issue in the United States. Recent data have shown at least 92 deaths per year where the primary source of injury was a tractor and the event was an overturn. An engineering intervention exists to prevent many of the fatalities, a ROPS and seatbelt. Standards have been developed that establish performance requirements for ROPS. These standards follow the premise that a ROPS should absorb much of the energy of an overturn and 
minimize possible injury to the driver. Accordingly, many standards require ROPS to absorb a certain amount of energy through ROPS deflection while preserving a clearance zone for the operator. This energy criterion is typically associated with the mass of the tractor. Some of the standards used today include newly revised OSHA requirements (similar to SAE J334 and J168) and SAE J2194.

Many tractors manufactured before 1970, pre-ROPS tractors, do not have axle housings specifically designed to support overturn loading through a ROPS. However, structural testing of many popular axle housing styles has shown that most possess sufficient strength to handle longitudinal loadings required by the static test procedures in SAE J2194. Many pre-ROPS, as well as post-ROPS, tractors do not have ROPS installed today. Of the 4.8 million tractors in the United States, past data have estimated approximately 2.3 million do not have ROPS installed. ROPS cost has been an issue for many tractor owners when deciding whether to install a ROPS on his/her tractor. CROPS research has shown that it is technically feasible to construct ROPS that will pass SAE J2194 testing in a weld-free design with common structural elements and fasteners.

Probabilistic design (PD) techniques have been used successfully to evaluate safety and reliability in a variety of fields. CROPS testing according to consensus standards can be expensive in time and materials. PD methods can be used to evaluate the reliability of CROPS designs by building upon a limited number of test points, FEA, response surface methods, and Monte Carlo simulations to better explore CROPS 
response to input parameter variability. These simulation methods can also be used to compare and evaluate ROPS performance standards such as OSHA 1928.52 and SAE $\mathrm{J} 2194$. 


\section{CHAPTER 3 - METHODS/RESULTS}

\subsection{General study description}

This study evaluated the reliability of a CROPS design to meet static testing requirements of SAE J2194 and OSHA regulations as found in 29CFR1928.52. The particular CROPS design evaluated was a Ford-3000 prototype. Reliability was assessed through probabilistic design (PD) methods utilizing finite element analysis (FEA), response surface methods, and Monte Carlo simulations considering variations in material and geometry input parameters for the Ford-3000 prototype. This study has provided information on how prototypes built to the conceptual design specifications will perform during SAE J2194 and/or OSHA regulation testing. These results have also facilitated comparisons between the SAE J2194 standard and OSHA regulations. The basic steps in this study were: (1) perform SAE J2194 experimental static test, (2) develop FEA model based upon SAE J2194 experimental static test data, (3) perform screening tests to identify important prototype factors influencing energy absorption in CROPS, (4) utilize design of experiments methods to identify important factors and estimate response surface, (5) perform Monte Carlo simulations on response surface to estimate reliability of design.

\subsection{Ford-3000 CROPS prototype}

The Ford-3000 CROPS prototype was designed as a weld-free ROPS constructed from common structural materials. Careful consideration was given during design to ensure that the CROPS would not negatively impact tractor utility. Discussions with 
tractor dealers and users aided development so that typical tractor implements and protective fender units could still be used. Figure 3-1 is a rendering of the Ford-3000 CROPS design. For clarity only the CROPS and rear axle housing are shown.

Similarly, only one fender is shown.

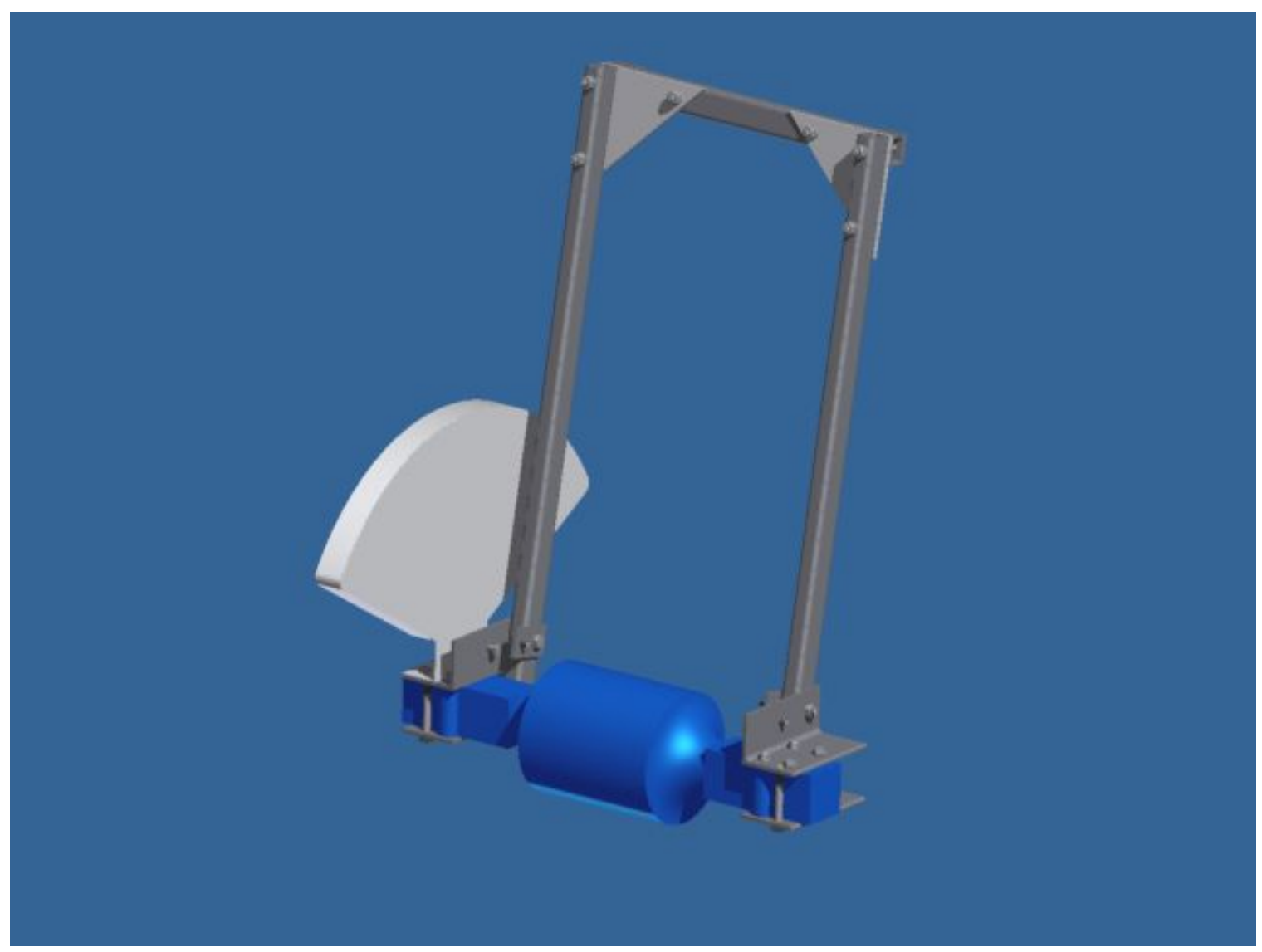

Figure 3-1 Ford-3000 CROPS design.

Complete engineering drawings to fabricate and assemble this CROPS can be found in Appendix A. 


\subsection{SAE J2194 static testing}

\subsubsection{Experimental equipment}

All SAE J2194 static testing was conducted in the NIOSH High Bay Laboratory in Morgantown, West Virginia. Components of the test facility include: test bed, hydraulic power supply, hydraulic actuators, hydraulic control equipment, data acquisition equipment, reaction frame, and overhead bridge crane.

The test bed provides secure anchor points for the tractor, reaction frame, and/or hydraulic actuators as shown in Figure 3-2.

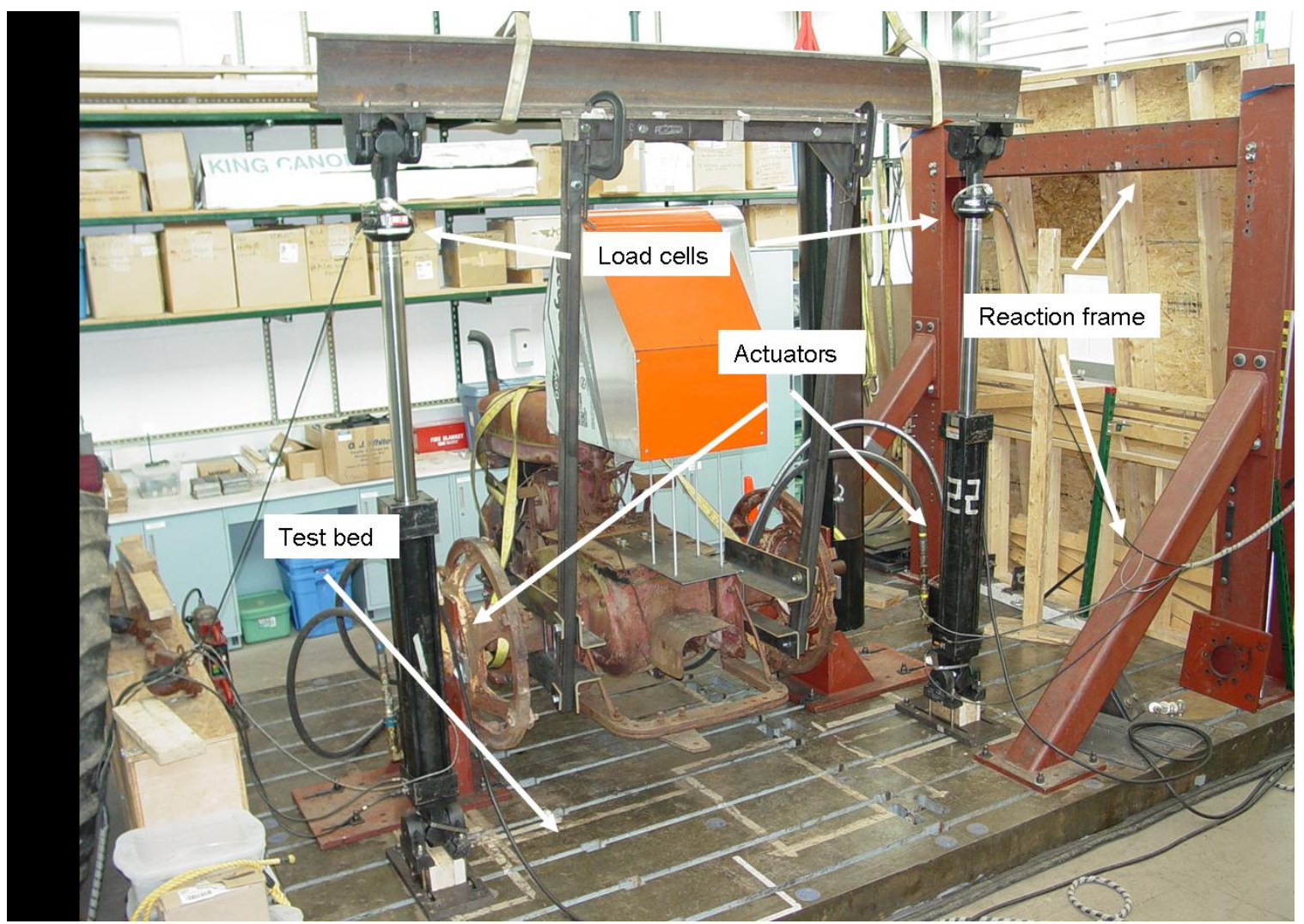

Figure 3-2 Static testing equipment. 
The test bed is assembled in four sections. When assembled, it provides a surface area measuring $10^{\prime}$ x 15'. T-slots run along the long dimension of the test bed for securing equipment.

The hydraulic power supply (HPS) is a model $510.10 \mathrm{C}$ manufactured by MTS Systems Corporation. This HPS can operate in adjustable low pressure or high pressure modes. For testing described in this research, low pressure was typically set to $500 \mathrm{psi}$ while high pressure was set to $2500 \mathrm{psi}$. Reservoir capacity for this pump is 37.5 gallons and rated flowrate at $3000 \mathrm{psi}$ is 10.1 gallons/minute. An integral fluidto-water heat exchanger keeps hydraulic fluid in an appropriate range, and an overtemperature switch shuts off the HPS if this temperature exceeds a pre-set limit (typically $\sim 125^{\circ} \mathrm{F}$ ). A low-level switch in the reservoir monitors for adequate fluid level and can also terminate HPS function.

To complete static testing, the High Bay Laboratory also includes two MTS 247.22 hydraulic actuators (see Figure 3-2). These actuators are double-acting, single-ended and can operate under servovalve control. Each actuator has a nominal force rating of $22.7 \mathrm{kip}(22,700 \mathrm{lb})$ and a stroke of 30 ". At the end of each actuator rod is a $20 \mathrm{kip}$ (20,000 lb) capacity load cell (see Figure 3-2). An LVDT is integral to the hollow rod of each actuator and records displacement of the actuator rod.

An MTS 458.20 MicroConsole (see Figure 3-3) controlled testing through use of servohydraulic devices. The MicroConsole could operate the servovalve in closed 
loop control for either displacement or load utilizing feedback from the LVDTs or load cells, respectively. An MTS MicroProfiler unit is incorporated into the MicroConsole chassis to generate pre-determined waveforms for load or displacement control. Output of the MicroProfiler is \pm 10 volts. A laptop running LabView monitored LVDT and load cell output to compute the energy absorbed under the load-deflection curve for portions of the static testing sequence which employed an energy criterion. A 13-Hz sampling rate was used for LVDT and load cell output. Area under the experimental load-deflection curve was approximated using a trapezoidal rule.

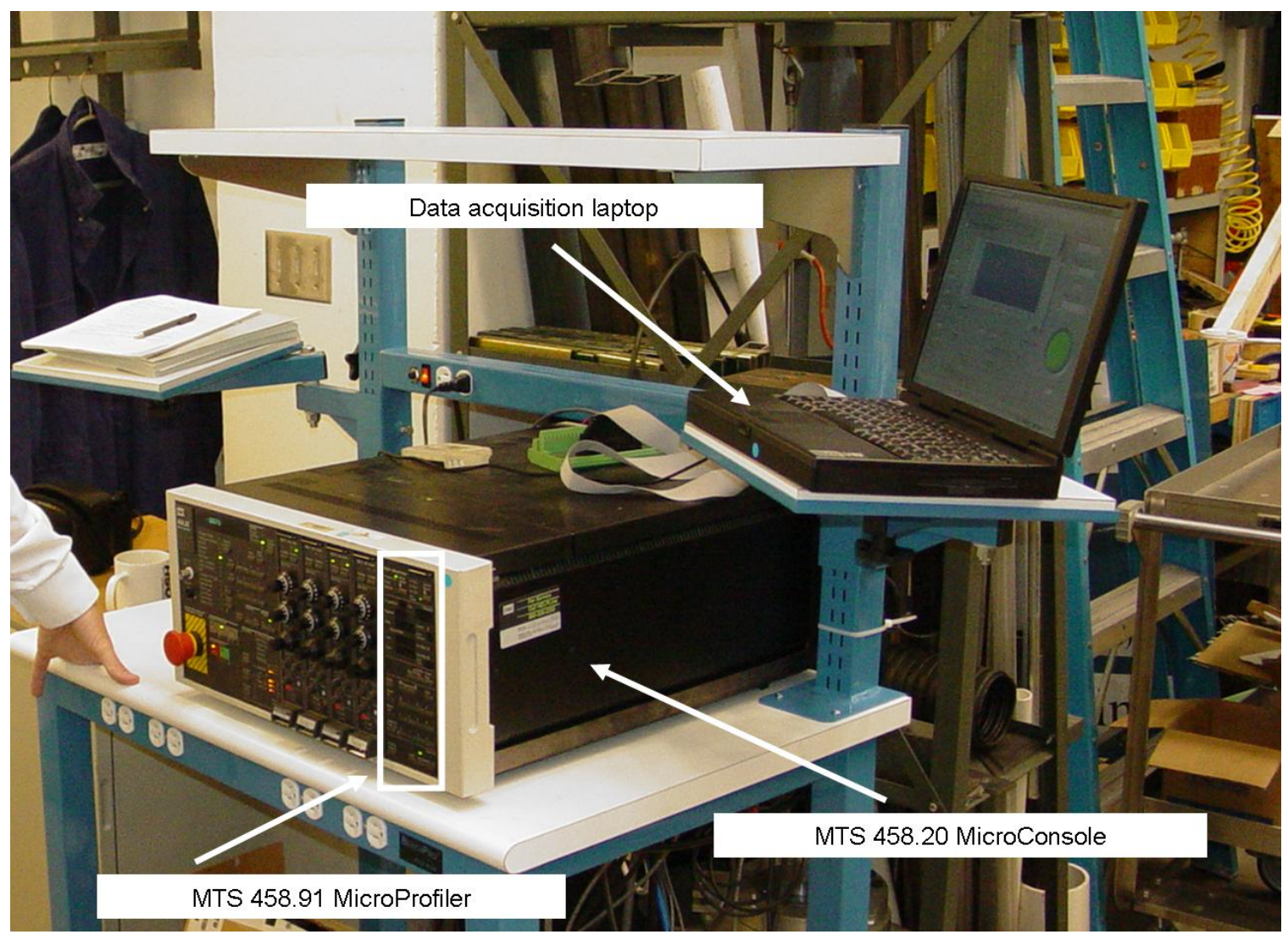

Figure 3-3 Data acquisition equipment. 
To apply horizontal loadings (longitudinal and transverse), a reaction frame was needed to mount the actuator(s). Figure 3-2 shows the stout reaction frame necessary to minimize reaction frame displacement during loading. Without a substantial structure to minimize reaction frame displacement during loading, the LVDT could not differentiate reaction frame displacement from CROPS movement. The reaction frame was designed so that worst case SAE J2194 loadings (non-symmetric horizontal loadings to frame) would produce only $1.5 \mathrm{~mm}$ maximum frame deflection (Brewer, Harris, Means, and Mucino, 1994). The required deflection measurement accuracy requirement in SAE J2194 is $3 \mathrm{~mm}$. A 5-ton overhead, bridge crane was necessary to place the tractor in the proper orientation on the test bed. During testing, the crane served as a redundant support device in case an actuator mounting bolt failed.

\subsubsection{Longitudinal loading}

The first static test in the SAE J2194 sequence is a longitudinal load from the rear for tractors with more than $50 \%$ unballasted weight on the rear wheels. According to the Nebraska Tractor Test \#883 (The University of Nebraska Agricultural Experiment Station, 1965), the data in Table 3-1 apply for a Ford-3000 4-speed diesel.

Table 3-1 Nebraska Tractor Test \#883 front and rear wheel weight distribution.
\begin{tabular}{|l|l|l|}
\hline & with ballast [lb] & without ballast [lb] \\
\hline Rear & 4453 & 2385 \\
\hline Front & 1610 & 1630 \\
\hline Total with operator & 6238 & 4190 \\
\hline
\end{tabular}

Longitudinal loading is defined as loading parallel to the longitudinal median plane of the tractor. The load is to be applied at the uppermost transverse member and at a 
distance one-sixth of the width of the top of the ROPS inward from the outside corner. Displacement rate is limited to $5 \mathrm{~mm} / \mathrm{sec}(0.197 \mathrm{in} / \mathrm{sec})$ to be considered static. As discussed in chapter 2, the test is terminated when there is structural failure, intrusion, exposure, or the energy criterion is met.

The energy criterion for the longitudinal load in SAE J2194 is $1.4 m_{t}[\mathrm{~J}]$, where $m_{t}$ is the reference mass (in $\mathrm{kg}$ ). The reference mass selected for testing the Ford-3000 prototype was $1995 \mathrm{~kg}(\sim 4400 \mathrm{lb})$. The only requirement from SAE J2194 for selection of the reference mass is that the reference mass must be greater than the tractor mass. Section 3.3 of SAE J2194 defines the tractor mass as: “...the mass of the unladen tractor in operating order with tanks and radiators full, protective structure with cladding and any wheel equipment or additional front wheel drive components required to support the tractor static weight. The operator, optional hitch equipment, optional ballast weights, additional wheel equipment, and other special equipment are not included."

According to this definition the tractor mass would be somewhat less than the unballasted weight provided in Table 3-1 since the operator is included in the Table 3-1 unballasted weight. Discussions with a ROPS manufacturer who worked with NIOSH in development of CROPS led to selection of $4400 \mathrm{lb}$. as the reference weight (mass) for SAE J2194 static testing. Using this reference mass value, the energy criterion for longitudinal loading was $1.4(1995 \mathrm{~kg})=2793 \mathrm{~J}=24,710 \mathrm{in}-\mathrm{lb}$. Figure 34 shows longitudinal loading of the Ford-3000 CROPS prototype. 


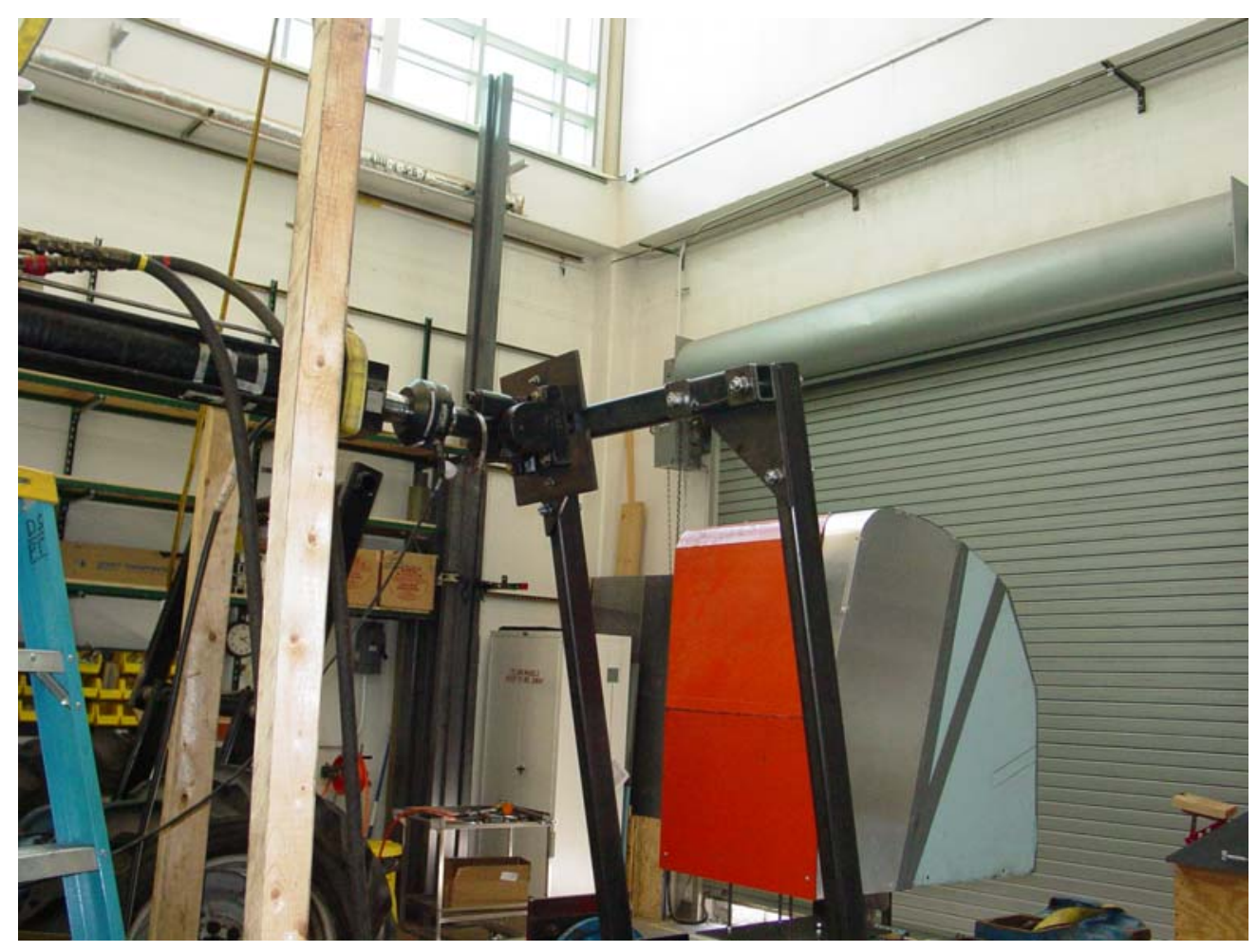

Figure 3-4 SAE J2194 longitudinal loading of Ford-3000 CROPS.

\subsubsection{First vertical crush test}

The second test in the SAE J2194 static test sequence is the vertical crush test. For this test the tractor is to be supported under the axles and a downward load applied with a stiff beam. The resultant crushing force is to be $20 m_{t}[\mathrm{~N}]$. Using the reference mass established previously, the load criterion was $20(1995 \mathrm{~kg})=39,900 \mathrm{~N}=8966$ lb. Displacement control mode was used to slowly increase the load to the load criterion. Figure 3-5 shows the experimental setup for the vertical crush load. 


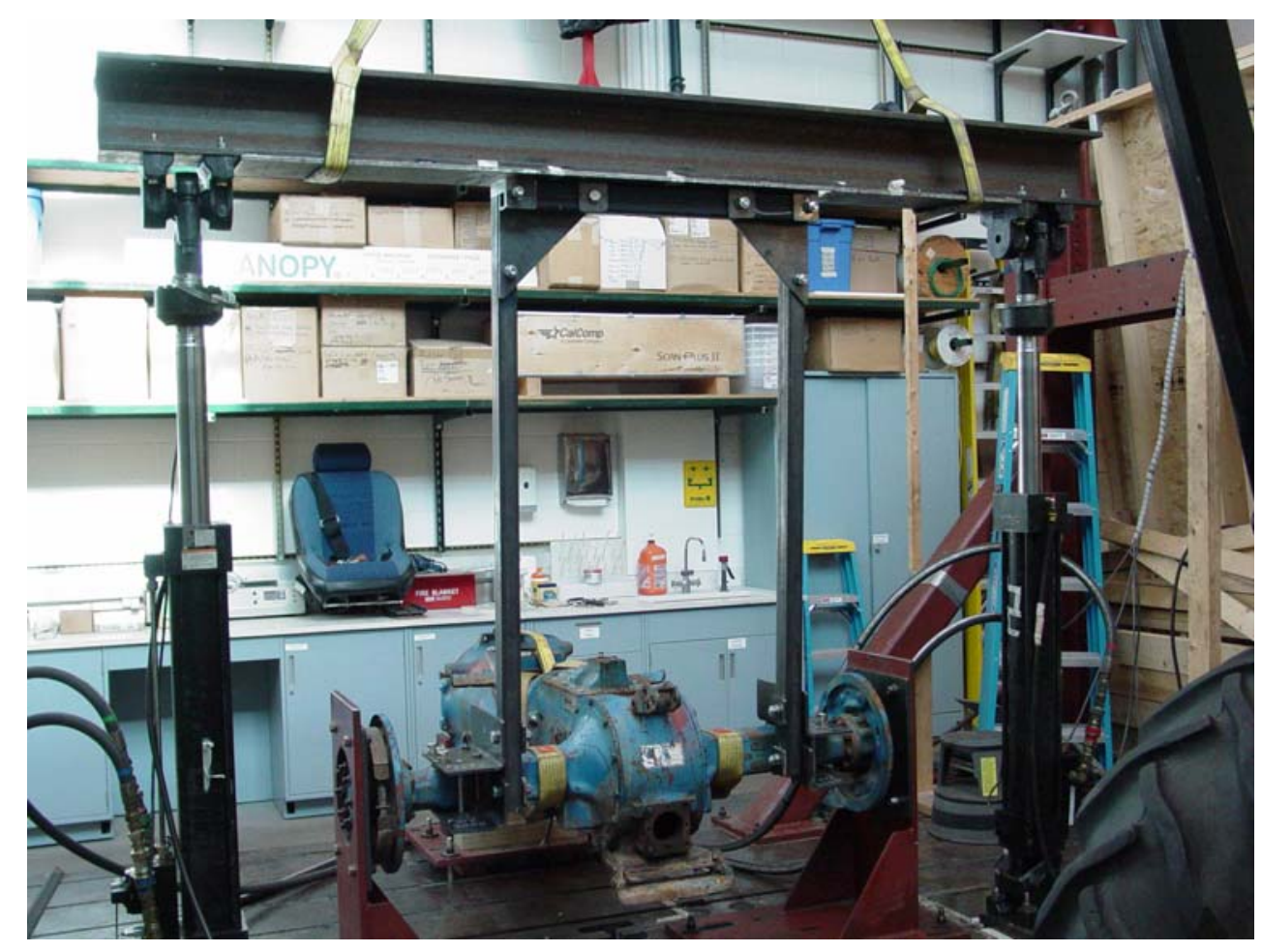

Figure 3-5 SAE J2194 vertical crush loading of Ford-3000 CROPS.

\subsubsection{Transverse loading}

The third test in the SAE J2194 sequence is a transverse loading. For ROPS which have undergone rear longitudinal loading ( $50 \%$ or more mass on rear wheels), the transverse loading is applied on the opposite side of, and normal to, the longitudinal median plane. Loading for this test was handled under displacement control of the MicroConsole. A constant displacement rate command of $\sim 0.5 \mathrm{~mm} / \mathrm{sec}(0.0197$ in/sec) was generated from the MicroProfiler. The transverse energy requirement is $1.75 m_{t}$ [Joules]. For the reference mass selected, the transverse energy requirement was $1.75(1995 \mathrm{~kg})=3491$ Joules $=30,886 \mathrm{in}$.-lb. Figure 3-6 shows the experimental setup for the transverse loading. 


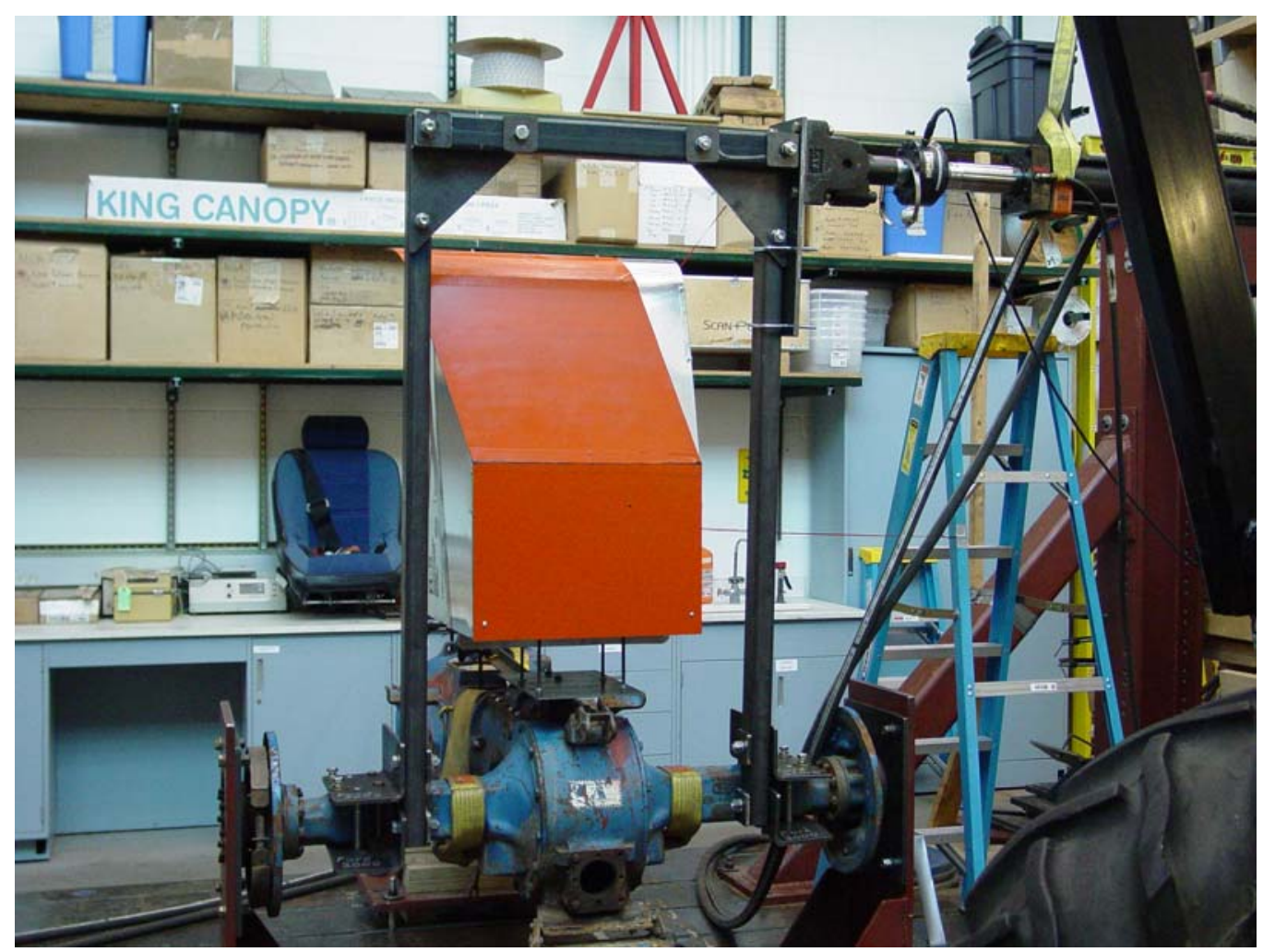

Figure 3-6 SAE J2194 transverse loading of Ford-3000 CROPS.

Note the orange addition to the clearance zone in Figure 3-6. Per SAE J2194, the upper portion of the clearance zone is allowed to tilt as shown during transverse loading.

To evaluate the exposure criterion, a ground plane had to be constructed which would adjust to the displacement of the CROPS during testing. The ground plane was represented by attaching red wire to the tractor points which would touch the ground during a side overturn. The three points used to construct the ground plane were the top of the right rear tire, the point of load application to the CROPS, and the right front hood point of the tractor. Figure 3-7 shows the exposure criterion being evaluated via the ground plane when the energy criterion has been achieved for the transverse loading. 


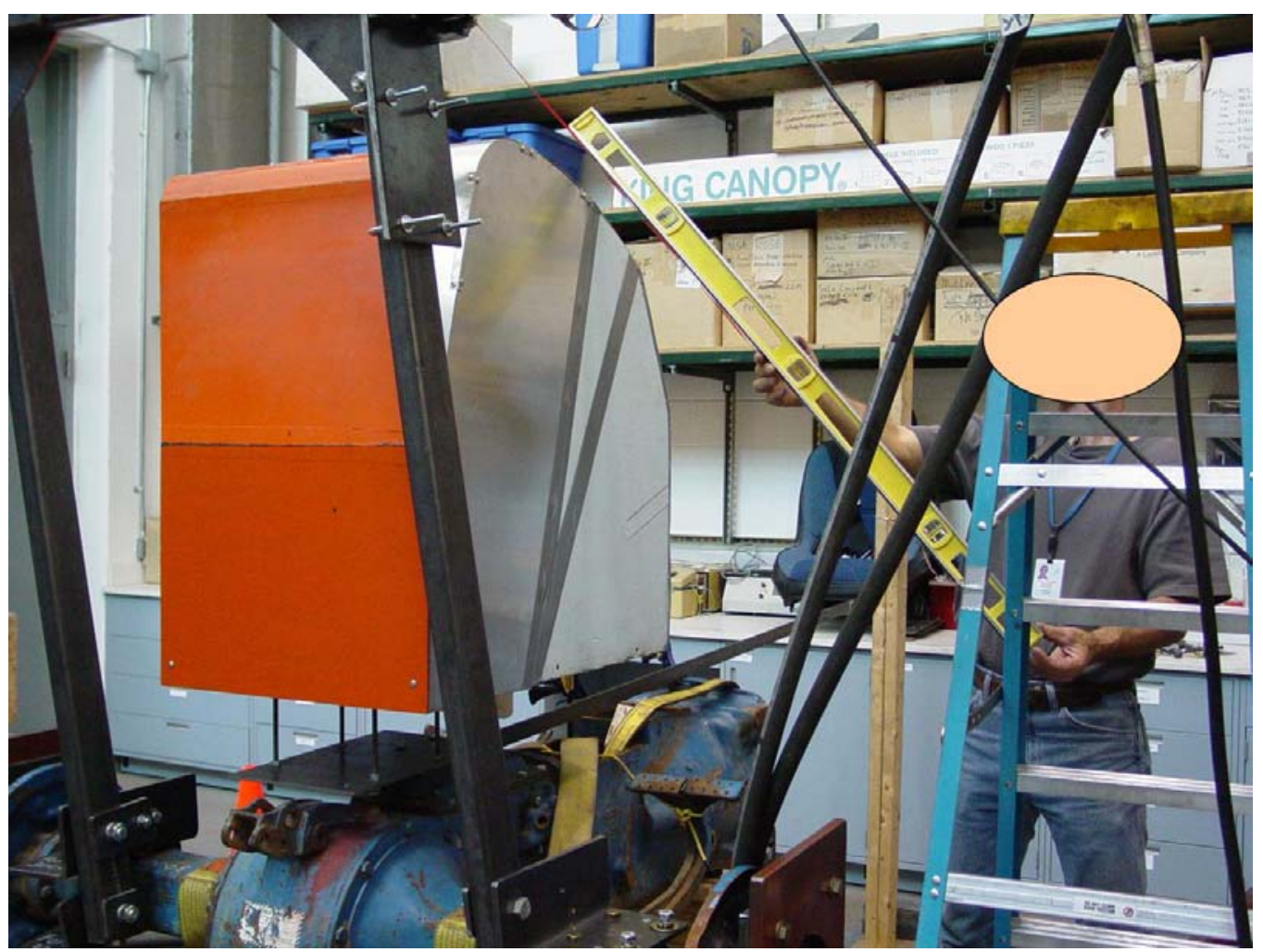

Figure 3-7 Assessing exposure criterion during transverse loading.

As shown in Figure 3-7, surrogate points were utilized for the top of the rear tire and the front of the tractor. These points were constructed from previous Ford-3000 tractor measurements collected in the field. For testing purposes, only the rear axle housing and a portion of the transmission housing were needed.

\subsubsection{Second vertical crush test}

A second vertical crush test is required and was performed with the same load criterion (8966 lb.) as identified previously. A summary of the SAE J2194 criteria utilized to test the Ford-3000 CROPS is listed in Table 3-2. 
Table 3-2 Summary of SAE J2194 test criteria.

\begin{tabular}{|c|c|c|}
\hline & Load criterion [lb.] & Energy criterion [in-lb.] \\
\hline Longitudinal load & $\mathrm{N} / \mathrm{A}$ & 24,710 \\
\hline $\mathbf{1}^{\text {st }}$ vertical crush & 8966 & $\mathrm{~N} / \mathrm{A}$ \\
\hline Transverse load & $\mathrm{N} / \mathrm{A}$ & 30,886 \\
\hline $\mathbf{2}^{\text {nd }}$ vertical crush & 8966 & $\mathrm{~N} / \mathrm{A}$ \\
\hline
\end{tabular}

\subsection{FEA model development}

\subsubsection{Element selection}

The commercial FEA software package, ANSYS (version 10.0), was utilized to develop an FEA model for SAE J2194 static testing of the Ford-3000 CROPS. To accurately model the SAE J2194 static test sequence (and later the OSHA regulation test sequence), the FEA model needed to exhibit the following qualities:

- Non-linear geometry (large deformation/displacements/rotations) and material properties (plastic deformation)

- Parameterized on important input parameters (geometry and material properties)

- Computationally simple to allow multiple runs

- Ability during longitudinal and transverse loading to calculate absorbed energy under force vs. deflection curve

- Ability during longitudinal and transverse loading to assess intrusion and exposure criteria

- Deformed model at end of each static test must be passed on to the next phase of static testing 
To create an efficient, yet accurate, FEA model of the Ford-3000 CROPS, beam elements (BEAM188) were selected in ANSYS. ANSYS labels these elements as 3-D linear finite strain beam elements. BEAM188 elements allow standard beam cross sections such as hollow rectangles and L-shaped sections. BEAM188 is based upon Timoshenko beam theory and allows for plasticity models. Timoshenko beam theory includes shear effects in the beam displacement formulation. Default implementation of the element includes six degrees of freedom at each node. The degrees of freedom include translations in the $\mathrm{x}, \mathrm{y}$, and $\mathrm{z}$ directions as well as rotations about the $\mathrm{x}, \mathrm{y}$, and $\mathrm{z}$ axes. Stress stiffening terms can also be included for this element.

The applicability of BEAM188 to any particular structural analysis can be assessed through use of the structure's slenderness ratio. Slenderness ratio is defined as:

$$
\text { s.r. }=\frac{G A L^{2}}{E I}
$$

where,

$$
\begin{aligned}
& \text { s.r. = slenderness ratio } \\
& G=\text { shear modulus } \\
& A=\text { area of cross section } \\
& L=\text { length of the member } \\
& E I=\text { flexural rigidity }
\end{aligned}
$$

For best performance of BEAM188, ANSYS recommends a slenderness ratio $>30$ (ANSYS online help files for BEAM188). In the case of the Ford-3000 CROPS, the beam cross section was loaded transversely during both the longitudinal and transverse loadings. Considering the case of longitudinal loading which yields the 
lowest s.r. (due to higher flexural rigidity), an approximate s.r. was calculated for common steel as (all units are in in. lb. system):

$$
\begin{aligned}
& G=\frac{E}{[2(1+v)]} \\
& G=\frac{30 e 6}{[2(1+0.29)]}=11.6 e 6 \\
& A=2.25 \\
& L=55.875 \\
& E=30 e 6 \\
& I=2.55 \\
& \text { s.r. }=1065
\end{aligned}
$$

BEAM188 elements can accommodate geometric nonlinearities. Geometric nonlinearities that are addressed within ANSYS include large strain, large rotation, and stress stiffening. Large strain (or finite strain) effects occur when strain exceeds a few percent and the changing geometry can no longer be considered negligible in strain calculations. Large rotation mathematical formulations are closely related to large strain theory. Stress stiffening refers to the stiffening of a structure due to its stress state. This is applicable to CROPS designs where the bending stiffness may be much less than the axial stiffness.

\subsubsection{Material properties}

BEAM188 elements can model nonlinear material behavior throughout the CROPS model. Rate-independent plasticity is used and requires the establishment of a yield 
criterion, flow rule, and hardening rule to capture the effects of permanent strain throughout the structure. For the Ford-3000 CROPS model, a von Mises stress yield criterion was used. Von Mises stress is an equivalent stress measure that combines the stress states in all three principal directions to derive one stress value for comparison against an allowable value. For BEAM188, an associative flow rule is utilized and yielding is assumed to proceed in a direction normal to the yield surface. The isotropic hardening rule for this element dictates that subsequent yield surfaces spread out from the site of yield initiation. In ANSYS software these nonlinear material property settings are summarized using the term BISO for bilinear isotropic hardening. The "bilinear" portion of this term refers to the manner in which the FEA software models the material stress-strain relationship. The stress-strain relationship is considered linear with a slope equal to the modulus of elasticity up to the yield stress. Stress-strain behavior after the yield stress is linear with a slope equal to the tangent modulus.

The required ANSYS inputs to model nonlinear material properties included Young's modulus, Poisson's ratio, yield stress, and tangent modulus. Initial values for Young's modulus, yield stress, and tangent modulus were determined from steel mill certification sheets for the steel used to fabricate the Ford-3000 prototypes. Additional discussion of the variation of these values follows in the discussion of probabilistic design simulation in section 3.6. 


\subsubsection{Model geometry}

The FEA model geometry was created by first establishing keypoints. These keypoints represented critical areas of the CROPS beam such as the beginning or end of a beam. Lines were generated through these keypoints and then evenly divided for mesh generation. Calculations in a previous section showed how the slenderness ratio of the CROPS uprights could be sufficiently modeled using BEAM188 elements. Additional features which had to be modeled included the crossbar, corner gusset plates, and axle housing attachment brackets. Figure 3-8 identifies these components.

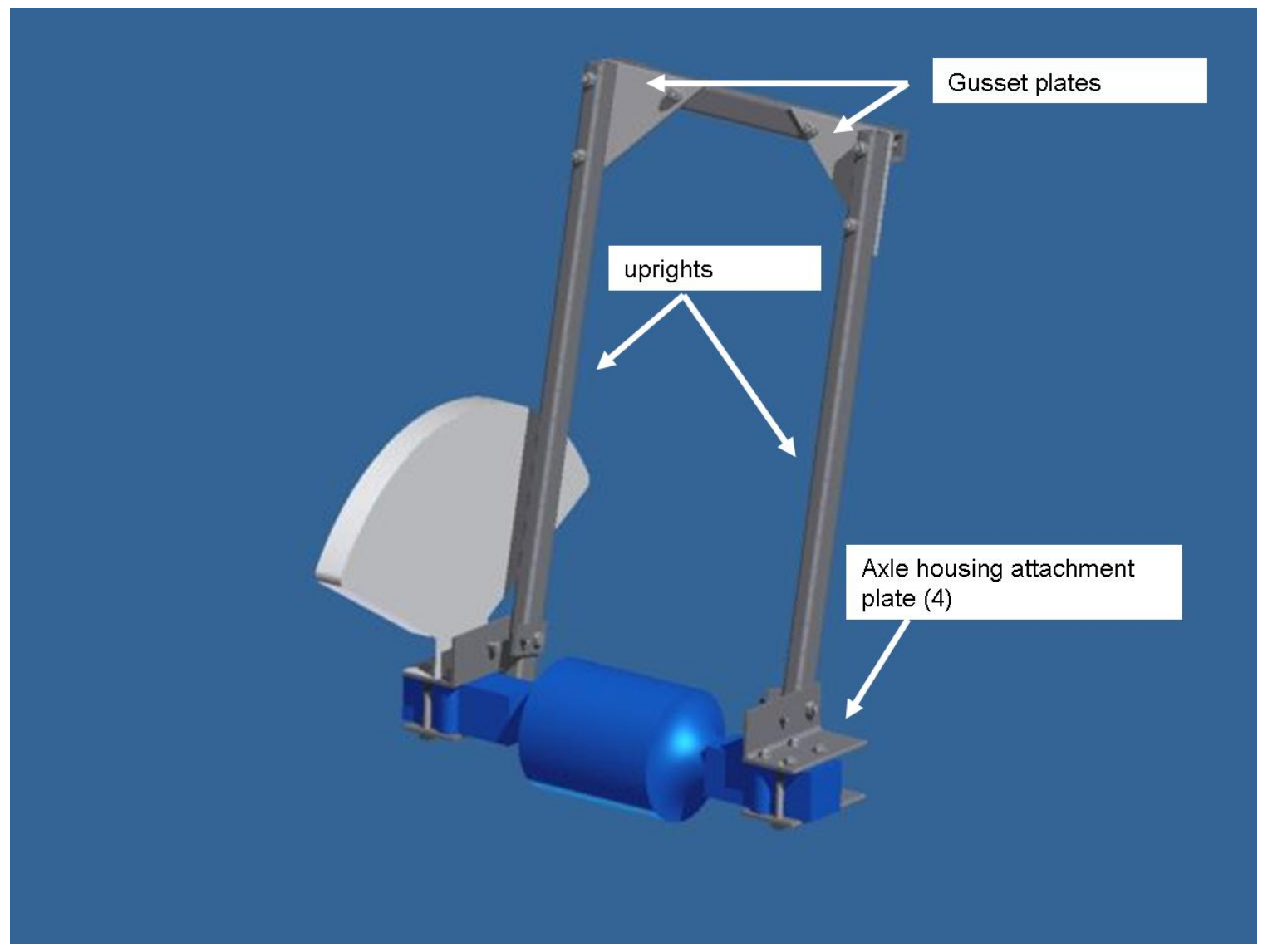

Figure 3-8 Ford-3000 CROPS. 
BEAM188 elements were utilized to represent the axle housing attachment plates as well as the gussets. One primary benefit of this is compatibility of element degrees of freedom at junction nodes. Utilizing Equation 3-1, the slenderness ratio for a top axle housing attachment bracket is 25 . Since the gusset plates simply serve as stiffeners within the CROPS, BEAM188 elements were used to minimize computational overhead during FEA solution. In all, the CROPS upright and crossbar beams, attachment brackets, and gusset plates were modeled using 30 beam elements as shown in Figure 3-9.

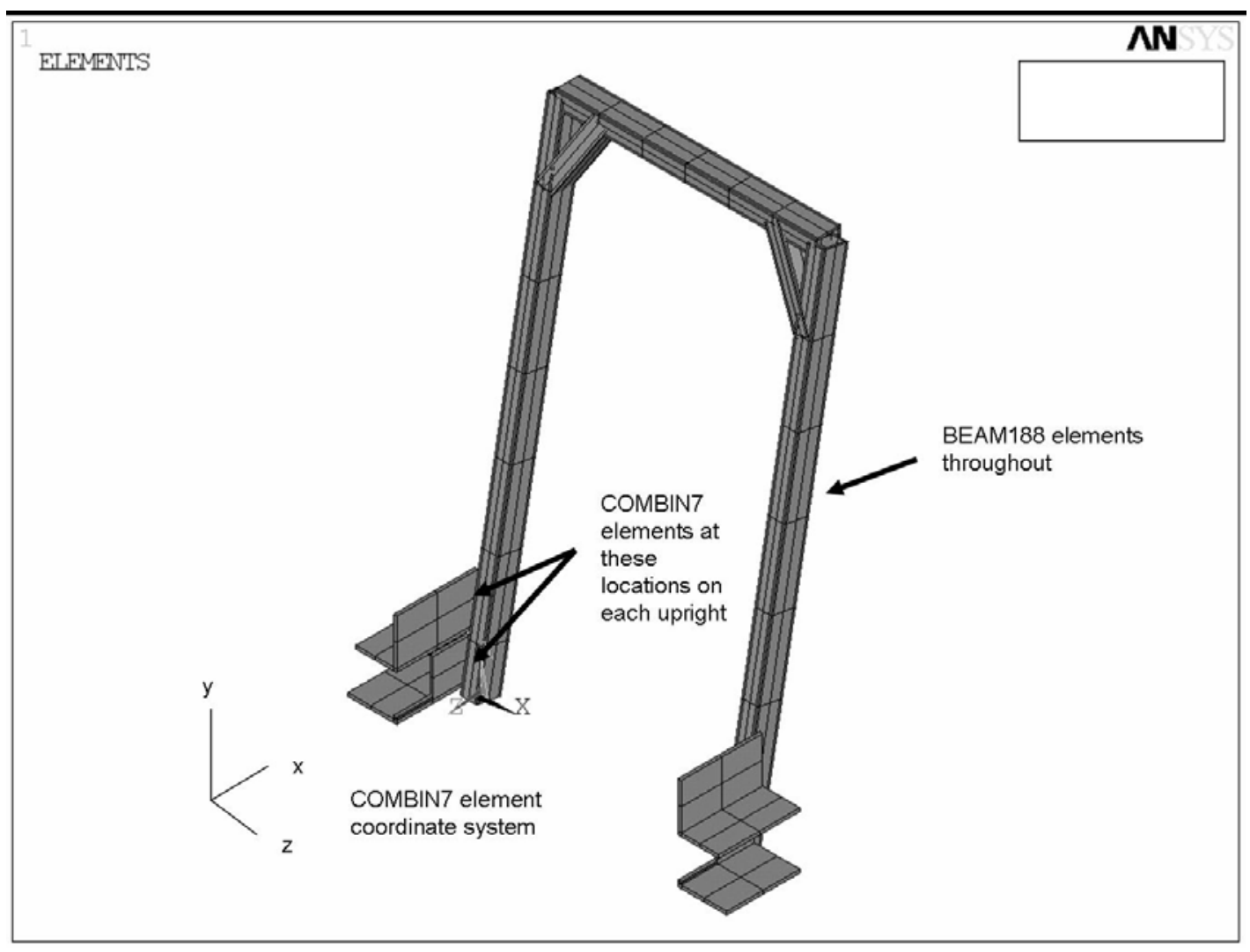

Figure 3-9 Ford-3000 FEA model. 


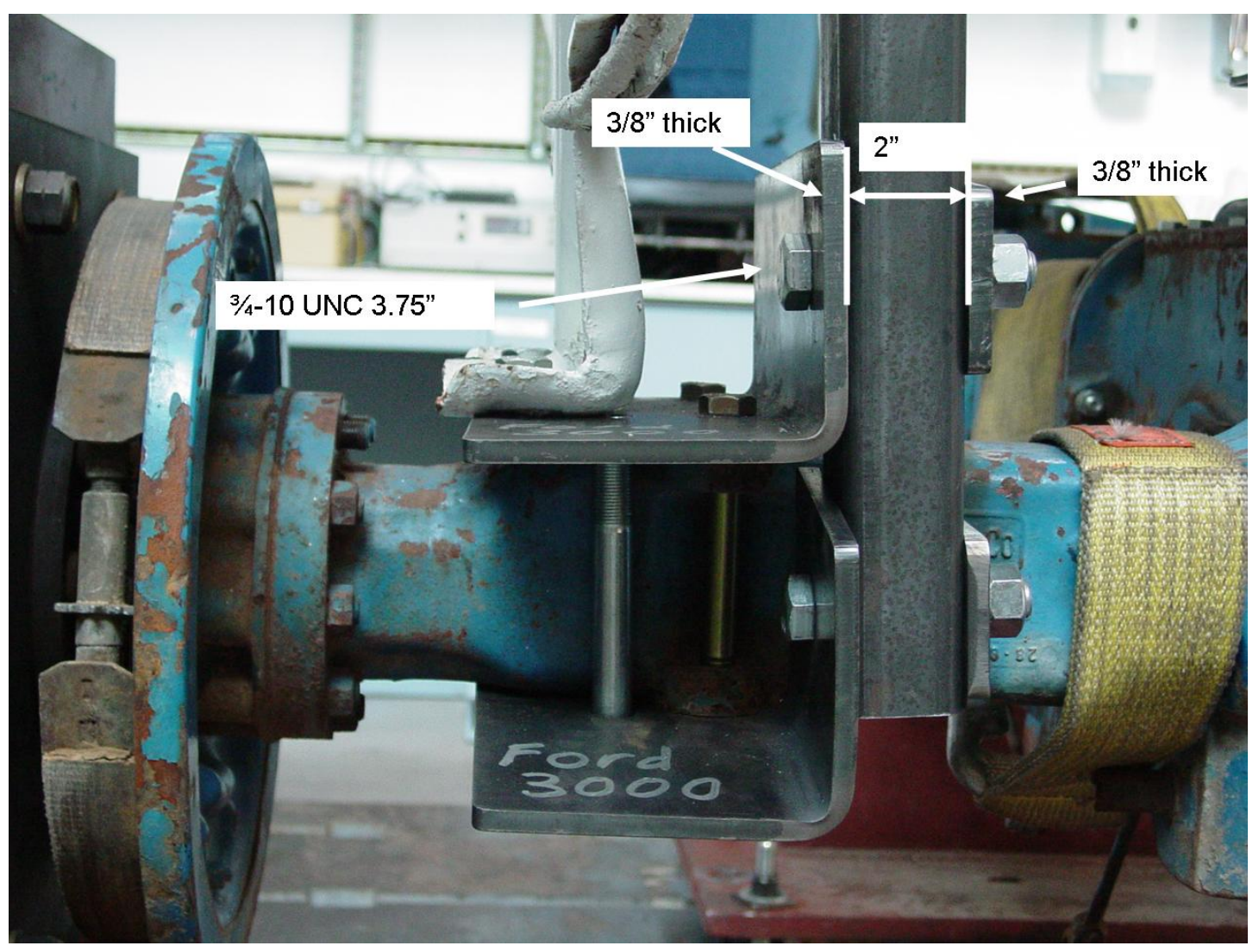

Figure 3-10 Bolted connection for upright to axle housing bracket during testing.

Bolted connections between the uprights and axle housing attachment brackets were represented as revolute joints through use of ANSYS COMBIN7 elements.

COMBIN7 elements have coincident end nodes so that they are not visible but serve as a mathematical representation of the joint. The FEA code uses spring, damper, and friction models to represent this element based upon the following inputs: X-Y translational stiffness $(\mathrm{K} 1), \mathrm{Z}$ direction stiffness $(\mathrm{K} 2)$, rotational-X and rotational- $\mathrm{Y}$ stiffness (K3), and friction torque (K6). The variable name in parentheses refers to the ANSYS COMBIN7 keyopt number. Complete sample FEA input files can be found in Appendix B. All of these values refer to the element coordinate system for COMBIN7 which has been established as shown in Figure 3-9. 
Theoretical calculations were performed to provide initial estimates of appropriate values for COMBIN7 input. For many of these calculations, the bolt was treated as a beam, and the stiffness value was calculated according to beam deflection theory. For $K 1$, an initial theoretical stiffness value was calculated by considering loading on the bolt to be as an end-loaded cantilever beam. The head of the bolt (3/4-10 UNC, 3.75" long) was considered fixed. The free length of the cantilever beam was considered as 2”. From beam deflection theory (Byars, Snyder, and Plants, 1983),

$$
y_{\max }=-\frac{P L^{3}}{3 E I}
$$

and, $\quad K 1=\frac{P}{y}=-\frac{3 E I}{L^{3}}$

where,

$$
\begin{aligned}
& L=2 \text { ”, } E=30 e 6 \mathrm{psi} \\
& I=\frac{\pi r^{4}}{4}=15.5 e-3 \mathrm{in}^{4} \text { (second moment of area about centroid axis for bolt) } \\
& |K 1|=174,375 \mathrm{lb} . / \mathrm{in} .
\end{aligned}
$$

For comparison $K 1$ was also calculated for a cantilever beam with two point loads as shown in Figure 3-11. 


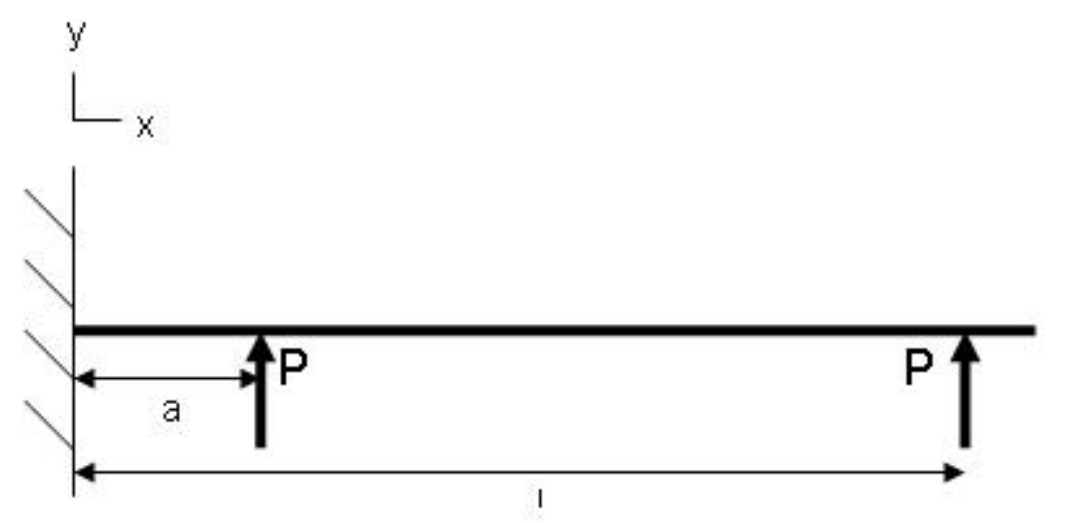

Figure 3-11 Cantilever beam under two point loads.

Based on superposition of two point load cases (Budynas and Nisbett, 2008),

$$
\begin{aligned}
& y=\frac{P x^{2}}{6 E I}(x-3 l)+\frac{P a^{2}}{6 E I}(x-3 a) \text { for } \mathrm{x}<\mathrm{a} \\
& y=\frac{P x^{2}}{6 E I}(x-3 l)+\frac{P a^{2}}{6 E I}(a-3 x) \text { for } \mathrm{a} \leq \mathrm{x} \leq 1
\end{aligned}
$$

When $\mathrm{x}=3 / 8$ " (beginning of upright tube wall in Figure 3-10), $K 1=F / y=2.65 e 6$ lb./in. When $\mathrm{x}=2-3 / 8$ " (other side of upright tube wall), $K 1=100.6 e 3 \mathrm{lb}$./in. For a point that would be at the upright tube cross-section centroid, $\mathrm{x}=1.375$ ”, $K 1=$ 244.8e3 lb./in. NOTE: Absolute stiffness values are used throughout.

$K 2, \mathrm{Z}$ direction stiffness, represents the axial stiffness of the bolted connection.

Budynas and Nisbett have described the spring analogy to calculating bolt stiffness.

$$
K_{b}=\frac{A_{d} A_{t} E}{A_{d} l_{t}+A_{t} l_{d}}=K 2
$$

where,

$$
\begin{aligned}
& A_{t}=\text { tensile stress area }=0.334 \text { in. }^{2} \\
& l_{t}=\text { length of threaded portion of grip }=3 / 4 "
\end{aligned}
$$




$$
\begin{aligned}
& A_{d}=\text { major diameter area of fastener }=0.442 \text { in. }^{2} \\
& l_{d}=\text { length of unthreaded portion in grip }=2 " \\
& K_{b}=4.43 \mathrm{e} 6 \mathrm{lb} . / \text { in. }=K 2
\end{aligned}
$$

K3 for COMBIN7 represents rotational-x and rotational-y stiffness of the bolted connection. Due to the manner in which this connection is fastened, rotation of this type should not be easy. The initial value was set to the relatively "stiff" value calculated for $K 2$ of $4.43 \mathrm{e} 6 \mathrm{lb} .-\mathrm{in} . / \mathrm{rad}$.

$K 6$, friction torque, was established in the model as the assembly torque applied to the connection. Preferred assembly torque is typically calculated as the torque required to induce $75 \%$ of the bolt proof load. As outlined in Budynas and Nisbett, recommended torque can be determined from the following,

$$
F_{p}=\text { proof load of bolt }=A_{t} S_{p}
$$

where,

$$
\begin{aligned}
& A_{t}=\text { bolt tensile area }=0.334 \text { in. }^{2} \\
& S_{p}=\text { minimum proof stress }=85,000 \text { psi }(\text { grade } 5)
\end{aligned}
$$

Therefore, $F_{p}=28,390 \mathrm{lb}$.

$$
\begin{aligned}
& F_{i}=\text { initial load }=0.75 F_{p}=21,293 \mathrm{lb} . \\
& T=\text { recommended torque }=K F_{i} d
\end{aligned}
$$

where,

$K=$ torque coefficient related to coefficient of friction, surface smoothness, accuracy, and degree of lubrication $\sim 0.20$ 


$$
d=\text { nominal bolt diameter }=3 / 4 "
$$

Therefore,

$$
T=266 l b .-f t .
$$

The actual friction torque is set at $240 \mathrm{lb}$.-ft. (2880 lb.-in.) since this value is within the range of typical torque wrenches.

A total of four COMBIN7 elements were used to represent the connection between the uprights and the axle housing bracket.

\subsubsection{Model execution}

Loading of the model was accomplished in a similar manner to displacement control in experimental testing. That is, the node at the point of load application was moved by a certain amount. During model solution, the FEA code solved for the necessary reaction force at this node to cause this displacement. Displacement was incremented $1 / 2$ " during each loop. After each increment, the reaction force at the node was solved for and absorbed energy (area under force vs. deflection curve as described in SAE J2194) was determined. This energy value was compared against the energy criterion for longitudinal and transverse loading sequences. If the required energy was not yet absorbed, another loop was initiated with a $1 / 2$ " displacement increment. Vertical crush loading was accomplished in a load control manner with the load criterion applied to the required nodes. 


\subsubsection{Evaluation of structural failure, exposure, and intrusion}

At the conclusion of the longitudinal, transverse, and second vertical crush loads, the intrusion criterion was evaluated. Intrusion required assessing whether the CROPS entered the clearance zone during simulation. To be conservative, the clearance zone of SAE J2194 was effectively enlarged. Intrusion was identified during the longitudinal test if the CROPS load application point crossed a vertical plane which included the most posterior points of the clearance zone and a horizontal plane which included the highest points of the clearance zone. Figure 3-12 shows each of these planes superimposed onto a picture taken during longitudinal loading of the Ford3000. Note that this intrusion evaluation simplification may miss some intrusions from longitudinal loading if only the uprights entered the clearance zone. However, this type of failure mechanism (separate from exposure or structural failure) has not been witnessed during ROPS or CROPS testing at the NIOSH High Bay Laboratory. 


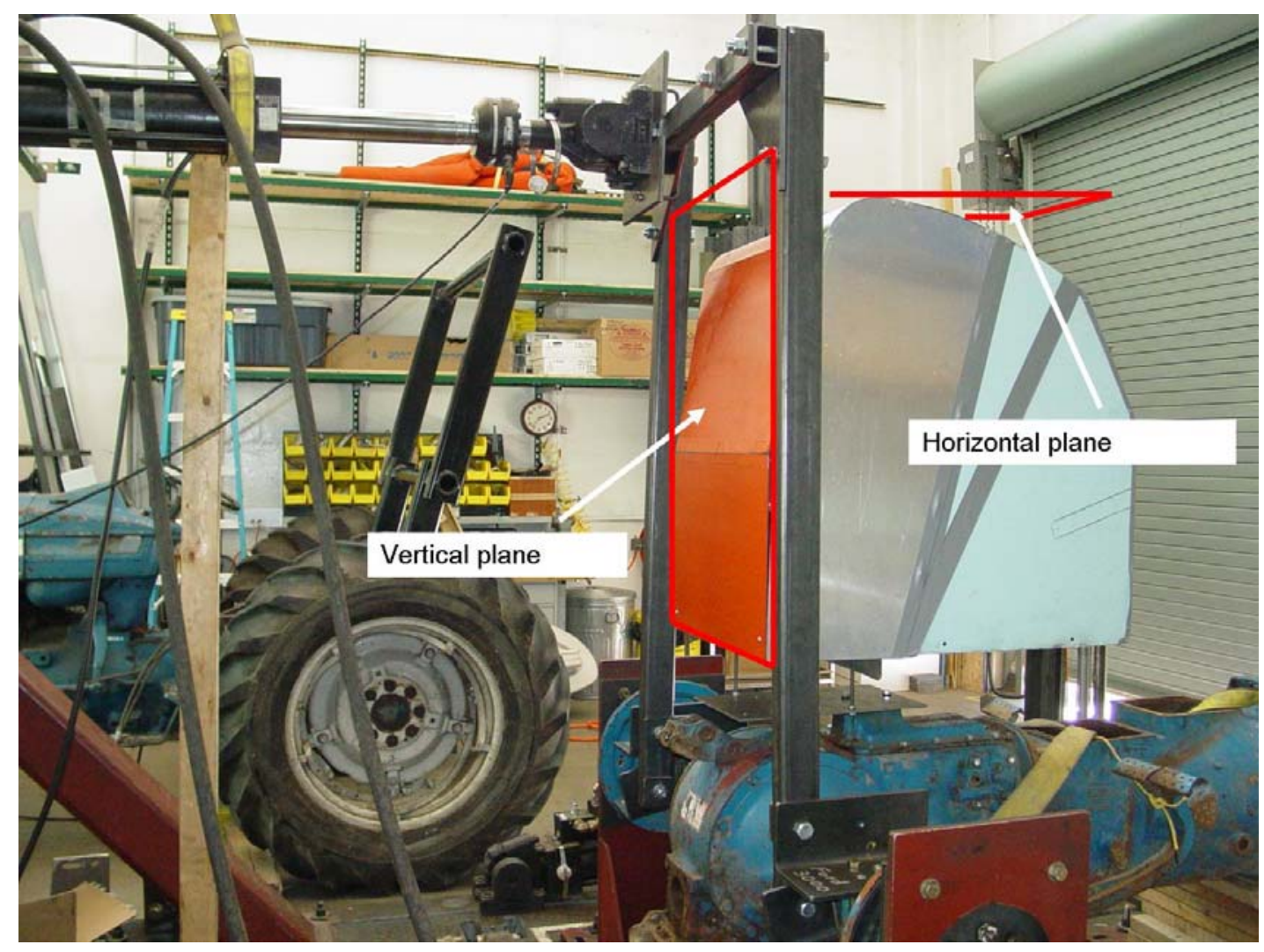

Figure 3-12 Intrusion planes for simulation of SAE J2194 longitudinal load.

Location of the clearance zone in experimental testing and simulation was based upon the seat reference point (SRP) as defined in SAE J2194. The SRP definition in SAE J2194 refers to a basic procedure in ISO 3462 (ISO, 1980) and requires that adjustable seats be in the rearmost and uppermost positions. The goal of the device specified in ISO 3462 is to determine the SRP as the intersection of a vertical tangential plane of the lower backrest and a horizontal plane. The horizontal plane should intersect the top surface of the seat pan at a point $150 \mathrm{~mm}$ (5.9 in.) in front of the SRP. ISO 3462 specifies a device which can help locate the SRP while under simulated occupant load (550 N or $124 \mathrm{lb})$. This device is shown in Figure 3-13. 


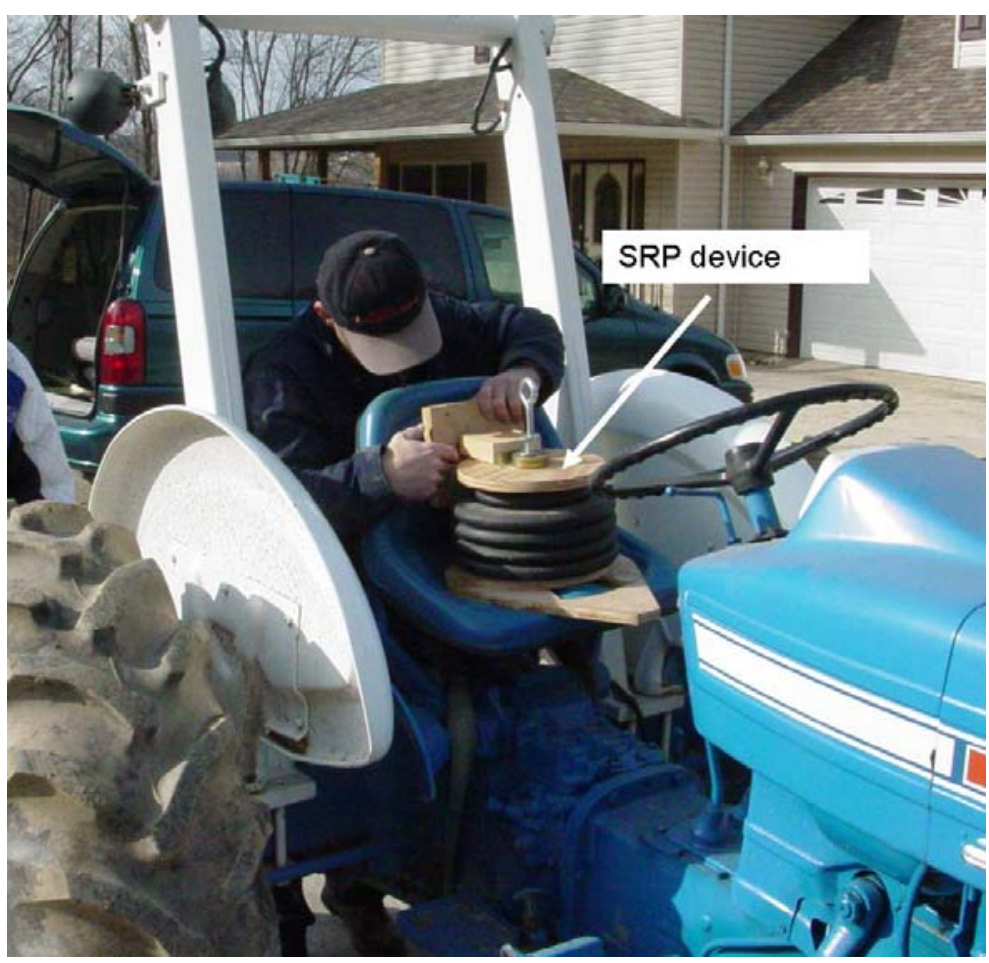

Figure 3-13 Seat reference point (SRP) device.

The SRP (in the ANSYS coordinate system) was 16, 20.631, 3.301. Intrusion was detected if the z-location of node 9 of the CROPS FEA model exceeded -0.969 " and the y-location of node 9 was less than 56.065". Intrusion was not evaluated during the transverse load simulation since an exposure infraction would occur first. Likewise, intrusion was not evaluated during the first vertical crush simulation since violations would be identified during the second vertical crush simulation. During the second vertical crush simulation, violation was detected if any nodes constituting the CROPS crossbar translated below the horizontal plane where $\mathrm{y}=56.411$ ”.

The exposure criterion evaluates whether the clearance zone would have been exposed to the ground plane if the tractor rolled in the direction from which the load was applied. Therefore, the first step in evaluating exposure for any load simulation 
was to develop a ground plane representation. During longitudinal loading simulation, the ground plane included the load application point on the CROPS and the backs of both rear tires (see Figure 3-14).

During simulation it had to be determined whether the ground plane had touched or passed through the clearance zone. To accomplish this, the ground plane had to be mathematically represented and then a comparison conducted to determine which side of the ground plane the clearance zone was on. In general, the equation for the ground plane could be established if a normal vector to this plane and a point located on the plane were determined. The normal vector was determined via the cross product of two vectors on the ground plane (vectors 1 and 2 in Figure 3-14).

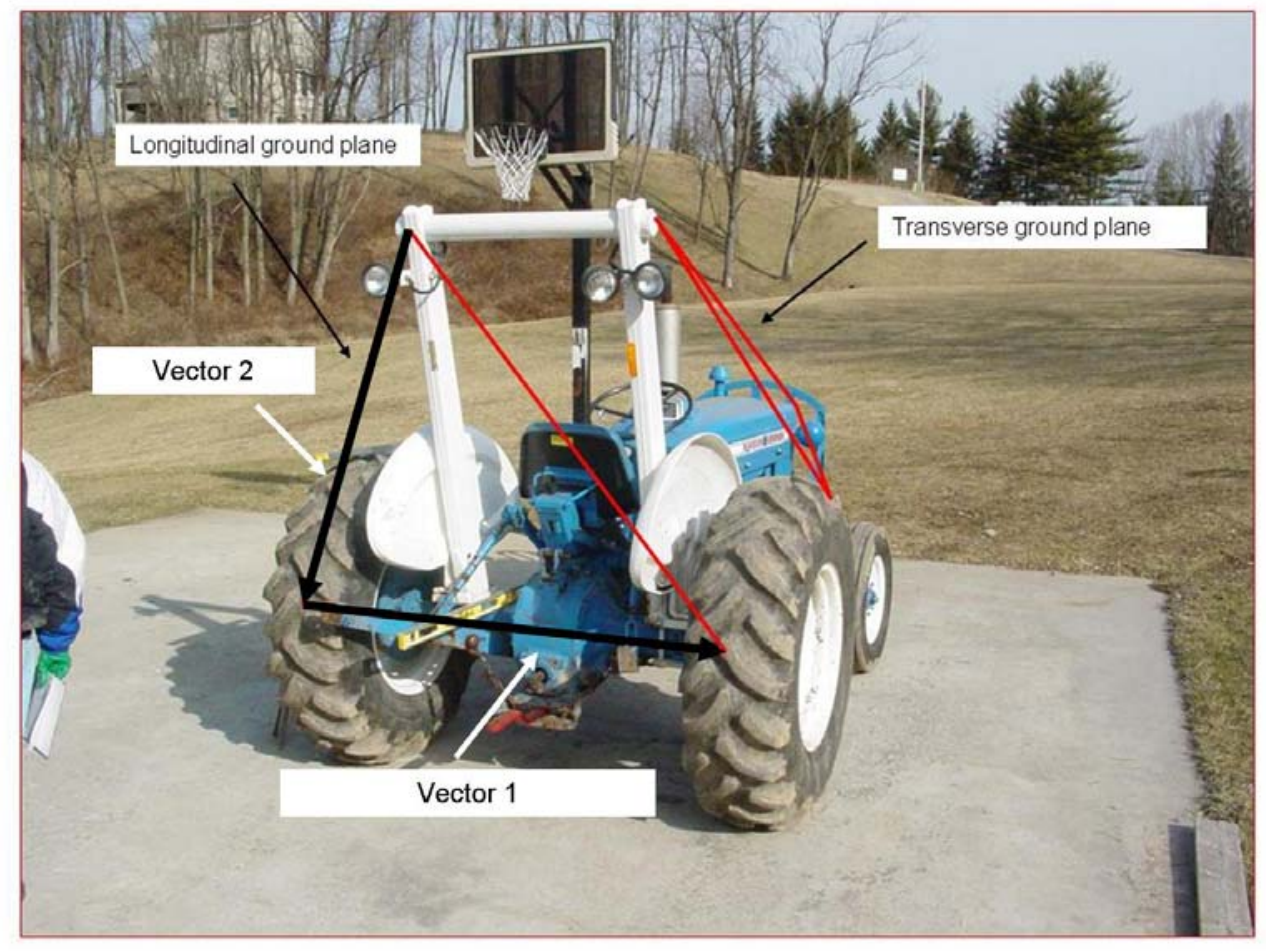

Figure 3-14 Mathematical determination of longitudinal load ground plane. 
One vector extended from one rear tire to the next. The second vector extended from the CROPS point of load application to a rear tire. The cross product of these two vectors provided a normal vector to the ground plane and allowed calculation of the ground plane equation. Mathematically this can be explained as follows (Edwards and Penney, 1986).

$$
\mathbf{n}=\mathbf{v}_{1} x \mathbf{v}_{2}
$$

where,

$\mathbf{n}=$ normal vector to ground plane in Figure 3-14

$\mathbf{v}_{\mathbf{1}}, \mathbf{v}_{\mathbf{2}}=$ vector 1 and vector 2 , respectively in Figure 3-14

$$
\mathbf{n}=n_{x} \mathbf{i}+n_{y} \mathbf{j}+n_{z} \mathbf{k}
$$

$$
\begin{aligned}
& |\mathbf{n}|=\sqrt{n_{x}{ }^{2}+n_{y}{ }^{2}+n_{z}{ }^{2}} \\
& \mathbf{n}_{u}=\left(\frac{n_{x}}{|\mathbf{n}|}\right) \mathbf{i}+\left(\frac{n_{y}}{|\mathbf{n}|}\right) \mathbf{j}+\left(\frac{n_{z}}{|\mathbf{n}|}\right) \mathbf{k}
\end{aligned}
$$

And, $\frac{n_{x}}{|\mathbf{n}|}=n_{u x}, \frac{n_{y}}{|\mathbf{n}|}=n_{u y}, \frac{n_{z}}{|\mathbf{n}|}=n_{u z}$

Then the equation for the ground plane is

$$
\left(n_{u x}\right) x+\left(n_{u y}\right) y+\left(n_{u z}\right) z+C=0
$$

Where, $C$ is a constant determined by a known point on the plane.

In the ANSYS input file of Appendix B, dgoal calculates constant $C$ when substituting a known point in the plane (back of right wheel). The input file then checks to see which side of ground plane the rear top left point of the clearance zone is. This is accomplished by comparing the constant (d1) calculated when using this point in the plane equation to dgoal. Exposure was detected if $d 1<d g o a l$. 
Exposure during transverse load simulation was modeled in a similar manner as longitudinal load simulation.

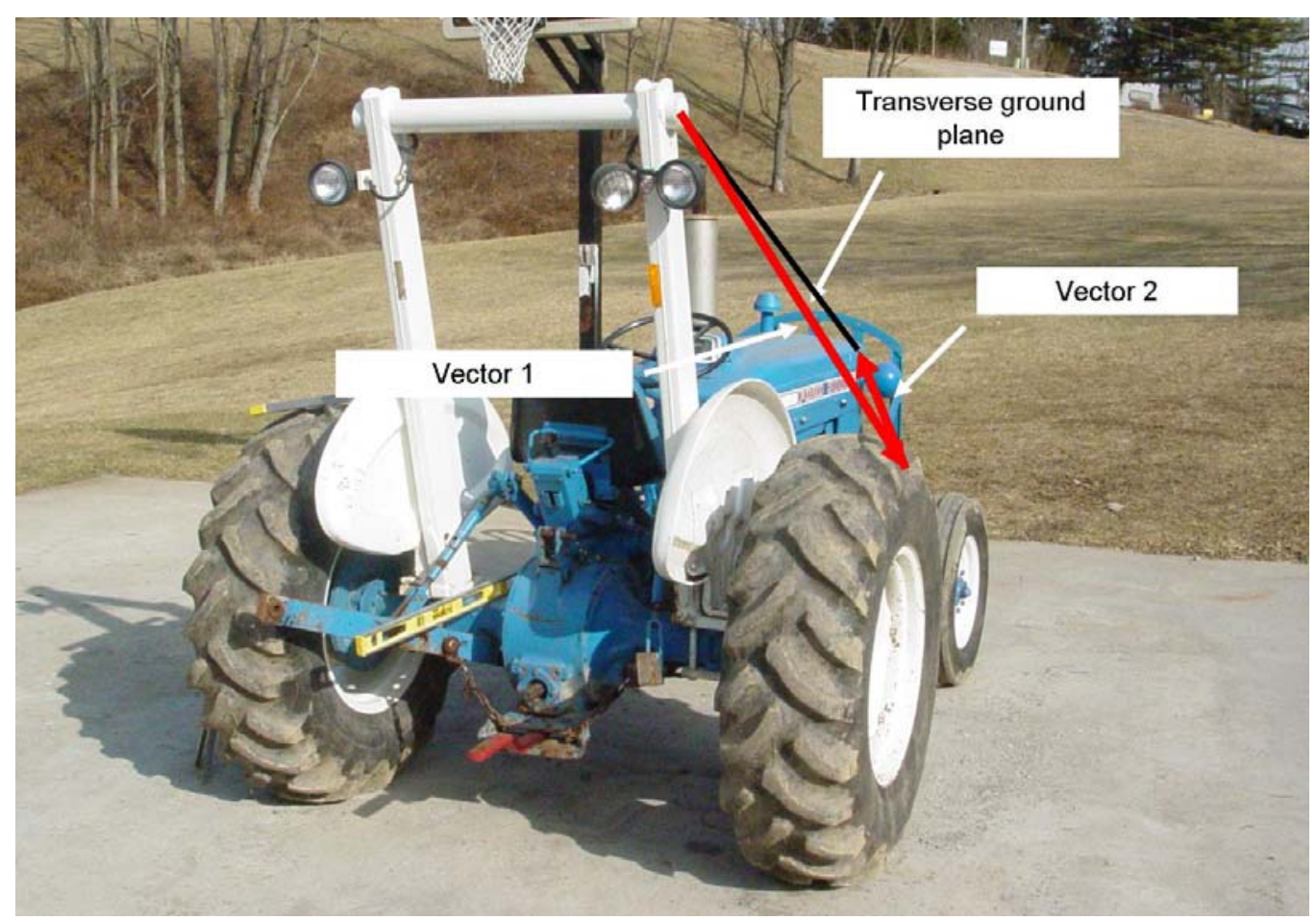

Figure 3-15 Mathematical determination of transverse load ground plane.

Vector 1 (see Figure 3-15) extended from the point of transverse load application to the outside edge of the right rear tire. Vector 2 extended from the end of vector 1 to the right front edge of the tractor hood. Using the previously outlined method, the distance from the transverse ground plane to several points on the SAE J2194 clearance zone was calculated. Distances were calculated for the following points (illustrated in Figure 3-16): I2, B2, C2, D2 


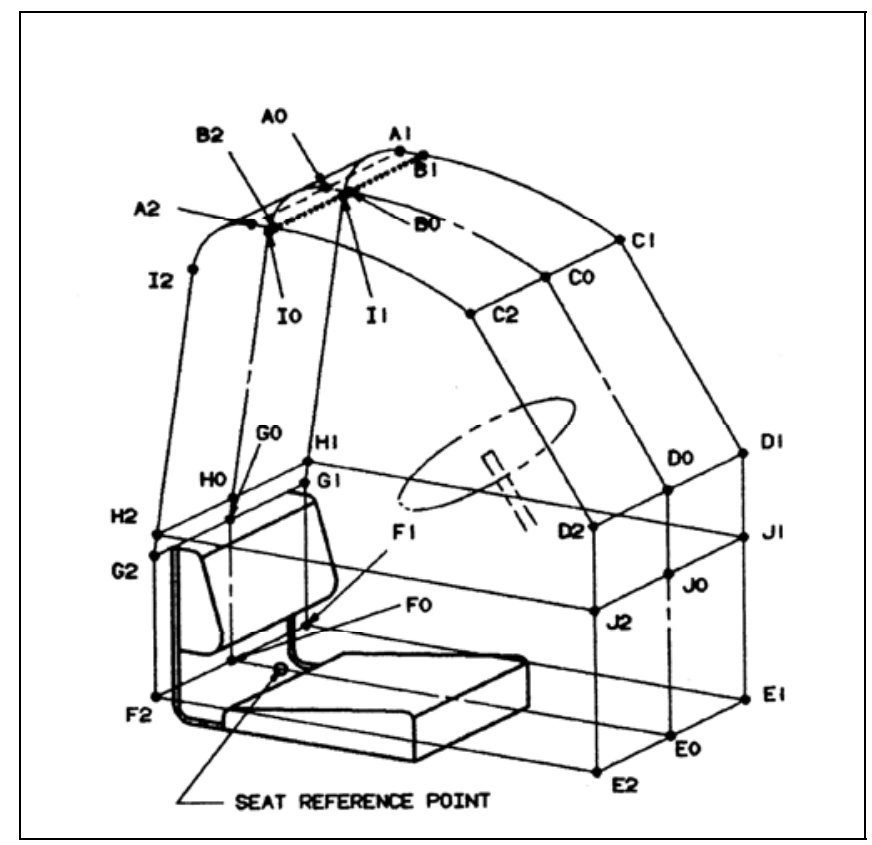

Figure 3-16 SAE J2194 clearance zone.

These distances were calculated as variables distanceI, distanceB, distanceC, and distanceD in the ANSYS input file. Negative distance values indicated the distance that particular point must move perpendicular to the transverse ground plane to enter the transverse ground plane. Positive distances indicated that the point had already passed through the plane.

Structural failure during simulation of SAE J2194 loading of CROPS was typically manifest through non-convergence of the FEA solution algorithm. This would typically occur when "plastic hinging" has occurred and the CROPS structure can no longer resist additional loadings without large displacements. 


\subsection{Comparison of SAE J2194 and FEA simulation results}

Evaluation of the FEA model was accomplished by comparing simulation results with actual SAE J2194 experimental test results for a Ford-3000. Of primary importance was matching of load and displacement data to accurately predict energy absorption within the CROPS structure. Figures 3-17 through 3-20 show experimental Ford3000 CROPS data and simulation results. Tables 3-3 through 3-6 display numerical data for a comparison of experimental and simulation data. For all SAE J2194 testing, a reference weight of $4400 \mathrm{lb}$. was used for the Ford-3000 tractor. Note that Figure 317 has an initial "bump" in the force vs. deflection curve. This could be the result of temporary increased stiffness in the CROPS structure as fasteners connecting the Lshaped plates to the uprights must overcome frictional clamping forces due to torque to move within the dimensional tolerances of holes in the L-shaped plates and upright tubing. Thru-holes in these plates are oversized for ease of assembly by $1 / 16$ ”. 
Ford-3000 CROPS Prototype

SAE J2194 Longitudinal Load

Tractor weight $=\mathbf{4 4 0 0 ~} \mathrm{lb}$

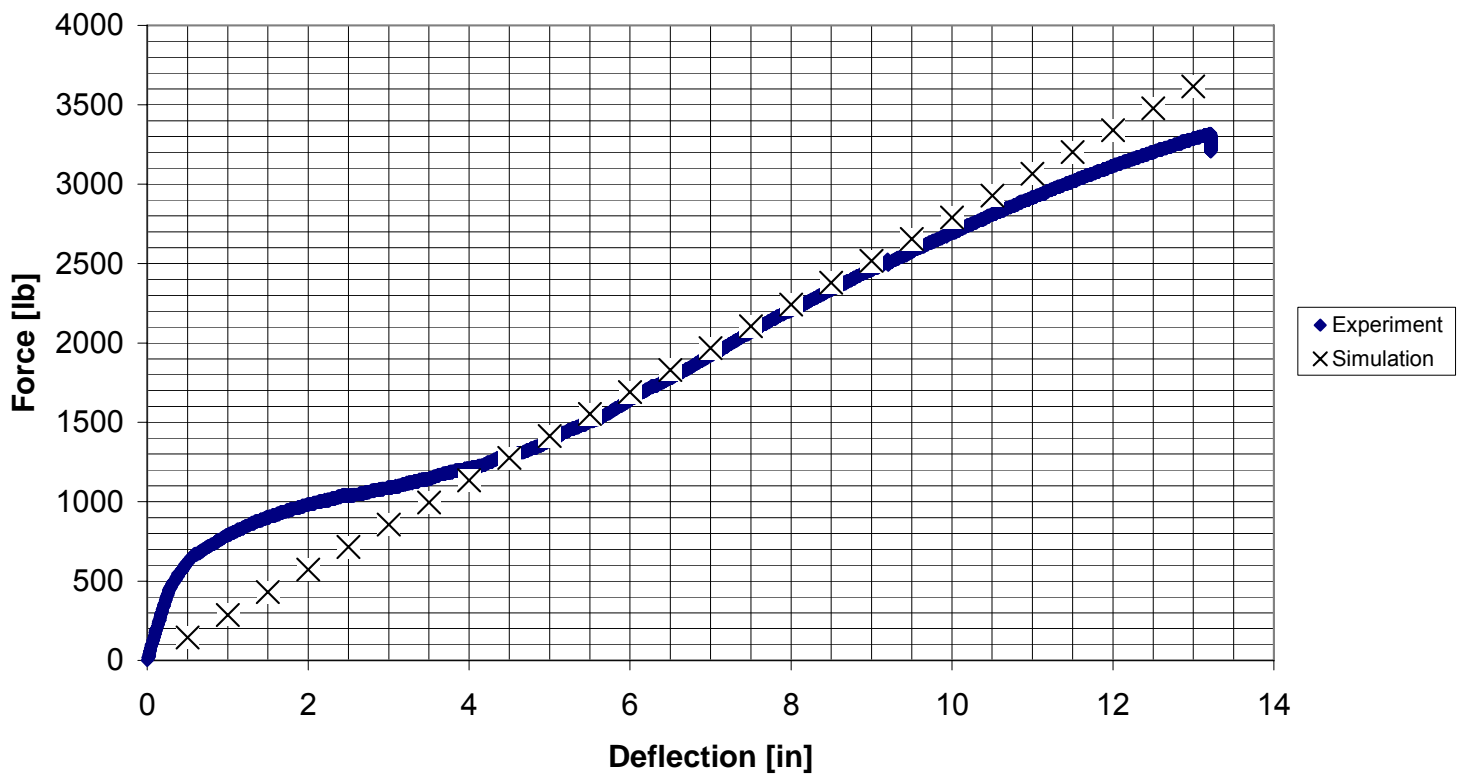

Figure 3-17 Force vs. deflection for longitudinal load. 
Table 3-3 Force vs. deflection data for Ford-3000 longitudinal SAE J2194 test.

\begin{tabular}{|c|c|c|c|}
\hline \multicolumn{2}{|c|}{ Force [lb.] } & \multirow[t]{2}{*}{ Deflection [in.] } & \multirow{2}{*}{$\begin{array}{c}\text { Error [\%] } \\
\text { (E-S)/E x } 100\end{array}$} \\
\hline Experiment & Simulation & & \\
\hline 615 & 144 & 0.5 & 77 \\
\hline 791 & 288 & 1.0 & 64 \\
\hline 898 & 431 & 1.5 & 52 \\
\hline 986 & 573 & 2.0 & 42 \\
\hline 1035 & 714 & 2.5 & 31 \\
\hline 1094 & 855 & 3.0 & 22 \\
\hline 1143 & 996 & 3.5 & 13 \\
\hline 1211 & 1136 & 4.0 & 6 \\
\hline 1289 & 1275 & 4.5 & 1 \\
\hline 1387 & 1414 & 5.0 & -2 \\
\hline 1504 & 1553 & 5.5 & -3 \\
\hline 1641 & 1691 & 6.0 & -3 \\
\hline 1777 & 1829 & 6.5 & -3 \\
\hline 1924 & 1967 & 7.0 & -2 \\
\hline 2070 & 2105 & 7.5 & -2 \\
\hline 2207 & 2242 & 8.0 & -2 \\
\hline 2334 & 2380 & 8.5 & -2 \\
\hline 2461 & 2517 & 9.0 & -2 \\
\hline 2568 & 2654 & 9.5 & -9 \\
\hline 2695 & 2791 & 10.0 & -4 \\
\hline 2812 & 2928 & 10.5 & -12 \\
\hline 2910 & 3065 & 11.0 & -5 \\
\hline 3018 & 3149 & 11.5 & -4 \\
\hline 3115 & 3340 & 12.0 & -7 \\
\hline 3193 & 3478 & 12.5 & -9 \\
\hline 3291 & 3615 & 13.0 & -10 \\
\hline
\end{tabular}


Ford-3000 CROPS Prototype

SAE J2194 Longitudinal Load

Tractor weight $=4400 \mathrm{lb}$

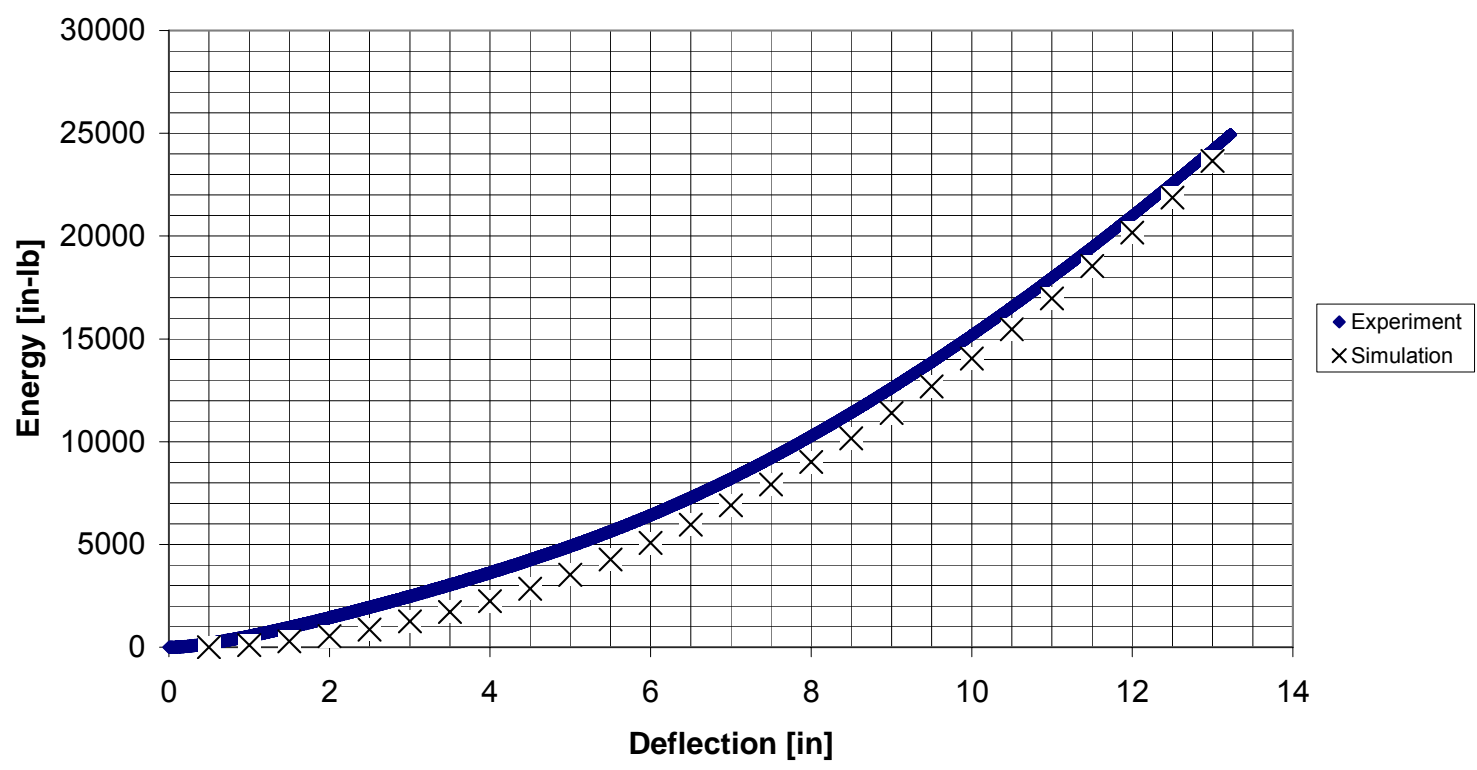

Figure 3-18 Energy vs. deflection for longitudinal load. 
Table 3-4 Energy vs. deflection data for Ford-3000 longitudinal SAE J2194 test.

\begin{tabular}{|c|c|c|c|}
\hline \multicolumn{2}{|c|}{ Energy [in.-lb.] } & \multirow[t]{2}{*}{ Deflection [in.] } & \multirow{2}{*}{$\begin{array}{c}\text { Error [\%] } \\
(\mathrm{E}-\mathrm{S}) / \mathrm{E} \times 100\end{array}$} \\
\hline Experiment & Simulation & & \\
\hline 184 & 36 & 0.5 & 80 \\
\hline 538 & 108 & 1.0 & 80 \\
\hline 970 & 288 & 1.5 & 70 \\
\hline 1440 & 538 & 2.0 & 63 \\
\hline 1945 & 860 & 2.5 & 56 \\
\hline 2473 & 1253 & 3.0 & 49 \\
\hline 3029 & 1715 & 3.5 & 43 \\
\hline 3629 & 2248 & 4.0 & 38 \\
\hline 4251 & 2851 & 4.5 & 33 \\
\hline 4914 & 3523 & 5.0 & 28 \\
\hline 5635 & 4265 & 5.5 & 24 \\
\hline 6414 & 5076 & 6.0 & 21 \\
\hline 7284 & 5956 & 6.5 & 18 \\
\hline 8206 & 6905 & 7.0 & 16 \\
\hline 9199 & 7923 & 7.5 & 14 \\
\hline 10266 & 9010 & 8.0 & 12 \\
\hline 11396 & 10165 & 8.5 & 11 \\
\hline 12615 & 11389 & 9.0 & 10 \\
\hline 13869 & 12682 & 9.5 & 9 \\
\hline 15182 & 14043 & 10.0 & 8 \\
\hline 16551 & 15473 & 10.5 & 7 \\
\hline 17976 & 16972 & 11.0 & 6 \\
\hline 19483 & 18539 & 11.5 & 5 \\
\hline 21010 & 20174 & 12.0 & 4 \\
\hline 22583 & 21879 & 12.5 & 3 \\
\hline 24199 & 23652 & 13.0 & 2 \\
\hline
\end{tabular}




\section{Ford-3000 CROPS Prototype}

SAE J2194 Transverse Load

Tractor weight $=\mathbf{4 4 0 0 \mathrm { lb }}$

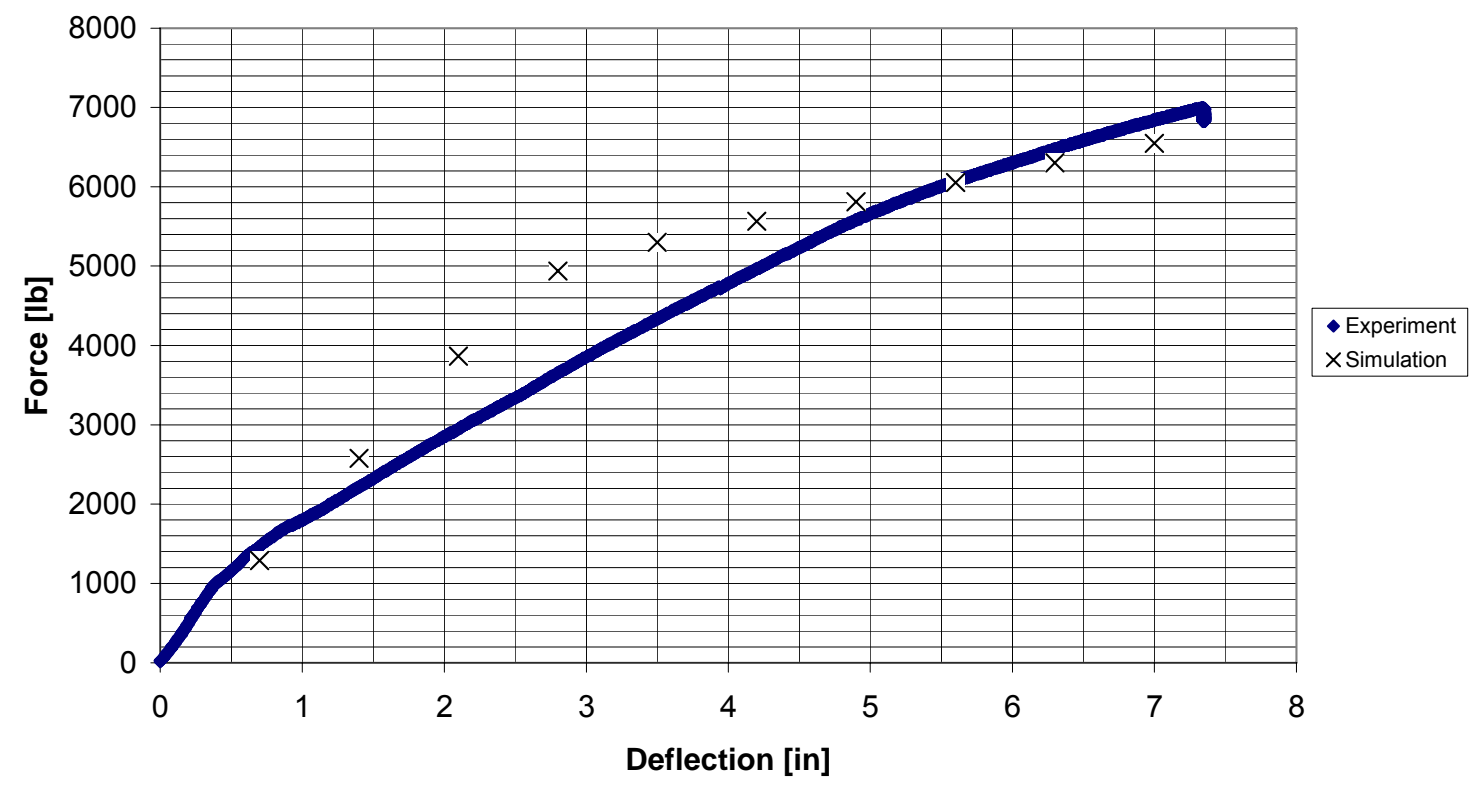

Figure 3-19 Force vs. deflection for transverse load.

Table 3-5 Force vs. deflection data for Ford-3000 transverse SAE J2194 test.

\begin{tabular}{|c|c|c|c|}
\hline \multicolumn{2}{|c|}{ Force [lb.] } & Deflection [in.] & $\begin{array}{c}\text { Error [\%] } \\
\text { (E-S)/E x 100 }\end{array}$ \\
\hline Experiment & Simulation & & 12 \\
\hline 1465 & 1289 & 0.7 & -16 \\
\hline 2217 & 2578 & 1.4 & -31 \\
\hline 2949 & 3866 & 2.1 & -35 \\
\hline 3652 & 4924 & 2.8 & -22 \\
\hline 4336 & 5283 & 3.5 & -12 \\
\hline 4971 & 5547 & 4.2 & -4 \\
\hline 5576 & 5790 & 4.9 & 0.5 \\
\hline 6064 & 6034 & 5.6 & 3 \\
\hline 6475 & 6279 & 6.3 & 5 \\
\hline 6836 & 6528 & 7 & \\
\hline
\end{tabular}


Ford-3000 CROPS Prototype

SAE J2194 Transverse Load

Tractor weight $=\mathbf{4 4 0 0} \mathrm{Ib}$

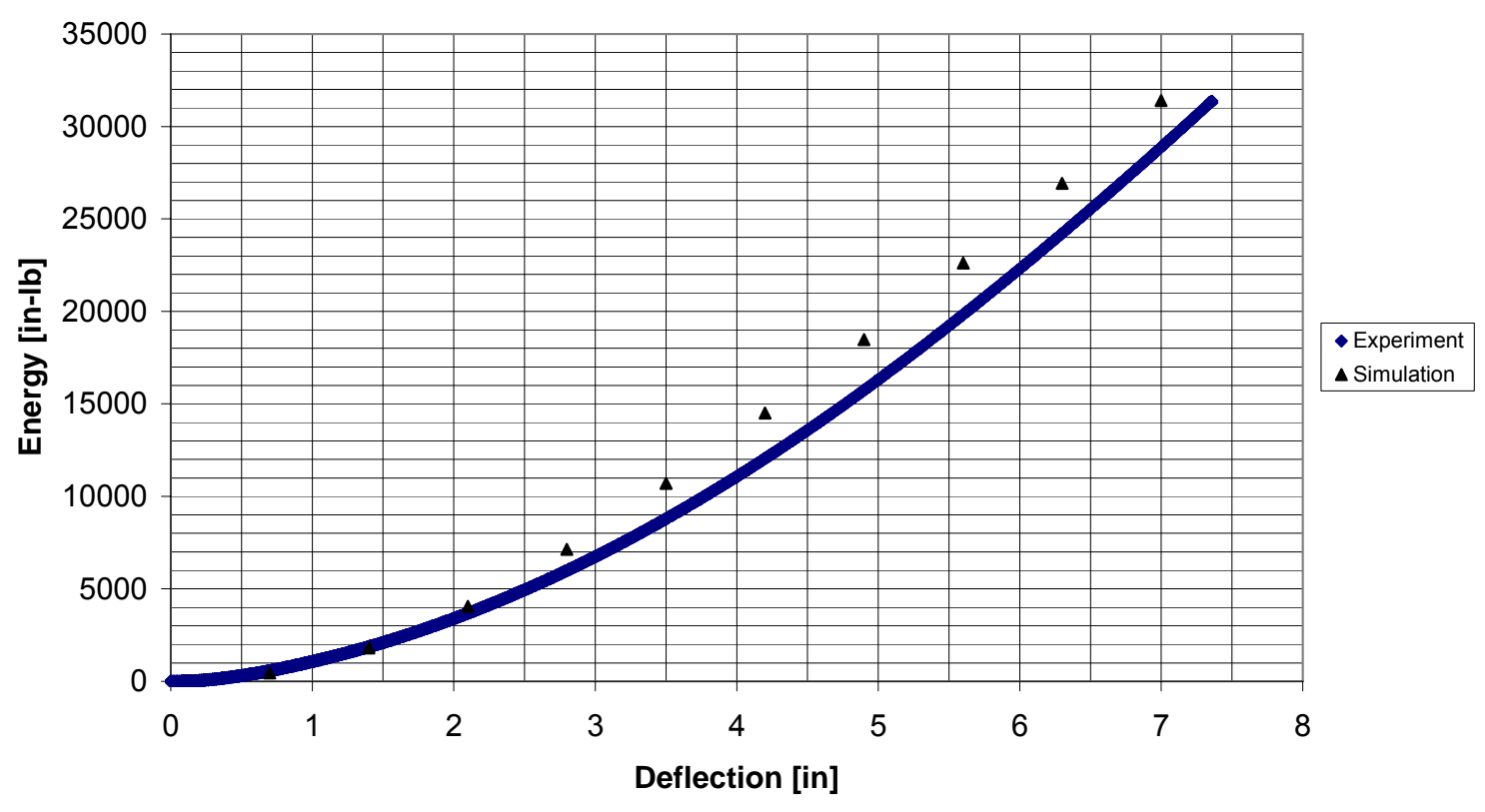

Figure 3-20 Energy vs. deflection for transverse load.

Table 3-6 Energy vs. deflection data for Ford-3000 transverse SAE J2194 test.

\begin{tabular}{|c|c|c|c|}
\hline \multicolumn{2}{|c|}{ Energy [in.-lb.] } & Deflection [in.] & $\begin{array}{c}\text { Error [\%] } \\
\text { (E-S)/E x 100 }\end{array}$ \\
\hline Experiment & Simulation & & 23 \\
\hline 582 & 451 & 0.7 & 3 \\
\hline 1866 & 1804 & 1.4 & -10 \\
\hline 3685 & 4060 & 2.1 & -19 \\
\hline 6003 & 7136 & 2.8 & -22 \\
\hline 8775 & 10709 & 3.5 & -20 \\
\hline 12045 & 14500 & 4.2 & -17 \\
\hline 15756 & 18468 & 4.9 & -14 \\
\hline 19802 & 22606 & 5.6 & -11 \\
\hline 24212 & 26916 & 6.3 & -9 \\
\hline 28896 & 31399 & 7 & \\
\hline
\end{tabular}

As described previously, finite element representation of the bolted connection was important to overall model performance. The results reported for the longitudinal and 
transverse tests were compiled with the following settings for the COMBIN7 elements:

Table 3-7 COMBIN7 element stiffness values.

\begin{tabular}{|c|c|c|c|}
\hline ANSYS variable & Physical meaning & Value & Units \\
\hline K1 & $\begin{array}{c}\text { x-y translational } \\
\text { stiffness }\end{array}$ & 35,750 & lb./in. \\
\hline K2 & z-direction stiffness & 21,400 & lb./in. \\
\hline K3 & $\begin{array}{c}\text { x-y rotational } \\
\text { stiffness }\end{array}$ & 25,000 & lb.-in./rad. \\
\hline TF & friction torque & 2880 & lb.-in. \\
\hline
\end{tabular}

Theoretical values for $K 1, K 2, K 3$, and $T F$ were calculated previously. When the initial theoretical values were employed in the FEA model, numerical instability resulted. This instability could arise from ill-conditioned matrices in the finite element solution. Such matrices could result from rapid changes in stiffness moving from one element to another within the FEA model. Instability is likely to result when the stiffness of neighboring elements is orders of magnitude different from neighboring elements.

To arrive at the values shown in Table 3-7, each value was altered by orders of magnitude from its theoretical prediction and then adjusted more finely until the experimental data was closely approximated. It is important to note that these COMBIN7 stiffness values may also be compensating for other mechanical behavior in the fastened connection that cannot easily be predicted through theoretical calculations. For example, the bottom L-shaped attachment plate bracket (see Figure 3-10 and Appendix A drawing for Item \#8) has a cut where a portion of the plate is bent upward to attach to an upright. This cut is a likely location for stress 
concentration that is not easily captured by the beam element FEA model. Some of the COMBIN7 stiffness values may be compensating for this change in stiffness.

\subsection{Probabilistic design simulation}

\subsubsection{Input variables, response variables, and probabilistic distribution}

Development of the FEA model for probabilistic design simulation (PDS) required three important steps. First, the input variables to be altered and the response variables to be monitored were selected. The following eight variables were chosen initially as input variables (ANSYS variable name in parentheses): beam width (BMWIDTH), beam depth (BMDEPTH), beam thickness (BMTHICK), yield stress (YSTRESS), tangent modulus (TMODULUS), plate thickness (LTHICK), plate yield stress (PYSTRESS), and plate tangent modulus (PTMODULUS). Each input variable was assigned a probabilistic distribution for use in the PDS module of the simulation software. Within the simulation software used, the possible distributions included: Gaussian, truncated Gaussian, lognormal option 1, lognormal option 2, triangular, uniform, exponential, beta, gamma, and Weibull.

The Gaussian distribution is also known as a normal distribution and can be described mathematically with the following equation (Moore and McCabe, 2003):

$$
f(x)=\frac{1}{\sigma \sqrt{2 \pi}} e^{-\frac{1}{2}\left(\frac{x-\mu}{\sigma}\right)^{2}}
$$


Graphically, this distribution follows Figure 3-21. The normal distribution accurately describes the distribution of many naturally occurring phenomena and is a symmetric distribution with two defining parameters, mean $(\mu)$ and standard deviation $(\sigma)$.

A truncated Gaussian distribution simply limits the maximum and/or minimum values that may be obtained.

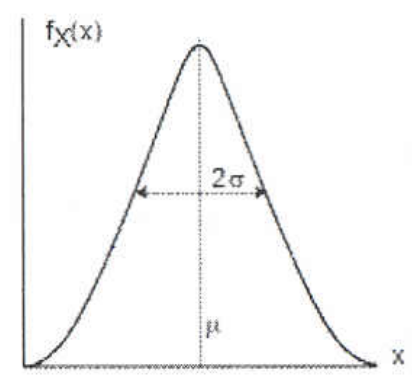

Figure 3-21 Normal distribution.

The lognormal distributions refer to situations where the natural log of the random variable is distributed normally. This skews the distribution to the right. The probability distribution follows the equation below. This distribution is a function of the logarithmic mean value $(\xi)$ and the logarithmic deviation $(\delta)$ and takes the shape shown in Figure 3-22.

$$
f(x)=\frac{1}{\sqrt{2 \pi x \sigma}} e^{-\frac{1}{2}\left(\frac{\ln x-\xi}{\delta}\right)^{2}}
$$

The FEA code allows for two lognormal options. Option 1 requires input of the mean value $\mu$ and the standard deviation $\sigma$. The software calculates logarithmic mean $\xi$ and logarithmic deviation $\delta$. For option 2 , the user directly inputs logarithmic mean $\xi$ and logarithmic deviation $\delta$. The lognormal distribution has application in areas such as fatigue loading endurance limits. 


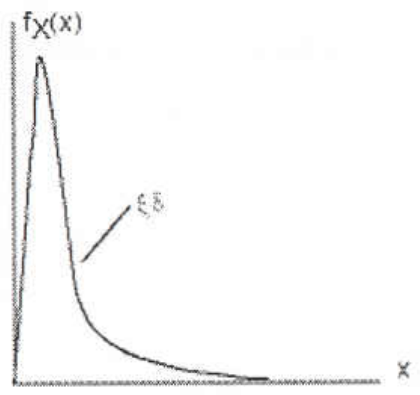

Figure 3-22 - Lognormal distribution.

The triangular distribution is often derived from expert opinion. A minimum value, maximum value, and most likely value are supplied. The result is the shape shown in Figure 3-23.

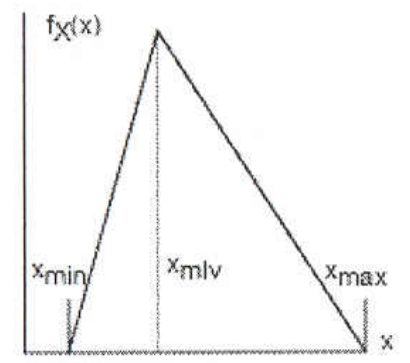

Figure 3-23 Triangular distribution

Uniform distribution implies that all variables between the minimum and maximum have equal likelihood. A graph of this function is displayed in Figure 3-24. This may be an appropriate distribution when the true distribution is not known. 


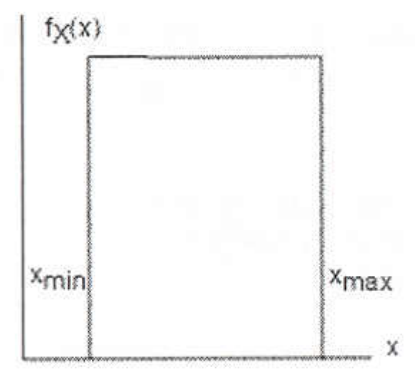

Figure 3-24 Uniform distribution.

An exponential function is employed where the probability density of a random input variable is decreasing and the input variable increases. This distribution can be used for time to failure estimates when the probability of failure is constant. The exponential probability distribution follows the function below:

$$
\begin{aligned}
& f(x)=\frac{1}{\beta} e^{-x / \beta} \text { for } x>0 . \\
& f(x)=0 \text { for } x \leq 0 .
\end{aligned}
$$

The general shape of this function is shown in Figure 3-25.

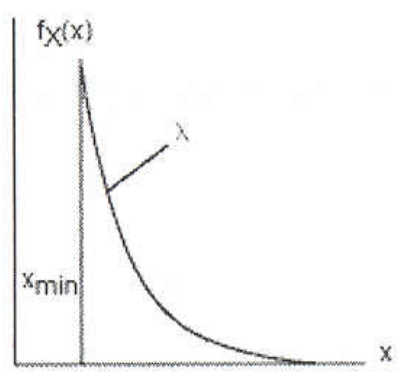

Figure 3-25 Exponential distribution

The gamma distribution is a more general form of the exponential distribution. This distribution makes use of the gamma function that is defined as:

$$
\Gamma(\alpha)=\int x^{\alpha-1} e^{-x} d x \text { for } \alpha>0 .
$$


The gamma distribution takes the form:

$$
\begin{aligned}
& f(x)=\frac{1}{\beta^{\alpha} \Gamma(\alpha)} x^{\alpha-1} e^{-x / \beta}, x>0 \\
& f(x)=0, \text { elsewhere }
\end{aligned}
$$

Where $\alpha>0$ and $\beta>0$. The exponential distribution results from $\alpha=1$. In general, the gamma distribution appears as shown in Figure 3-26.

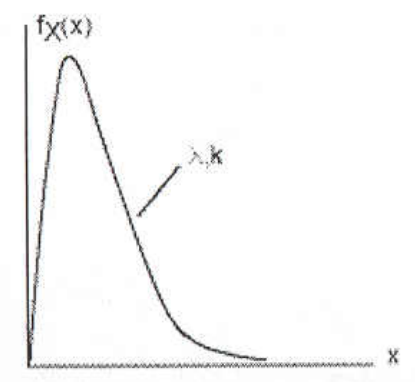

Figure 3-26 Gamma distribution.

The Weibull distribution is similar to the gamma and exponential distribution and has many of the same applications. This distribution is especially applicable to time to failure and life length assessments for components. The general form of the Weibull distribution follows:

$$
\begin{aligned}
& f(x)=\alpha \beta x^{\beta-1} e^{-\alpha x \beta}, x>0 \\
& f(x)=0, \text { elsewhere. }
\end{aligned}
$$

The general shape of the Weibull distribution is displayed in Figure 3-27. 


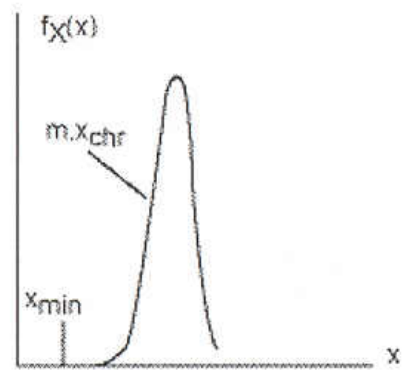

Figure 3-27 Weibull distribution.

For the input parameters chosen in the initial evaluation of the Ford-3000 CROPS simulation, a truncated Gaussian (normal) distribution was selected. Selection of this distribution was justified by previous research which evaluated 57,390 certified mill test reports and identified a Gaussian distribution of ASTM A36 yield point data (Federal Emergency Management Agency, 1997). Other researchers have suggested that process variation (such as beam cross sectional properties) follows a Gaussian distribution (Figiola and Beasley, 1991). The truncated version of the distribution was appropriate since standard specifications often provided minimum and/or maximum values.

All materials used in the experimental tests were provided from the steel mill based upon standard specifications. For the 2" x 3 " x 0.25 " tubing, the standard is ASTM A 500, "Standard Specification for Cold-Formed Welded and Seamless Carbon Steel Structural Tubing in Rounds and Shapes" (ASTM, 2001). In this standard, shaped structural tubing is divided into four categories (Grade A-D). Tubing utilized in the Ford-3000 CROPS prototype was Grade B quality with an ultimate strength of 68,200 psi and a yield (by $0.2 \%$ offset) of 57,500 psi. ASTM A 500 requires a minimum 
tensile (ultimate) strength of 58,000 psi and a minimum yield strength of 46,000 psi.

The FEA software required the following inputs for the truncated Gaussian distribution: average, standard deviation, minimum, and maximum. The minimum value was set at the minimum permissible under the ASTM A 500 standard. The other values were determined by examining certification sheets for steel used to test various products in the NIOSH High-Bay laboratory. Table 3-8 lists the data used to determine distribution parameters.

Table 3-8 Steel properties of CROPS beam materials.

\begin{tabular}{|c|c|c|c|}
\hline Heat number & $\begin{array}{c}\text { Yield strength } \\
\text { [psi] }\end{array}$ & $\begin{array}{c}\text { Tensile strength } \\
\text { [psi] }\end{array}$ & Elongation [\%] \\
\hline BETH/422N1991 & 56500 & 67000 & 30.00 \\
\hline BETH/432K5532 & 60500 & 68500 & 25.00 \\
\hline BETH/422N1992 & 54500 & 64000 & 28.00 \\
\hline ST9282 & 57500 & 68200 & 28.00 \\
\hline Maximum & 60500 & 68500 & 30.00 \\
Average & $\mathbf{5 7 2 5 0}$ & $\mathbf{6 6 9 2 5}$ & $\mathbf{2 7 . 7 5}$ \\
Standard dev. & $\mathbf{2 5 0 0}$ & $\mathbf{2 0 5 5}$ & $\mathbf{2 . 0 6}$ \\
\hline
\end{tabular}

*Used to fabricate Ford-3000 CROPS prototype

Yield strength values were read directly from this table. The tangent modulus distribution parameters were determined by using all three columns of data from the table. All materials were assumed to behave in a linear manner until the yield stress with a slope on the stress-strain curve equal to the Young's modulus. After reaching the yield point, the material was assumed to behave linearly following a curve of lower slope set equal to the tangent modulus. The following relationship was used to calculate tangent modulus:

$$
E_{t \text { modulus }}=\frac{\sigma_{\text {tensile }}-\sigma_{\text {yield }}}{\text { elongation }-0.002}
$$


Table 3-9 ASTM A 500 beam steel tangent modulus values.

\begin{tabular}{|c|c|}
\hline Heat number & Tangent modulus \\
\hline BETH/422N1991 & 35235 \\
\hline BETH/432K5532 & 32258 \\
\hline BETH/422N1992 & 34173 \\
\hline ST9282 & 38489 \\
\hline Maximum & $\mathbf{3 8 4 8 9}$ \\
Average & $\mathbf{3 5 0 3 9}$ \\
Standard dev. & $\mathbf{2 6 0 9}$ \\
\hline
\end{tabular}

Maximum and minimum limits on the geometric properties such as beam depth, beam width, and beam thickness are set by specification in the ASTM A 500 standard. For the beam width (2" dimension), the allowed variation is \pm 0.02 ". For the beam depth (3" dimension), the allowed variation is \pm 0.025 ". Standard deviation for these measurements was estimated at one-fourth of the range according to Tchebysheff's theorem (Scheaffer, Mendehall III, and Ott, 2006). This equates to 0.01 " for beam width and 0.0125 " for beam depth and thickness.

Steel plate used to fabricate reinforcement plates and brackets was manufactured according to ASTM A 36, "Standard Specification for Carbon Structural Steel" (ASTM, 2005). This standard governs the chemical composition of the plates as well as tensile strength, yield strength, and elongation requirements. Tensile strength values are to be between 58,000 and 80,000 psi. Minimum elongation (in 8") is $20 \%$. The minimum yield point is 36,000 psi. To approximate the plate yield stress distribution, the average value was assumed equal to the reported value for the steel used in the Ford-3000 CROPS prototype. This value is 52,000 psi. The maximum yield stress value could be estimated by assuming a symmetric distribution about the average. However, this results in a maximum yield stress of 68,000 psi which could 
be greater than the tensile strength. Consequently, the maximum yield stress will be set equal to the minimum tensile strength of 58,000. As mentioned previously, Tchebysheff's theorem was used as an initial estimate of the standard deviation for this distribution. This resulted in an estimated standard deviation of 5,500 psi. Using the maximum tensile stress of $80,000 \mathrm{psi}$ and the minimum yield stress, a maximum tangent modulus was calculated as $157,895 \mathrm{psi}((80,000-36,000) /(0.23-0.002))$. The minimum tangent modulus was calculated as $(58,000-36,000) /(0.23-0.002)=96,491$ psi. The average tangent modulus for the distribution was calculated using mill sheet data for A36 material used in the NIOSH High Bay Laboratory. For this material, the tensile stress was listed as 74,000 psi and the yield stress was listed as 52,000. Elongation was 21.4\%. Utilizing Equation 3-23, the tangent modulus could be estimated as 103,774 psi. The standard deviation was estimated from Tchebysheff's theorem as 15,351 psi. Variation in plate thickness was estimated from manufacturing specifications (Speedymetals, 2008). Table 3-10 summarizes the truncated Gaussian distribution parameters utilized in the FEA code.

Table 3-10 Truncated Gaussian distribution parameters for FEA code.

\begin{tabular}{|c|c|c|c|c|}
\hline & minimum & average & maximum & std. dev. \\
\hline ASTM A 500 & & & & \\
\hline BMWIDTH & $1.98 \mathrm{in}$. & $2.0 \mathrm{in}$. & $2.02 \mathrm{in}$. & $0.010 \mathrm{in}$. \\
\hline BMDEPTH & $2.975 \mathrm{in}$. & $3.0 \mathrm{in}$. & $3.025 \mathrm{in}$. & $0.0125 \mathrm{in}$. \\
\hline BMTHICK & $0.225 \mathrm{in}$. & $0.25 \mathrm{in}$. & $0.275 \mathrm{in}$. & $0.0125 \mathrm{in}$. \\
\hline YSTRESS & $46,000 \mathrm{psi}$ & $57,250 \mathrm{psi}$ & $60,500 \mathrm{psi}$ & $2500 \mathrm{psi}$ \\
\hline TMODULUS & $32,258 \mathrm{psi}$ & $35,039 \mathrm{psi}$ & $38,489 \mathrm{psi}$ & $2609 \mathrm{psi}$ \\
\hline ASTM A 36 & & & & \\
\hline LTHICK & $0.345 \mathrm{in}$. & $0.375 \mathrm{in}$. & $0.405 \mathrm{in}$. & $0.015 \mathrm{in}$. \\
\hline PYSTRESS & $36,000 \mathrm{psi}$ & $52,000 \mathrm{psi}$ & $58,000 \mathrm{psi}$ & $5500 \mathrm{psi}$ \\
\hline PTMODULUS & $96,491 \mathrm{psi}$ & $103,774 \mathrm{psi}$ & $157,895 \mathrm{psi}$ & $15,351 \mathrm{psi}$ \\
\hline
\end{tabular}




\subsubsection{Screening tests}

With the distributions estimated for each random input variable, the FEA model was executed in the PDS mode. A direct Monte Carlo method was used where each random input variable was randomly assigned a value according to the probabilistic distribution chosen. The model was executed in a mode that called for 30 loops or termination after the mean of the input variables converged to $1 \%$ and the standard deviation converged to $2 \%$. This model did not converge through all portions of SAE J2194 testing during loop 6 . Table 3-11 shows the randomly assigned parameters for the loop where failure occurred.

Table 3-11 CROPS parameter values for simulation failure.

\begin{tabular}{|c|c|}
\hline Parameter name & Parameter value \\
\hline BMWIDTH & $1.996^{\prime \prime}$ \\
\hline BMDEPTH & $3.008^{\prime \prime}$ \\
\hline BMTHICK & $0.246 "$ \\
\hline YSTRESS & $59,959 \mathrm{psi}$ \\
\hline TMODULUS & $36,745 \mathrm{psi}$ \\
\hline LTHICK & $0.364 "$ \\
\hline PYSTRESS & $41,708 \mathrm{psi}$ \\
\hline PTMODULUS & $99,034 \mathrm{psi}$ \\
\hline
\end{tabular}

The ASTM A 36 parameters (which refer to the L-shaped axle housing attachment plates and are listed in Table 3-10) were adjusted to their average values while maintaining all ASTM A 500 properties at the values listed in Table 3-11. This allowed some assessment of whether FEA convergence issues were related to structural performance of the axle housing attachment plates. With LTHICK, PYSTRESS, and PTMODULUS at average values, the model successfully moved beyond previous convergence difficulties. 
Using the parameters listed in Table 3-11, the vertical crush load value was altered until the FEA model converged through all four loads (longitudinal, vertical 1, transverse, vertical 2) of the SAE J2194 static test sequence. Convergence did not occur until the vertical crush load was lowered to $2750 \mathrm{lb}$.

The FEA input code was modified to perform testing as described in 29 OSHA 1928.52. The primary differences between SAE J2194 static testing and OSHA testing are: (1) only longitudinal and transverse loading required by OSHA testing, (2) increased energy criteria for both longitudinal and transverse OSHA testing, and (3) different means for assessing exposure during OSHA testing (i.e. critical dimensions rather than the SAE J2194 clearance zone).

As stated earlier in Chapter 2, the OSHA requirements follow much of what was initially included in SAE J334. The rear (longitudinal) and side (transverse) energy requirements follow Equations 2-1 and 2-2. With a reference weight of 4400lb., the resulting rear load energy requirement is $24,816 \mathrm{in}$.-lb. The OSHA standard allows the field upset test to be skipped if the rear load energy requirement is raised by $15 \%$ to $28,538 \mathrm{in}$.-lb. The side load energy requirement is $29,796 \mathrm{in}$.-lb. To avoid the field upset test, this value increases to 34,265 in.-lb.

Exposure and intrusion are evaluated through the use of dimensions discussed previously in Chapter 2. Figures 3-28 and 3-29 display the critical dimensions. 


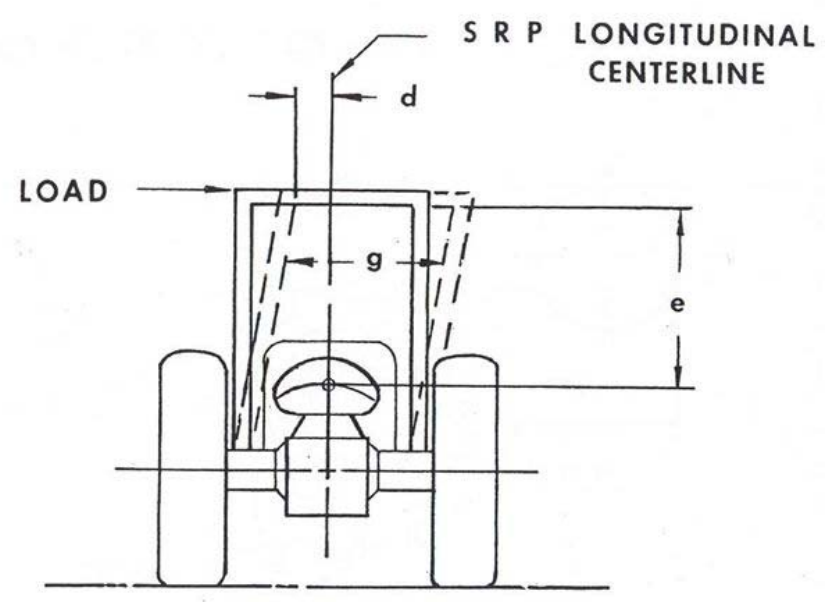

Figure 3-28 Critical dimensions for OSHA 1928.52 transverse load.

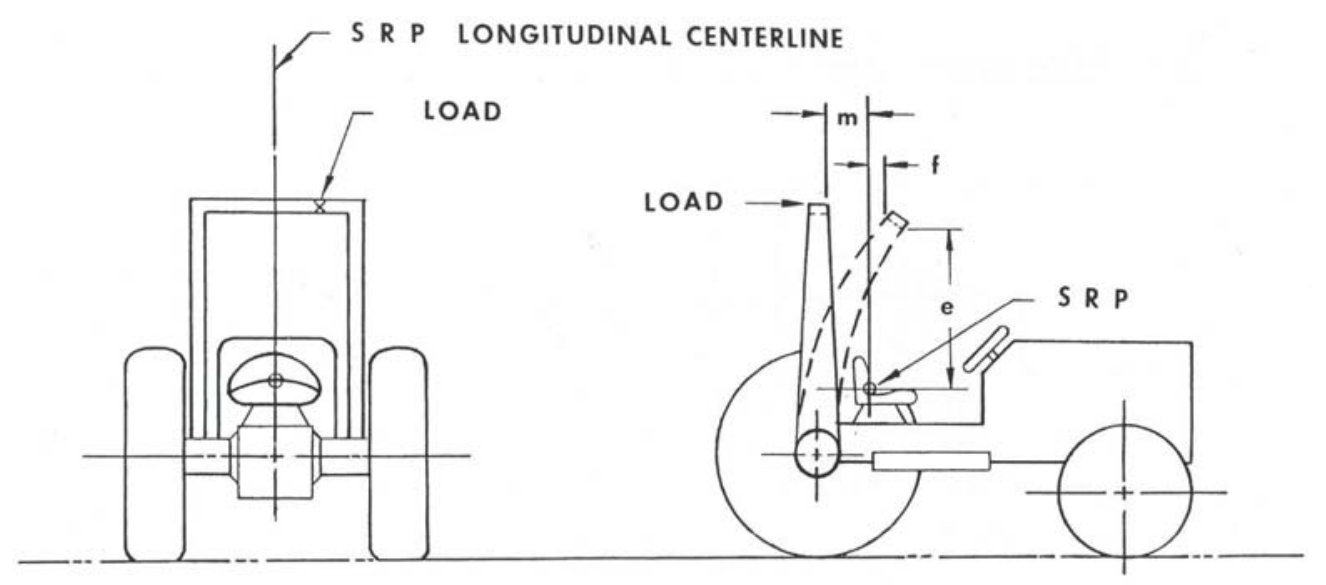

Figure 3-29 Critical dimensions for OSHA 1928.52 longitudinal load.

Based on these figures, the following dimensional requirements must be met.

Table 3-12 OSHA required dimensions.

\begin{tabular}{|c|c|}
\hline Dimension & Requirement \\
\hline $\mathrm{d}$ & $\geq 2 "$ \\
\hline $\mathrm{e}$ & $\geq 30 "$ \\
\hline $\mathrm{f}$ & $\leq 4 "$ \\
\hline $\mathrm{g}$ & $\geq 24^{\prime \prime}$ \\
\hline $\mathrm{m}$ & $\leq 12^{\prime \prime}$ \\
\hline
\end{tabular}


Fifty initial Monte Carlo loops through the OSHA static test sequence were conducted. All loops successfully solved within the FEA code, and no intrusion/exposure failures were detected.

Initial factors of interest in the PDS model included: upright beam thickness, beam cross-section width, beam cross-section depth, beam yield stress, tangent modulus for beam, axle housing attachment plate thickness, axle housing attachment plate yield stress, and axle housing attachment plate tangent modulus. Only two of these variables had significant influence at the $2.5 \%$ level for transverse load level (RFX) during the OSHA test. These variables were beam thickness (BMTHICK) and beam yield stress (YSTRESS). Sensitivity was calculated in the FEA code through use of a nonparametric statistic, Spearman's rank correlation. Each random input variable mentioned above was evaluated for correlation with the output variable quantifying transverse load level (RFX). ANSYS employs a standard procedure as outlined in many statistics text (e.g. Dowdy, Wearden, Chilko, 2004).

$$
r_{s}=\frac{\sum\left(r_{x}-\bar{r}_{x}\right)\left(r_{y}-\bar{r}_{y}\right)}{\sqrt{\sum\left(r_{x}-\bar{r}_{x}\right)^{2} \sum\left(r_{y}-\bar{r}_{y}\right)^{2}}}
$$

where,

$$
\begin{aligned}
& r_{x}=\text { rank of the } x \text { variable } \\
& r_{y}=\text { rank of companion } y \text { variable. }
\end{aligned}
$$

By manipulating the equation we can show that:

$$
r_{s}=1-\frac{6 \sum d^{2}}{N\left(N^{2}-1\right)}
$$


where,

$$
\begin{aligned}
& d=r_{x}-r_{y} \\
& N=\text { number of sample points }
\end{aligned}
$$

The null hypothesis of independence of $r_{x}$ and $r_{y}$ implies:

$$
E\left(r_{s}\right)=0 \text { and } V\left(r_{s}\right)=\frac{1}{N-1}
$$

Where,

$$
\begin{aligned}
& E\left(r_{s}\right)=\text { the expected value of } r_{s} \\
& V\left(r_{s}\right)=\text { the variance of } r_{s}
\end{aligned}
$$

With more than $10 \mathrm{x}-\mathrm{y}$ pairs, $r_{s}$ can be approximated by a normal distribution and the null hypothesis can be tested with a $z$ test:

$$
Z=\frac{r_{s}-0}{\sqrt{\frac{1}{N-1}}}=r_{s} \sqrt{N-1}
$$

This leads to the following sensitivity table for all random input variables:

Table 3-13 Sensitivity for random input variables with respect to transverse load.

\begin{tabular}{|c|c|}
\hline Random input variable & Sensitivity $\left(\mathbf{r}_{\mathbf{s}}\right)$ \\
\hline YSTRESS $^{*}$ & $6.4840 \mathrm{e}-001$ \\
\hline BMTHICK $^{*}$ & $4.7236 \mathrm{e}-001$ \\
\hline BMWIDTH & $-1.3479 \mathrm{e}-001$ \\
\hline BMDEPTH & $9.6471 \mathrm{e}-002$ \\
\hline TMODULUS & $-2.2555 \mathrm{e}-001$ \\
\hline LTHICK & $-1.4987 \mathrm{e}-001$ \\
\hline PYSTRESS & $1.7830 \mathrm{e}-001$ \\
\hline PTMODULUS & $4.6531 \mathrm{e}-002$ \\
\hline
\end{tabular}

* indicates significance at the $2.5 \%$ level

Knowing that the limiting $z$-value to show $2.5 \%$ significance is 1.96 and the number of samples was 50, the critical $r_{s}$-value was determined as $\left|r_{s}\right|>0.280$. 
Similarly, the Spearman rank sensitivity was calculated for other important response variables during OSHA transverse loading. Table 3-14 shows the sensitivity values for the response variable $D T$. $D T$ is the FEA variable for dimension $d$ in Figure 3-28.

Table 3-14 Sensitivity of random input variables with respect to DT.

* indicates significance at the $2.5 \%$ level

\begin{tabular}{|c|c|}
\hline Random input variable & Sensitivity $\left(\mathbf{r}_{\mathbf{s}}\right)$ \\
\hline BMTHICK $^{*}$ & $6.1998 \mathrm{e}-001$ \\
\hline BMWIDTH $^{*}$ & $-6.0547 \mathrm{e}-001$ \\
\hline YSTRESS $^{*}$ & $3.3186 \mathrm{e}-001$ \\
\hline BMDEPTH & $1.7719 \mathrm{e}-002$ \\
\hline TMODULUS & $-2.7371 \mathrm{e}-003$ \\
\hline LTHICK & $-7.4670 \mathrm{e}-002$ \\
\hline PYSTRESS & $-1.3546 \mathrm{e}-001$ \\
\hline PTMODULUS & $1.3306 \mathrm{e}-001$ \\
\hline
\end{tabular}

Table 3-15 shows the sensitivity values for the response variable ET. ET is the FEA variable for dimension $e$ in Figure 3-28.

Table 3-15 Sensitivity of random input variables with respect to ET.

\begin{tabular}{|c|c|}
\hline Random input variable & Sensitivity $\left(\boldsymbol{r}_{\mathbf{s}}\right)$ \\
\hline YSTRESS $^{*}$ & $6.6579 \mathrm{e}-001$ \\
\hline BMTHICK $^{*}$ & $5.6773 \mathrm{e}-001$ \\
\hline BMWIDTH & $-1.0511 \mathrm{e}-001$ \\
\hline BMDEPTH & $5.8631 \mathrm{e}-002$ \\
\hline TMODULUS & $-1.1914 \mathrm{e}-003$ \\
\hline LTHICK & $-1.0324 \mathrm{e}-002$ \\
\hline PYSTRESS & $1.1280 \mathrm{e}-001$ \\
\hline PTMODULUS & $1.6860 \mathrm{e}-001$ \\
\hline
\end{tabular}

* indicates significance at the $2.5 \%$ level

Previous ROPS testing experience suggests that a key consideration during OSHA static testing should be performance under transverse load. However, to investigate possible failures during OSHA longitudinal loading, a Spearman rank sensitivity analysis was also performed after 50 simulation loops of the longitudinal portion of 
the OSHA test. The resulting data are presented in Tables 3-16 through 3-19. These data represent the sensitivity of each random input variable to the output variables longitudinal load (RFZ) and the dimensions $m, f$, and $e$ (see Figure 3-29).

Table 3-16 Sensitivity of random input variables with respect to RFZ.

\begin{tabular}{|c|c|}
\hline Random input variable & Sensitivity $\left(\boldsymbol{r}_{\mathbf{s}}\right)$ \\
\hline BMTHICK $^{*}$ & $8.2137 \mathrm{e}-001$ \\
\hline YSTRESS $^{*}$ & $4.4586 \mathrm{e}-001$ \\
\hline BMWIDTH & $6.6891 \mathrm{e}-002$ \\
\hline BMDEPTH & $1.9448 \mathrm{e}-002$ \\
\hline TMODULUS & $-1.5918 \mathrm{e}-001$ \\
\hline LTHICK & $-1.0228 \mathrm{e}-002$ \\
\hline PYSTRESS & $2.4634 \mathrm{e}-002$ \\
\hline PTMODULUS & $5.7383 \mathrm{e}-002$ \\
\hline
\end{tabular}

* indicates significance at the $2.5 \%$ level

Table 3-17 Sensitivity of random input variables with respect to $M$.

\begin{tabular}{|c|c|}
\hline Random input variable & Sensitivity $\left(\boldsymbol{r}_{\mathbf{s}}\right)$ \\
\hline BMDEPTH $^{*}$ & -1.0000 \\
\hline BMWIDTH & $-1.3834 \mathrm{e}-001$ \\
\hline BMTHICK & $2.6559 \mathrm{e}-001$ \\
\hline YSTRESS & $-9.6567 \mathrm{e}-002$ \\
\hline TMODULUS & $6.9388 \mathrm{e}-002$ \\
\hline LTHICK & $-9.5990 \mathrm{e}-002$ \\
\hline PYSTRESS & $-9.0804 \mathrm{e}-002$ \\
\hline PTMODULUS & $2.8283 \mathrm{e}-002$ \\
\hline
\end{tabular}

* indicates significance at the $2.5 \%$ level

Table 3-18 Sensitivity of random input variables with respect to $F$.

\begin{tabular}{|c|c|}
\hline Random input variable & Sensitivity $\left(\mathbf{r}_{\mathbf{s}}\right)$ \\
\hline BMDEPTH $^{*}$ & -1.0000 \\
\hline BMWIDTH & $-1.3834 \mathrm{e}-001$ \\
\hline BMTHICK & $2.6559 \mathrm{e}-001$ \\
\hline YSTRESS & $-9.6567 \mathrm{e}-002$ \\
\hline TMODULUS & $6.9388 \mathrm{e}-002$ \\
\hline LTHICK & $-9.5990 \mathrm{e}-002$ \\
\hline PYSTRESS & $-9.0804 \mathrm{e}-002$ \\
\hline PTMODULUS & $2.8283 \mathrm{e}-002$ \\
\hline
\end{tabular}

* indicates significance at the $2.5 \%$ level 
Table 3-19 Sensitivity of random input variables with respect to $E$.

\begin{tabular}{|c|c|}
\hline Random input variable & Sensitivity $\left(r_{\mathbf{s}}\right)$ \\
\hline BMTHICK $^{*}$ & $7.8977 \mathrm{e}-001$ \\
\hline YSTRESS $^{*}$ & $4.1743 \mathrm{e}-001$ \\
\hline BMWIDTH & $9.9928 \mathrm{e}-002$ \\
\hline BMDEPTH & $8.4754 \mathrm{e}-002$ \\
\hline TMODULUS & $-1.6043 \mathrm{e}-001$ \\
\hline LTHICK & $-2.3208 \mathrm{e}-001$ \\
\hline PYSTRESS & $3.9904 \mathrm{e}-002$ \\
\hline PTMODULUS & $6.8427 \mathrm{e}-002$ \\
\hline
\end{tabular}

$*$ indicates significance at the $2.5 \%$ level

\subsubsection{Development and evaluation of response surfaces}

Based upon the results of the screening tests performed in section 3.6.2, response surfaces were developed to predict output variables for various combinations of the input variables. Development of response surfaces was limited to OSHA testing simulations. As described previously, SAE J2194 static testing simulations identified combinations of input parameters where the Ford-3000 CROPS could not meet the failure criteria of all test phases. This presented a discontinuity in the response of the CROPS structure and prevented the mathematical modeling of a continuous surface.

The transverse (and final) loading phase of OSHA testing was of special interest and was chosen for detailed response surface analysis. Table 3-14 shows that three variables were significantly correlated with dimension $d$ (FEA variable DT) during transverse loading. These variables were upright/crossbar beam thickness (BMTHICK), upright/crossbar beam width (BMWIDTH), and upright/crossbar beam yield stress (YSTRESS). 
Using these three influential variables only, a central composite design (CCD) was run to evaluate the design space. A three factor CCD design is shown graphically in Figure 3-30. Simulations were run at the extreme of each factor (corners of the cube) as well as the mid-point (center of cube). Additionally, six runs were conducted at axial points (points extended normal to each cube face). This CCD design resulted in 15 simulation runs and was a resolution $\mathrm{V}$ design. A resolution $\mathrm{V}$ design ensured that second order interaction effects were not confounded with each other.

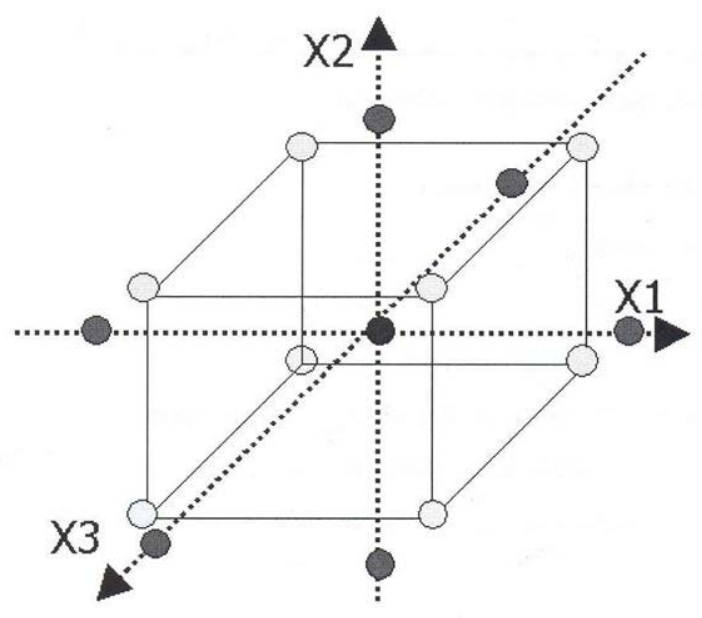

Figure 3-30 CCD simulation description.

A response surface was developed based upon the results of the 15 trials to predict dimension $d$ (output variable DT in FEA input file) during transverse loading. The response surface was a quadratic regression which included all linear and cross terms. In general, the response surface had the form: 


$$
y=c_{0}+\sum_{i=1}^{N R V} C_{i} X_{i}+\sum_{i=1}^{N R V} \sum_{j=1}^{N R V} C_{i j} X_{i} \times X_{j}
$$

where,

$c_{0}$ is the coefficient of the constant term

$c_{i}, \mathrm{i}=1, \ldots \mathrm{NRV}$ are the coefficients of the linear terms

$c_{i j}, \mathrm{i}=1, \ldots \mathrm{NRV}$ and $\mathrm{j}=1, \ldots \mathrm{NRV}$ are the coefficients of the quadratic terms

In the regression analysis, the coefficients were estimated so that the sum of squared differences between the true simulation results and the values of the approximation function were minimized. The regression algorithm employed by the FEA code was forward-stepwise-regression. Forward-stepwise-regression is an iterative process whereby regression terms are added to the model if they produce a significant improvement in the regression results. The level of significance in the improvement is measured by a partial F-test as shown in Equation 3-28.

$$
F_{p+1}^{*}=\frac{S S E_{p}-S S E_{p+1}}{v_{p}-v_{p+1}} / \frac{S S E_{p+1}}{v_{p+1}}
$$

where,

$$
\begin{aligned}
& F_{p+1}^{*}=\text { partial Fisher } F \text {-test statistic } \\
& S S E_{p}=\text { error sum of squares in the regression model with } p \text { terms } \\
& S S E_{p+1}=\text { error sum of squares in the regression model with } p+1 \text { terms } \\
& v_{p}=n-p=\text { the degrees of freedom in the regression model with } p \text { terms }
\end{aligned}
$$


$v_{p+1}=n-(p+1)=$ the degrees of freedom in the regression model with $p+1$

terms

If the condition in Equation 3-29 is met, the additional term is considered to have caused a significant improvement in the regression model.

$$
F_{p+1}^{*}>F(1-\alpha \mid 1, n-(p+1))
$$

where,

$$
\begin{aligned}
& F\left(\ldots \mid v_{1}, v_{2}\right)=\text { the inverse cumulative distribution function of the Fisher } F- \\
& \text { distribution with } v_{1} \text { numerator degrees of freedom and } v_{2} \text { denominator } \\
& \text { degrees of freedom } \\
& \alpha=\text { significance level }
\end{aligned}
$$

With a choice of several terms to add to the regression model, only the term with the maximum $F_{p+1}^{*}$ (if satisfying Equation 3-29) is added on each iterative step. Additionally, a significance evaluation is performed on all terms in the regression model to see if they are still significant after adding the newest term. Any term will be removed from the model if it does not meet conditions of Equations 3-28 and 3-29.

Based upon this forward-stepwise-regression, the following variables and coefficients were included in the model (A detailed listing of the regression results is provided in Appendix C): 
Table 3-20 Regression coefficients for response surface to predict variable DT.

\begin{tabular}{|c|c|}
\hline Term & Coefficient \\
\hline CONSTANT & 7.23333 \\
\hline BMWIDTH_scaled & $1.29093 \mathrm{e}-001$ \\
\hline BMTHICK_scaled & $1.34797 \mathrm{e}-001$ \\
\hline YSTRESS_scaled & $1.34797 \mathrm{e}-001$ \\
\hline
\end{tabular}

Scaling for each of the variables was handled as follows:

BMWIDTH_scaled $=8.76610 \mathrm{e}+001 *$ BMWIDTH $-1.75322 \mathrm{e}+002$

BMTHICK_scaled $=7.01288 \mathrm{e}+001 *$ BMTHICK $-1.75322 \mathrm{e}+001$

YSTRESS_scaled $=3.46344 \mathrm{e}-004 *$ YSTRESS $-1.92496 \mathrm{e}+001$

The entire regression equation is DT $=$ Sum of (Coefficient*Term).

Values for each CCD simulation point and the estimated value from the regression equation are listed in Table 3-21.

Table 3-21 Response surface predictions for DT variable at CCD sample points.

\begin{tabular}{|c|c|c|c|}
\hline Sample & Residual value & Sampled value & $\begin{array}{c}\text { Approximated } \\
\text { value }\end{array}$ \\
\hline 1 & $-2.333333 \mathrm{e}-001$ & 7.000000 & 7.233333 \\
\hline 2 & $-6.633514 \mathrm{e}-003$ & 7.009593 & 7.016226 \\
\hline 3 & $3.996685 \mathrm{e}-002$ & 7.490407 & 7.450441 \\
\hline 4 & $-6.633513 \mathrm{e}-003$ & 7.000000 & 7.006634 \\
\hline 5 & $3.996685 \mathrm{e}-002$ & 7.500000 & 7.460033 \\
\hline 6 & $-6.633514 \mathrm{e}-003$ & 7.000000 & 7.006634 \\
\hline 7 & $3.996685 \mathrm{e}-002$ & 7.500000 & 7.460033 \\
\hline 8 & $1.710562 \mathrm{e}-001$ & 7.005704 & 6.834648 \\
\hline 9 & $-9.853681 \mathrm{e}-002$ & 6.994296 & 7.092833 \\
\hline 10 & $-9.853681 \mathrm{e}-002$ & 7.005704 & 7.104241 \\
\hline 11 & $1.318701 \mathrm{e}-001$ & 7.494296 & 7.362426 \\
\hline 12 & $-9.853681 \mathrm{e}-002$ & 7.005704 & 7.104241 \\
\hline 13 & $1.318701 \mathrm{e}-001$ & 7.494296 & 7.362426 \\
\hline 14 & $1.318701 \mathrm{e}-001$ & 7.505704 & 7.373834 \\
\hline 15 & $-1.377229 \mathrm{e}-001$ & 7.494296 & 7.632019 \\
\hline
\end{tabular}


The $r$-squared coefficient of determination for this response surface was 0.7930557 .

The root mean square for the response surface was 0.1310427 . The predicted lowest simulation value for DT was derived by utilizing minimum distribution values for BMWIDTH, BMTHICK, and YSTRESS with the regression equation coefficients of Table 3-20. In order, the minimum values were 1.98”, 0.225 ", and 46000 psi. This resulted in a minimum predicted DT value of 6.32345 ". The margin of error for the response surface was $\pm t^{*} S E$, where $t^{*}$ follows the $t$ distribution with $11 \mathrm{~d}$.f. and for $95 \%$ confidence interval was 2.201. SE was the standard error for DT prediction and was equivalent to the root mean square error of 0.1310427 . As a result, the margin of error was $(2.201) *(0.1310427)=0.28842$ ". Combining the minimum predicted value of DT and the margin of error yielded a 95\% confidence interval for simulations of minimum BMWIDTH, BMTHICK, and YSTRESS values of (6.0350”,6.6118”). That is, $95 \%$ of all simulations utilizing the minimum values for BMWIDTH, BMTHICK, and YSTRESS should fall within the range of 6.0350" and 6.6118”.

A similar procedure was followed for dimension $e(E T)$ in Figure 3-28. Although Table 3-15 shows only two statistically significant input variables (YSTRESS and BMTHICK), the three variables of highest sensitivity were used (YSTRESS, BMTHICK, and PTMODULUS) to conduct CCD for ET. Table 3-22 lists the regression coefficients for the variables. 
Table 3-22 Regression coefficients for response surface to predict variable ET.

\begin{tabular}{|c|c|}
\hline Term & Coefficient \\
\hline CONSTANT & 37.9251 \\
\hline BMTHICK_scaled & $2.26535 \mathrm{e}-002$ \\
\hline YSTRESS_scaled & $2.36515 \mathrm{e}-002$ \\
\hline PTMODULUS_scaled * PTMODULUS_scaled & $-1.03057 \mathrm{e}-002$ \\
\hline BMTHICK_scaled ${ }^{*}$ YSTRESS_scaled & $1.83924 \mathrm{e}-002$ \\
\hline
\end{tabular}

Scaling for each of the variables was handled as follows:

PTMODULUS_scaled $=1.08293 \mathrm{e}-004 *$ PTMODULUS $-1.21406 \mathrm{e}+001$

BMTHICK_scaled $=7.01288 \mathrm{e}+001 *$ BMTHICK $-1.75322 \mathrm{e}+001$

YSTRESS_scaled $=3.46344 \mathrm{e}-004 *$ YSTRESS $-1.92496 \mathrm{e}+001$

Values for each CCD simulation point and the estimated value from the regression equation are listed in Table 3-23.

Table 3-23 Response surface predictions for ET variable at CCD sample points.

\begin{tabular}{|c|c|c|c|}
\hline Sample & Residual value & Sampled value & $\begin{array}{c}\text { Approximated } \\
\text { value }\end{array}$ \\
\hline 1 & $-2.874882 \mathrm{e}-002$ & 37.89630 & 37.92505 \\
\hline 2 & $4.001567 \mathrm{e}-004$ & 37.89630 & 37.89590 \\
\hline 3 & $4.001567 \mathrm{e}-004$ & 37.89630 & 37.89590 \\
\hline 4 & $4.130455 \mathrm{e}-003$ & 37.89108 & 37.88695 \\
\hline 5 & $1.085488 \mathrm{e}-002$ & 37.97401 & 37.96315 \\
\hline 6 & $4.246195 \mathrm{e}-003$ & 37.88952 & 37.88528 \\
\hline 7 & $1.098060 \mathrm{e}-002$ & 37.97581 & 37.96483 \\
\hline 8 & $2.546417 \mathrm{e}-003$ & 37.88938 & 37.88683 \\
\hline 9 & $2.546417 \mathrm{e}-003$ & 37.88938 & 37.88683 \\
\hline 10 & $-2.808555 \mathrm{e}-004$ & 37.89508 & 37.89536 \\
\hline 11 & $-2.808555 \mathrm{e}-004$ & 37.89508 & 37.89536 \\
\hline 12 & $-2.850516 \mathrm{e}-004$ & 37.89707 & 37.89735 \\
\hline 13 & $-2.850516 \mathrm{e}-004$ & 37.89707 & 37.89735 \\
\hline 14 & $-3.112324 \mathrm{e}-003$ & 37.97633 & 37.97944 \\
\hline 15 & $-3.112324 \mathrm{e}-003$ & 37.97633 & 37.97944 \\
\hline
\end{tabular}

The $r$-squared coefficient of determination for this response surface is 0.943 . 


\subsubsection{Monte Carlo simulations and reliability prediction}

Monte Carlo simulations (10,000 trials) were performed utilizing the response surface to predict distance $d$ (DT) at the conclusion of the transverse loading of the OSHA test. The histogram in Figure 3-31 shows the distribution of this distance variable over the 10,000 Monte Carlo simulations.

\section{NNSYS}

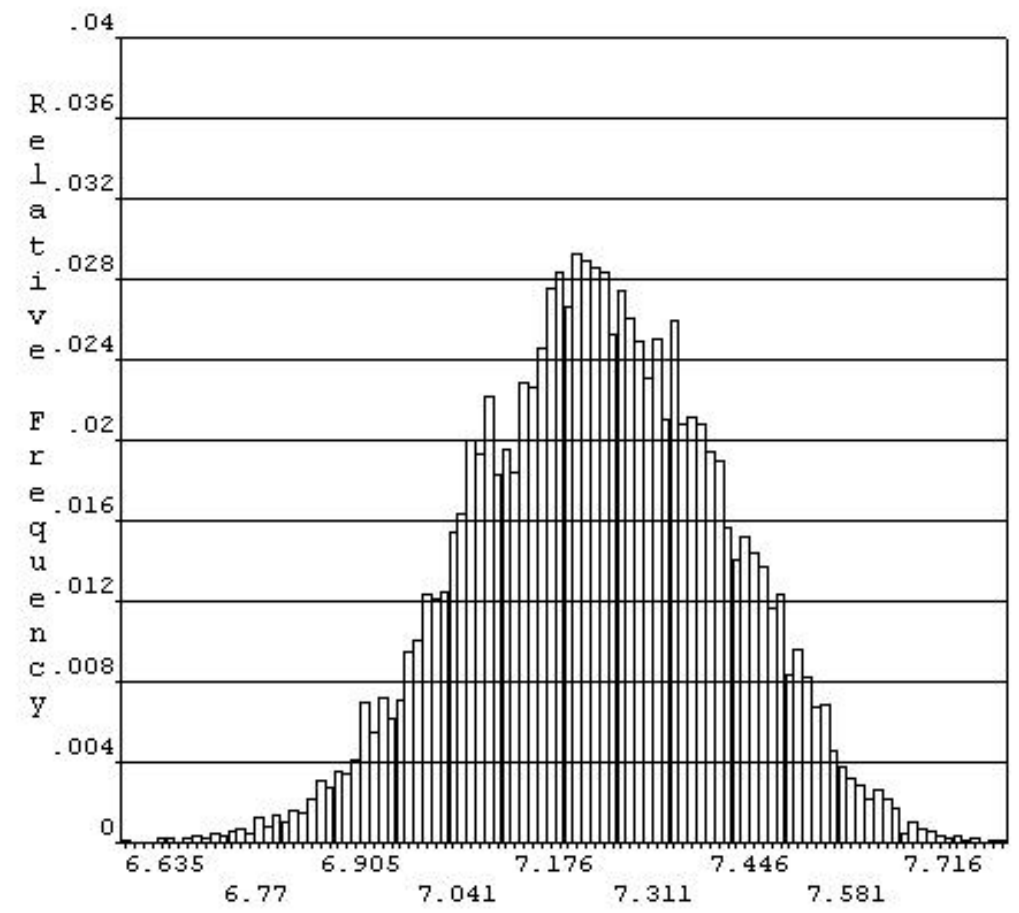
ME $M N \quad 0.72892 \mathrm{E}+01$
STDEV $0.17417 \mathrm{E}+00$
SKEW $-0.81921 \mathrm{E}-01$
KURT $-0.21370 \mathrm{E}+04$
MIN $\quad 0.66354 \mathrm{E}+01$
$\operatorname{MAX} \quad 0.78508 \mathrm{E}+01$

Figure 3-31 Distance from longitudinal centerline (DT) when meeting transverse energy criterion during 10,000 Monte Carlo simulations.

Based upon these results, the probability could be calculated that $d$ (DT) would be less than 2" and the simulated CROPS would fail the transverse portion of the OSHA test. It can be anticipated from Figure 3-31 that this probability is quite low, and indeed it was calculated from the distribution within the FEA code as $0 \%$. 


\section{CHAPTER 4 - DISCUSSION}

\subsection{Static test predictions}

\subsubsection{SAE J2194 testing}

Probabilistic design simulations conducted in this research suggest that the Ford-3000

CROPS design presented could fail SAE J2194 testing for the reference weight (4400

lb.) and probabilistic distribution of input variables selected in these analyses. Table

3-11 lists the parameter values utilized in the simulation loop where SAE J2194

requirements could not be met. Comparing this table to the Gaussian distribution

parameters in Table 3-10, the ASTM A 36 properties were all below average while

the ASTM A 500 properties were split between being above average and below

average. Table 4-1 shows the deviation from average for each of the parameters in the

particular simulation loop where SAE J2194 test criteria were not satisfied. The last

three rows of Table 4-1 represent ASTM A 36 properties.

Table 4-1 CROPS parameter values for failed SAE J2194 simulation loop.

\begin{tabular}{|c|c|c|}
\hline Parameter name & Parameter value & $\begin{array}{c}\text { Distance from average [sd = } \\
\text { standard deviation] }\end{array}$ \\
\hline BMWIDTH & $1.996 "$ & $-0.4 \mathrm{sd}$ \\
\hline BMDEPTH & $3.008 "$ & $0.64 \mathrm{sd}$ \\
\hline BMTHICK & $0.246 "$ & $-0.32 \mathrm{sd}$ \\
\hline YSTRESS & $59,959 \mathrm{psi}$ & $1.08 \mathrm{sd}$ \\
\hline TMODULUS & $36,745 \mathrm{psi}$ & $0.65 \mathrm{sd}$ \\
\hline LTHICK & $0.364 "$ & $-0.73 \mathrm{sd}$ \\
\hline PYSTRESS & $41,708 \mathrm{psi}$ & $-1.87 \mathrm{sd}$ \\
\hline PTMODULUS & $99,034 \mathrm{psi}$ & $-0.31 \mathrm{sd}$ \\
\hline
\end{tabular}


These data suggest that additional attention should be given to performance of the ASTM A 36 attachment plates as future CROPS prototypes are developed. As an example, thicker material or additional bracing may be needed in this area.

\subsubsection{OSHA 1928.52 testing}

Simulation and failure prediction for OSHA testing concentrated on transverse loading. This was reasonable since no longitudinal failures were detected during the 50 PDS loops described in section 3.6.2. Response surfaces were constructed to predict OSHA dimension $d(\mathrm{DT})$ and $e(\mathrm{ET})$. The response surface to predict DT was a linear combination of parameters BMWIDTH, BMTHICK, and YSTRESS as shown in Table 3-20. Table 3-22 lists the coefficients for the response surface to predict ET. In addition to linear terms for BMTHICK and YSTRESS, quadratic terms for PTMODULUS and a cross (or interaction) term for BMTHICK and YSTRESS were included. This highlights the need to understand the variation in the BMTHICK and YSTRESS input variables. Predicted DT values varied from 6.635" to 7.851". No simulation scenarios were discovered or predicted that would indicate an OSHA static test failure of the Ford-3000 CROPS prototype.

\subsection{Research limitations}

\subsubsection{Experimental limitations}

Experimental data must always be evaluated with due consideration to the accuracy of measurement equipment used. With static testing of CROPS, accuracy of equipment in the NIOSH High Bay Laboratory must be considered. Most 
importantly, the static test data was affected by the accuracy of the MTS load cell and LVDT. This equipment is regularly calibrated by an organization certified by the American Association of Laboratory Accreditation (A2LA). Calibration of the force transducer (load cell) was conducted in accordance with ASTM E4-03 and results are traceable to the National Institute of Standards and Technology. Acceptable tolerance under this standard is $\pm 1.0 \%$ of force applied. Table $4-2$ shows the calibration data for each actuator under tension and compression.

Table 4-2 Actuator calibration data for force transducer.

\begin{tabular}{|c|c|c|c|c|c|c|c|}
\hline \multicolumn{4}{|c|}{ Tension } & \multicolumn{4}{|c|}{ Compression } \\
\hline \multicolumn{2}{|c|}{ Actuator 1} & \multicolumn{2}{|c|}{ Actuator 2} & \multicolumn{2}{|c|}{ Actuator 1} & \multicolumn{2}{|c|}{ Actuator 2} \\
\hline $\begin{array}{l}\text { Reading } \\
\text { ( } \pm 10 \text { volts) }\end{array}$ & $\begin{array}{l}\text { Error } \\
\%\end{array}$ & $\begin{array}{l}\text { Reading } \\
\text { ( } \pm 10 \text { volts) }\end{array}$ & $\begin{array}{l}\text { Error } \\
\%\end{array}$ & $\begin{array}{l}\text { Reading } \\
\text { ( } \pm 10 \text { volts) }\end{array}$ & $\begin{array}{l}\text { Error } \\
\%\end{array}$ & $\begin{array}{l}\text { Reading } \\
\text { ( } \pm 10 \text { volts) }\end{array}$ & $\begin{array}{l}\text { Error } \\
\%\end{array}$ \\
\hline 0.000 & 0.00 & 0.000 & 0.00 & 0.000 & 0.00 & 0.000 & 0.00 \\
\hline-1.001 & 0.10 & -0.998 & -0.20 & 0.998 & 0.00 & 1.000 & 0.00 \\
\hline-1.997 & -0.15 & -1.998 & -0.10 & 1.999 & 0.00 & 2.001 & 0.05 \\
\hline-3.989 & -0.28 & -3.989 & -0.28 & 3.993 & -0.01 & 4.001 & 0.03 \\
\hline-5.996 & -0.07 & -5.985 & -0.25 & 5.994 & -0.01 & 6.000 & 0.00 \\
\hline-7.978 & -0.28 & -7.985 & -0.19 & 8.000 & 0.00 & 8.000 & 0.00 \\
\hline-9.987 & -0.13 & -9.984 & -0.16 & 9.999 & 0.00 & 9.998 & -0.02 \\
\hline
\end{tabular}

Table 4-3 shows calibration data for each MTS LVDT.

Table 4-3 Actuator calibration data for LVDT.

\begin{tabular}{|c|c|c|c|}
\hline \multicolumn{2}{|c|}{ LVDT \#1 } & \multicolumn{2}{|c|}{ LVDT \#2 } \\
\hline Reading ( \pm 10 volts) & Error \% & Reading ( \pm 10 volts) & Error \% \\
\hline 6.952 & -0.48 & 6.943 & -0.57 \\
\hline 5.998 & -0.02 & 5.960 & -0.40 \\
\hline 3.988 & -0.12 & 3.986 & -0.14 \\
\hline 1.985 & -0.15 & 1.997 & -0.03 \\
\hline 0.000 (start) & & 0.000 (start) & \\
\hline 0.000 (return) & & 0.000 (return) & \\
\hline 0.000 (return) & & 0.000 (return) & \\
\hline 0.000 (start) & & 0.000 (start) & \\
\hline-1.974 & -0.26 & -1.990 & -0.10 \\
\hline-3.961 & -0.39 & -3.988 & -0.12 \\
\hline-5.954 & -0.46 & -5.987 & -0.13 \\
\hline-6.941 & -0.59 & -6.981 & -0.19 \\
\hline
\end{tabular}




\subsubsection{Simulation limitations}

Simulation limitations of the FEA model must also be considered when evaluating the data from this research. As described previously, displacement at the point of load application for both the transverse and longitudinal tests is applied via 0.5 " increments. This is consistent with measurement requirements for dimensions of the critical zone in OSHA 1928.52. However, this induces some error if the energy criterion is reached during (rather than at the end) of an increment.

Something that was difficult to capture accurately in the FEA model was the effect of machining tolerances (or "slop") in the CROPS prototype. Each bolted connection of the CROPS prototype had a dimensional tolerance (typically $1 / 16$ ") added to thru hole diameters to allow easier insertion of bolts during assembly. Many of these bolted connections were at the bottom of the CROPS and thereby affect the movement at the crossbar height of the CROPS more substantially than holes located higher up the CROPS upright. In addition to the displacement differences between experimental and simulation results this may have caused, the stiffness of the overall structure can be affected as bolts may move within the added dimensional tolerance of the hole until the CROPS can "lock up". This could be reflected in differences in the initial slope of the force vs. deflection curves for the experimental and simulation results.

It was mentioned previously that conservative estimates were employed in the FEA model to evaluate intrusion and exposure criteria of SAE J2194 (see section 3.4.5). 
No conservative estimates were needed to evaluate the OSHA standard since exposure and intrusion rely on dimensions alone and not a volume.

In order to complete the nonlinear simulation of the FEA model, material models for CROPS material behavior had to be declared. For the simulations in this research, a bilinear model was used to capture the nonlinear CROPS behavior as discussed in section 3.4.2. This material behavior assumption does not completely match how the material will deform during experimental testing. Sample specimen tensile testing per an ASTM protocol would provide more complete data on material response and would allow a more accurate description of the nonlinear response. However, this type of testing is expensive and/or time consuming. Bilinear curves can be constructed from material properties supplied by the steel mill. Tables 3-3 and 3-5 show accuracy of $10 \%$ and $5 \%$ for predicting final load levels during longitudinal and transverse SAE J2194 testing. This compares favorably with force measurement accuracy of $\pm 5 \%$ in OSHA requirements.

A requirement of SAE J2194 is that all materials exhibit certain levels of Charpy impact toughness under cold temperatures. It has been assumed in this study that all prototype materials meet the Charpy impact requirements. These material requirements are summarized in Table 4-4: 
Table 4-4 Minimum V-notch impact strengths (see ASTM A 370)

\begin{tabular}{|c|c|}
\hline Specimen Size [mm] & Impact Strength [J] \\
\hline $10 \times 10$ & 11.0 \\
\hline $10 \times 9$ & 10.0 \\
\hline $10 \times 8$ & 9.5 \\
\hline $10 \times 7.5$ & 9.5 \\
\hline $10 \times 7$ & 9.0 \\
\hline $10 \times 6.7$ & 8.5 \\
\hline $10 \times 6$ & 8.0 \\
\hline $10 \times 5$ & 7.5 \\
\hline $10 \times 4$ & 7.0 \\
\hline $10 \times 3.3$ & 6.0 \\
\hline $10 \times 3$ & 6.0 \\
\hline $10 \times 2.5$ & 5.5 \\
\hline
\end{tabular}

Testing conducted according to ASTM procedures at an A2LA accredited lab produced the following results for five samples at $-22^{\circ} \mathrm{F}$. The specimen cross-section evaluated was $10 \times 5 \mathrm{~mm}$. The impact strength at all sample points was well above the 7.5 $\mathrm{J}$ requirement listed in Table 4-4.

Table 4-5 Charpy test results for sample ASTM A 500 CROPS material.

\begin{tabular}{|c|c|}
\hline Sample \# & Impact Strength [J] \\
\hline 1 & 72 \\
\hline 2 & 54 \\
\hline 3 & 73 \\
\hline 4 & 61 \\
\hline 5 & 60 \\
\hline
\end{tabular}

Table 4-5 indicates that it is possible for ASTM A 500 tubing to handle the Charpy impact requirements necessary for a ROPS material.

A limitation for the FEA model was that tube holes were not geometrically represented. Representing these thru holes in the model would have likely required a different type of element such as a shell or solid and would have also required many more elements. This would have substantially increased the computer solution time for the models by increasing the model degrees of freedom. Stress and displacement 
prediction accuracy may have been improved by such a model, but the results have shown that the beam models work reasonably well to predict overall deformation of the CROPS. Tube hole assumptions could also have affected the overall stiffness of the axle housing attachment plate-upright joint. This may also explain some differences between theoretical COMBIN7 element stiffness values and the values that were finally adopted for the model based upon experimental data.

Assumptions regarding the probabilistic distribution of input variables also likely influenced the final results predicted through the response surface method. The probabilistic distribution for two of the three statistically significant variables (BMTHICK and YSTRESS) was fairly well defined. The beam thickness variable (BMTHICK) distribution was largely determined through allowable limits established in the specification standard ASTM A 500. The standard is clear on allowable maximum and minimum values, however, the standard deviation for this distribution was estimated using Tchebysheff's theorem as mentioned previously. Empirically determining the standard deviation would have been preferred if sufficient tubular samples had been available. Beam yield stress (YSTRESS) minimum was clearly defined within the ASTM A 500 standard. However, information about the standard deviation and maximum was determined from steel mill certification sheets for the limited numbers of steel tube utilized in the lab. These data provided reasonable estimates of distribution properties, but additional samples/information would have improved this estimate. Information on beam tangent modulus (TMODULUS) was based upon data provided with the steel mill certification sheets. This was a derived 
property. Some additional inaccuracy should be expected in this variable compared to BMTHICK and YSTRESS which are measured directly. This distribution estimate would have also benefited from additional sample data. Additional samples are costly in terms of money and time and were not a feasible option for this project.

Care must be exercised in applying the COMBIN7 stiffness values for the Ford-3000 model to CROPS designs for other tractor types. Designs having similar joint geometry for coupling the upright tubing to the tractor axle housing would be good candidates for using similar stiffness values as those listed in Table 3-7. Designs with different tubing cross-sectional properties (e.g. beam width), L-shaped attachment plate thicknesses, or bolt specifications (e.g. bolt diameter) may require modification of these stiffness values. Extensive testing of the COMBIN7 stiffness values for multiple CROPS designs was not included as part of this research project. If available, pilot test data similar to SAE J2194 loading(s) should be evaluated to assist in determining the most appropriate stiffness values.

\subsection{Implications for SAE and OSHA ROPS testing}

Based upon the response surfaces generated for the OSHA simulations, no scenarios were identified where the Ford-3000 CROPS design would fail. However, the PDS evaluation of the CROPS Ford-3000 model indicated potential failure during the SAE J2194 test sequence. One interpretation of this result is that SAE J2194 testing may be more conservative than OSHA 1928.52 test requirements. That is, ROPS designs 
are conceivable that would pass the OSHA test sequence but fail the SAE J2194 sequence.

It is hoped that the model and modeling concepts developed in this research will be useful in predicting the performance of future CROPS designs. The design, development, and test cycle is time consuming and costly; reducing the number of iterations through this cycle should facilitate the process of retrofitting tractors with CROPS and reducing the number of tractor overturn fatalities in the U.S. each year. The model and techniques developed in this research allow evaluation of testing standards for conditions outside of the average. It is important to understand how a design will perform over the expected range of input variable values. Techniques presented in this research can assist the designer to identify those input variables most likely to affect CROPS performance. 


\section{CHAPTER 5 - CONCLUSIONS AND RECOMMENDATIONS}

\subsection{Conclusions}

The primary aim of this research project was to probabilistically evaluate the performance of assembled rollbar designs (CROPS) on SAE J2194 and OSHA 1928.52 standards. In addition, the SAE and OSHA standards were to be compared to evaluate whether one standard was more conservative than the other.

CROPS performance was assessed using the prototype design for the Ford-3000 tractor. This prototype was tested per SAE J2194 static testing requirements at the NIOSH High Bay Lab facility. These results served as the baseline for final development of the FEA model. The FEA model was constructed using nonlinear beam elements (BEAM188 in ANSYS). Revolute joint elements (COMBIN7) with spring stiffness values were used to model the bolted connections to the tractor axle housing. For the longitudinal and transverse tests with energy criteria, the simulations were executed in a displacement control manner, very similar to how actual testing occurred. For these tests, loading was added in $1 / 2$ " increments with the energy, exposure, and intrusion criteria checked during each loop. The vertical crush tests of SAE J2194 were handled by linearly ramping to the final load. When the energy criterion was met, the simulation longitudinal load error was $10 \%$. For the transverse load, the simulation error was 5\%. At the longitudinal loading simulation end point, energy absorbed in the simulation differed from experimental energy absorbed by $2 \%$. For transverse loading the difference was $9 \%$. 
Probabilistic design simulation requires that random input variables for the FEA model be identified and an estimated distribution be attributed to each variable. Initially, the following variables were included as random input variables in the FEA model (FEA variable name in parentheses): beam width (BMWIDTH), beam depth (BMDEPTH), beam thickness (BMTHICK), yield stress (YSTRESS), tangent modulus (TMODULUS), plate thickness (LTHICK), plate yield stress (PYSTRESS), and plate tangent modulus (PTMODULUS). Simulation loops were conducted with each input variable being assigned a value from the respective probabilistic distribution. During these simulation loops, the model identified potential failure of the Ford-3000 CROPS prototype during the SAE J2194 static test sequence. Using the same input variable probabilistic distribution, 50 simulation loops were conducted for static test requirements found in OSHA 1928.52. Evaluation of Spearman rank sensitivity showed that three of these variables had significant influence at the $2.5 \%$ level for output variable $d$ (DT) during transverse loading. $D$ is a critical dimension defined in OSHA 1928.52 for tracking rollbar transverse movement during transverse loading. The significant variables were beam thickness (BMTHICK), beam width (BMWIDTH), and beam yield stress (YSTRESS).

Using the three identified, influential variables, a response surface was developed to predict $d$ (DT) during OSHA transverse testing. The $r$-squared coefficient of determination for the $d$ (DT) response surface was 0.79 . Based upon the mathematical representation of this response surface, 10000 Monte Carlo calculations were 
performed. Based upon the distribution of these variables, it was calculated that there was $0 \%$ probability of the CROPS design failing critical $d$ requirements of OSHA 1928.52 .

One of the aims of this study was to compare SAE J2194 testing to OSHA 1928.52 testing. Initial simulation of the Ford-3000 CROPS prototype using average values for all input parameters indicated that the design would pass SAE J2194 testing. However, when probabilistic distributions were applied to the input parameters, the simulation indicated potential failure during SAE J2194 testing. When similar probabilistic techniques were applied to the Ford-3000 CROPS model under OSHA test requirements, no failures were predicted. The implication from these simulation data is that the SAE static test sequence could be a more conservative design test than the OSHA static test series.

This research has advanced the state of the art in CROPS research through development of a CROPS evaluation tool and technique that can facilitate future CROPS development. Experimental testing is costly in terms of materials and time to conduct. The research presented herein describes a methodology for minimizing the number of prototypes which undergo experimental testing. This is possible by simulating conceptual CROPS designs and identifying potential poor performers before experimental testing is conducted. 
Techniques outlined in this research allow a probabilistic evaluation of CROPS performance that could not easily be conducted experimentally. It would be difficult to experimentally evaluate CROPS components with specific input variable values such as yield stress or beam width. The simulation techniques of this research allow evaluation of input variable variation impact on output variable results.

Additionally, the current research has provided a means for comparing CROPS performance during SAE and OSHA testing. This type of simulation comparison has identified scenarios where a CROPS design may fail SAE J2194 testing but pass OSHA 1928.52 testing.

\subsection{Recommendations for future work}

As research answers some questions, it raises others. The research described herein is no different. The simulation data predict potential failure of the SAE J2194 test for the Ford-3000 CROPS. It would be beneficial to the comparison of SAE and OSHA testing if experimental results for both series of tests were available.

In the discussion of the FEA model results, it was discussed how the simulation and experimental force vs. deflection curves diverge somewhat at the beginning of loading. It is conjectured that much of this difference can be attributed to the structure needing to move some before "locking up". This is caused when "slop" or geometric tolerances are designed as part of each hole. Holes were not machined to the exact dimension of the bolt that must pass through it. Additional simulation work may be 
able to capture this phenomenon even more accurately. One possibility is to use gap elements which allow a certain amount of displacement before stiffness is activated. Of course any additional complexities added to the simulation model will negatively affect run time and must be balanced against the incremental gains in accuracy.

Through simulation, there may be a way to adjust the test parameters of OSHA 1928.52 so that results equivalent to SAE J2194 are produced. The OSHA test is a simpler test to execute since it does not involve vertical crush tests. If the OSHA test requirements can be adjusted so that it is as conservative as the SAE test, the time necessary to test CROPS could be shortened by utilizing OSHA testing alone.

The goal of static testing is to predict what will happen to the CROPS during an overturn event. The criteria of static test procedures could be refined by collecting additional experimental data to characterize the loads induced during overturns. This would be a challenge since many variables influence the loading of a ROPS during overturn even if procedures are followed such as contained in SAE J2194. Some of the variables that would need examined include tractor speed, ground hardness, and overturn rate. 


\section{BIBLIOGRAPHY}

American Society of Agricultural Engineers. (1967). S305. Operator protection for wheeled-type agricultural tractors.

American Society of Agricultural Engineers. (1974). S306-1974. Protective frame for agricultural tractors - Test procedures and performance requirements.

American Society of Agricultural Engineers. (1974). S336.1-1974. Protective enclosures for agricultural tractors - Test procedures and performance requirements.

American Society for Testing and Materials. (1976). ASTM A 370-76. Standard methods and definitions for mechanical testing of steel products.

American Society for Testing and Materials. (2001). ASTM A 500-01a. Standard specification for cold-formed welded and seamless carbon steel structural tubing in rounds and shapes.

American Society for Testing and Materials. (2005). ASTM A 36/A 36M-05. Standard specification for carbon structural steel.

Ayers, P.D. (1997). ROPS design for pre-ROPS tractors. Journal of Agromedicine, 4, $(3 / 4): 309-311$.

Ayers, P.D. and Liu, J. (2001). ROPS design and testing for agricultural tractors. ASAE Meeting Paper No. 01-8034. St. Joseph, Mich: ASAE.

Brewer, C.D., Harris, J.R., Means, K.H., Mucino, V.H. (1994). Proposed ROPS reaction frame design. Unpublished manuscript.

Budynas, R.G. and Nisbett, J.K. (2008). Shigley's Mechanical Engineering Design ( $8^{\text {th }}$ ed.). New York: McGraw-Hill.

Byars, E.F., Snyder, R.D., Plants, H.L. (1983). Engineering Mechanics of Deformable Bodies $\left(4^{\text {th }}\right.$ ed.). New York: Harper \& Row.

CDC. (1983). Farm-tractor associated deaths-Georgia. Morbidity and Mortality Weekly Report, 32, (37):481-482.

CDC. (1993). Public health focus: Effectiveness of rollover protective structures for preventing injuries associated with agricultural tractors. Morbidity and Mortality Weekly Report, 42, (3):57-59. 
Day, L. (2003). Tractor occupational safety and health update. Tractor-related injury and death meeting. 2003 Feb 13-14; Pittsburgh, PA.

Donham, K., Osterberg, D., Meyers, M., Lehtola, C., Rautiainen, R., Loveless, L., Bedford, L. (eds). (1997). Tractor risk abatement and control: The policy conference. Iowa's Center for Agricultural Safety and Health, and The Great Plains Center for Agricultural Health, The University of Iowa, Iowa City, IA.

Dowdy, S., Wearden, S., Chilko, D. (2004). Statistics for Research $\left(3^{\text {rd }}\right.$ ed.). Hoboken, NJ: John Wiley \& Sons, Inc.

Edwards, Jr., C.H. and Penney, D.E. (1986). Calculus and Analytic Geometry $\left(2^{\text {nd }}\right.$ ed.). Englewood Cliffs, NJ: Prentice-Hall, Inc.

Etherton, J.R., Myers, J.R., Jensen R.C., Russell J.C., Braddee R.W. (1991). Agricultural machine-related deaths. American Journal of Public Health, 81, 766-768.

Federal Emergency Management Agency. (1997). FEMA-288. Background reports: Metallurgy, fracture mechanics, welding, moment connections, and frame systems behavior.

Figliola, R.S. and Beasley, D.E. (1991). Theory and Design for Mechanical Measurements. New York: John Wiley \& Sons, Inc.

Fredrikkson, L.A. and Schramm, U. (2001). Combining response surface optimization and stochastic analysis for crashworthiness design - an introductory study. Shock and Vibration, 8, 21-31.

Hallman, E.M. (2005). ROPS retrofitting: Measuring effectiveness of incentives and uncovering inherent barriers to success. Journal of Agricultural Safety and Health, 11, (1):75-84.

Hammersley, J.M. and Handscomb, D.C. (1964). Monte Carlo Methods. New York: John Wiley \& Sons, Inc.

Hard, D.L., Myers, J.R., and Gerberich, S.G. (2002). Traumatic injuries in agriculture. Journal of Agricultural Safety and Health, 8, (1):51-65.

Harris, J.R., Cantis, D.M., McKenzie, E.A., Jr., Etherton, J.R., Ronaghi, M. (2005). Commercialization of Cost-Effective Rollover Protective Structures (CROPS). Proceedings of the National Institute for Farm Safety (NIFS) Annual Conference; 2005 June 26-30; Wintergreen, Virginia.

Harris, J.R., McKenzie, Jr. E.A., Etherton, J.R., Cantis, D.M. (2002). Designing costeffective rollover protective structures (CROPS) at NIOSH. Proceedings of 
the National Institute for Farm Safety (NIFS) Annual Conference; 2002 June 23-27; Ponte Vedra, Florida.

Harris, J.R., Mucino, V.H., Etherton, J.R., Snyder, K.A., Means, K.H. (2000). Finite element modeling of ROPS in static testing and rear overturns. Journal of Agricultural Safety and Health, 6, (3):215-225.

ISO. (1980). ISO 3462. Tractors and machinery for agriculture and forestry - Seat reference point - Method of determination.

Johnson, C.M. and Ayers, P.D. (1994). Testing of roll-over protective structures (ROPS) designed for pre-ROPS tractors. In Proc. 1994 International Summer Meeting, Paper No. 94-5003. Kansas City, Missouri, 19-22 June.

Kelsey, T.W., May, J.J., and Jenkins, P.L. (1996). Farm tractors and the use of seat belts and roll-over protective structures. American Journal of Industrial Medicine, 30, 447-451.

Li, Z. and Ayers, P.D. (1997). Strength test for pre-ROPS tractor axle housings. Journal of Agromedicine, 4, (3/4):303-307.

Liu, J. and Ayers, P.D. (2000). ROPS design and dynamic deflection with prevention effectiveness evaluation. 2000. In 2000 Conference of the National Institute for Farm Safety, paper \#00-04. Dubuque, IA. 24-29 June.

MacCollum, D.V. (1984). Lessons from 25 years of ROPS. Professional Safety, 29. (1), 25-31.

Magnusson, S.E., Frantzich, H., and Harada, K. (1996). Fire safety design based on calculations: Uncertainty analysis and safety verification. Fire Safety Journal, 27, 305-334.

Moberg, H.A. (1973). Dynamic testing of tractor protection cabs - development of method, practical experiences. SAE paper \# 730761.

Moore, D.S. and McCabe, G.P. (2003). Introduction to the practice of statistics. New York: W.H. Freeman and Company.

Myers, J.R. (2003). Tractor occupational safety and health update. Tractor-related injury and death meeting. 2003 Feb 13-14; Pittsburgh, PA.

Munse, W.H. (1990). Fatigue, brittle fracture, and lamellar tearing. In E.H. Gaylord, Jr. and C.N. Gaylord (Eds.), Structural engineering handbook United States: McGraw-Hill Publishing Company.

National Safety Council. (1983). Accident facts. 
NIOSH. (1992). Surgeon General's conference on agricultural safety and health. DHHS (NIOSH) publication number 92-105.

OSHA. (2006). CPL 02-00-051 - CPL 2-0.51J - Enforcement exemptions and limitations under the Appropriations Act. [On-line] Available: www.osha.gov/pls/oshaweb/owadisp.show document?p table=DIRECTIVES \&p id=1519\#ENFOR

OSHA. (1991). Standard interpretation - 11/05/1991 Rollover Protective Structures used on agricultural wheeled tractors.

Pacific Northwest Agricultural Safety and Health Center. (2004). National tractor safety initiative.

Powers, J.R., Harris, J.R., Etherton, J.R., Snyder, K.A., Ronaghi, M., Newbraugh, B.H. (2001). Performance of an automatically deployable ROPS on ASAE tests. Journal of Agricultural Safety and Health, 7, (1):51-61.

Ross, B. and DiMartino, M. (1982). Rollover protective structures-their history and development. Professional Safety, 27, (5):15-23.

Scheaffer, R.L., Mendenhall III, W., Ott, R.L. (2006). Elementary survey sampling. $\left(6^{\text {th }}\right.$ ed.). United States of America: Duxbury.

Society of Automotive Engineers. (1968). SAE J334-1968. Protective frame test procedures and performance requirements.

Society of Automotive Engineers. (1970). SAE J334a-1970. Protective frame test procedures and performance requirements.

Society of Automotive Engineers. (1971). SAE J394. Minimum performance criteria for roll-over protective structure for rubber-tired front end loaders and rubbertired dozers.

Society of Automotive Engineers. (1999). SAE J1194 NOV1999. Rollover protective structures (ROPS) for wheeled agricultural tractors.

Society of Automotive Engineers. (2002). SAE J2194 AUG2002. Roll-Over protective structures (ROPS) for wheeled agricultural tractors.

Speedymetals. (2008). [Online] Available:

www.speedymetals.com/information/Material29.html. 
Springfeldt, B., Thorson, J., and Lee, B.C. (1998). Sweden's thirty-year experience with tractor rollovers. Journal of Agricultural Safety and Health, 4, (3):173180 .

Srivastava, A.K. and Rehkugler, G.E. (1976). Strain rate effects in similitude modelling of plastic deformation of structures subject to impact loading. Transactions of the American Society of Agricultural Engineers, 19, (4):617621, ASAE paper \# 75-1048.

Struttmann, T.W., Brandt, V.A., Morgan, S.E., Piercy, L.R., Cole, H.P. (2001). Equipment dealers' perceptions of a community-based rollover protective structures promotion campaign. The Journal of Rural Health., 17, (2):131-139.

Teaford, W.J. (1993). Roll-over protective structures (ROPS) for wheeled agricultural tractors. In Winter Meeting of ASAE (ASAE Distinguished Lecture Series). Chicago, IL, 15 Dec.

Thiruppukuzhi, S.V. and Arslanoglu, Z. (2004). Designing robust products using a combination of simulation, experimental and statistical techniques. Annual Reliability and Maintainability Symposium, 2004 Proceedings, 308-313.

Tomas, J.A., Tran, H.H., and Altamore, P.F. (1996). Certification of roll-over protection systems for heavy vehicles by computer simulation. In Fifteenth International Technical Conference on the Enhanced Safety of Vehicles, paper \# 96-S11-O-04, p. 1840-1844, Melbourne, Australia. 13-16 May.

The University of Nebraska Agricultural Experiment Station. (1965). Nebraska Tractor Test \#883.

U.S. Department of Agriculture (1997). 1997 Census of Agriculture. Washington, DC: National Agricultural Statistics Service. [On-line] Available: http://www.nass.usda.gov/census/

U.S. Department of Labor, Bureau of Labor Statistics. (2003). Census of fatal occupational injuries.

U.S. G.P.O. (1974). Federal Register, Vol. 39, No.122 - Monday, June 24, 1974.

U.S. G.P.O. (2005). Federal Register, Vol. 70, No. 249 - Thursday, December 29, 2005.

Woodward, J.L. and Swan, S. (1980). ROPS field performance-a status report. SAE Paper \# 800679.

Yeh, R.E. (1976). Elements of ROPS engineering. Tech Rep Syst ASM n 76-46. 
APPENDIX A: Ford-3000 Prototype Drawings 


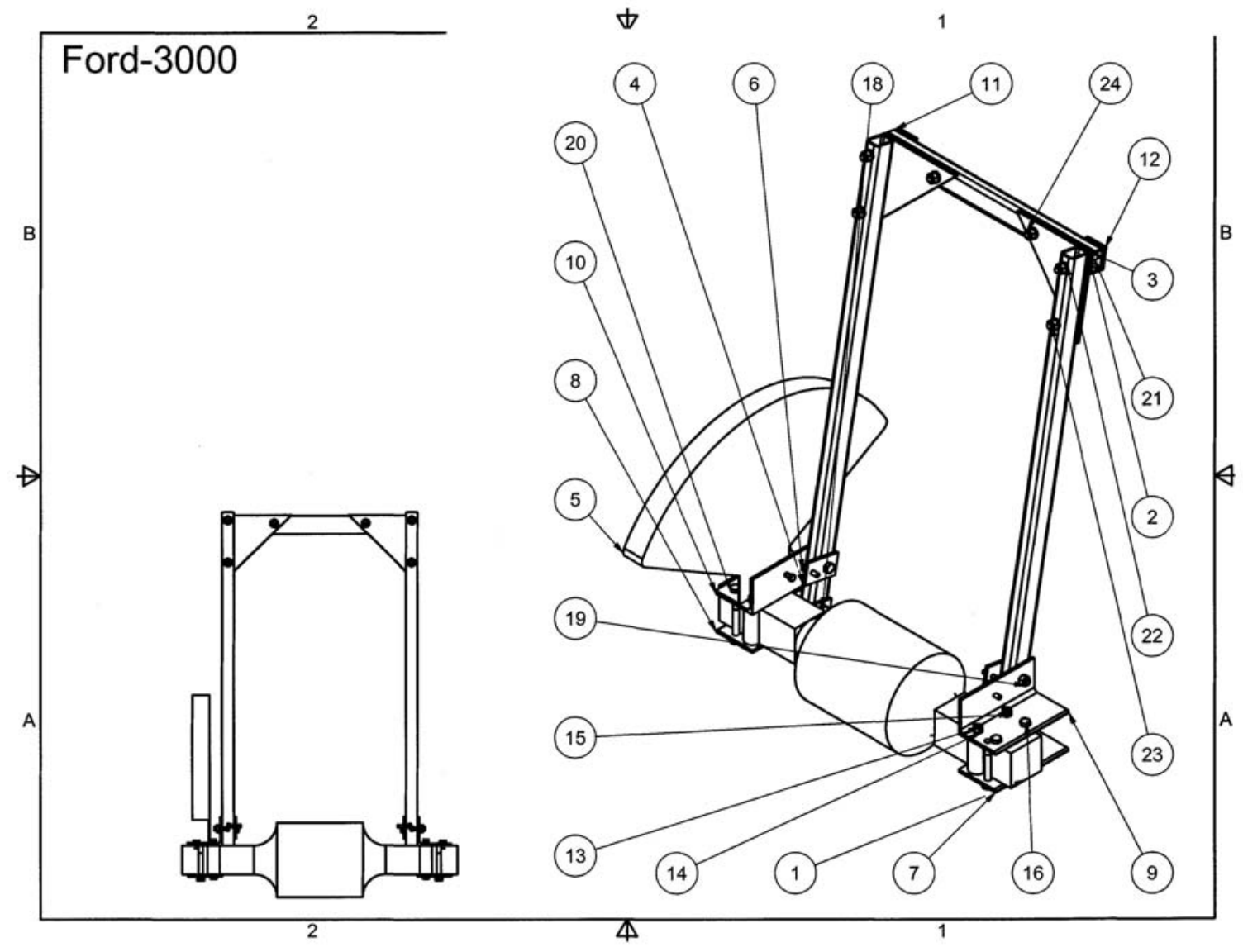




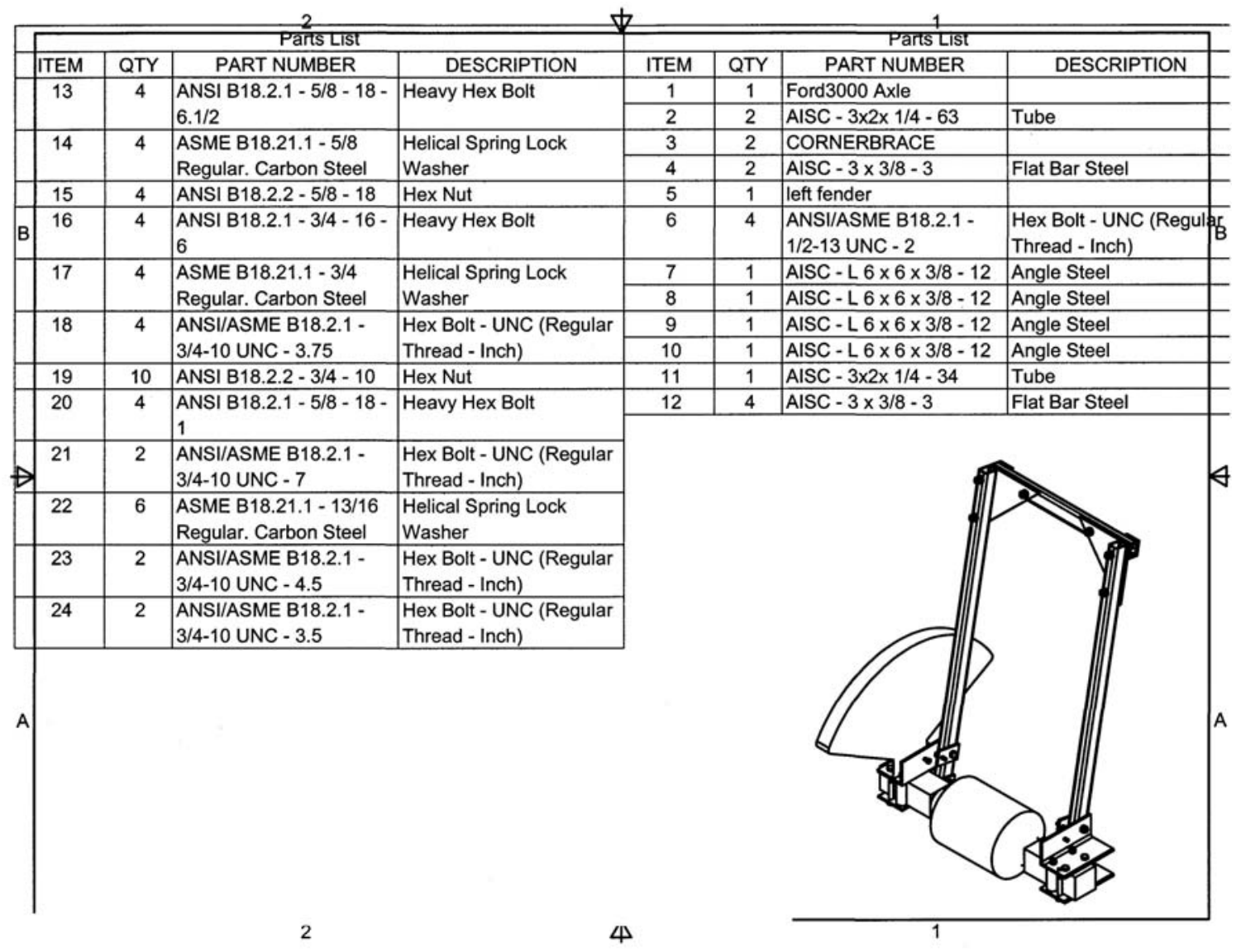




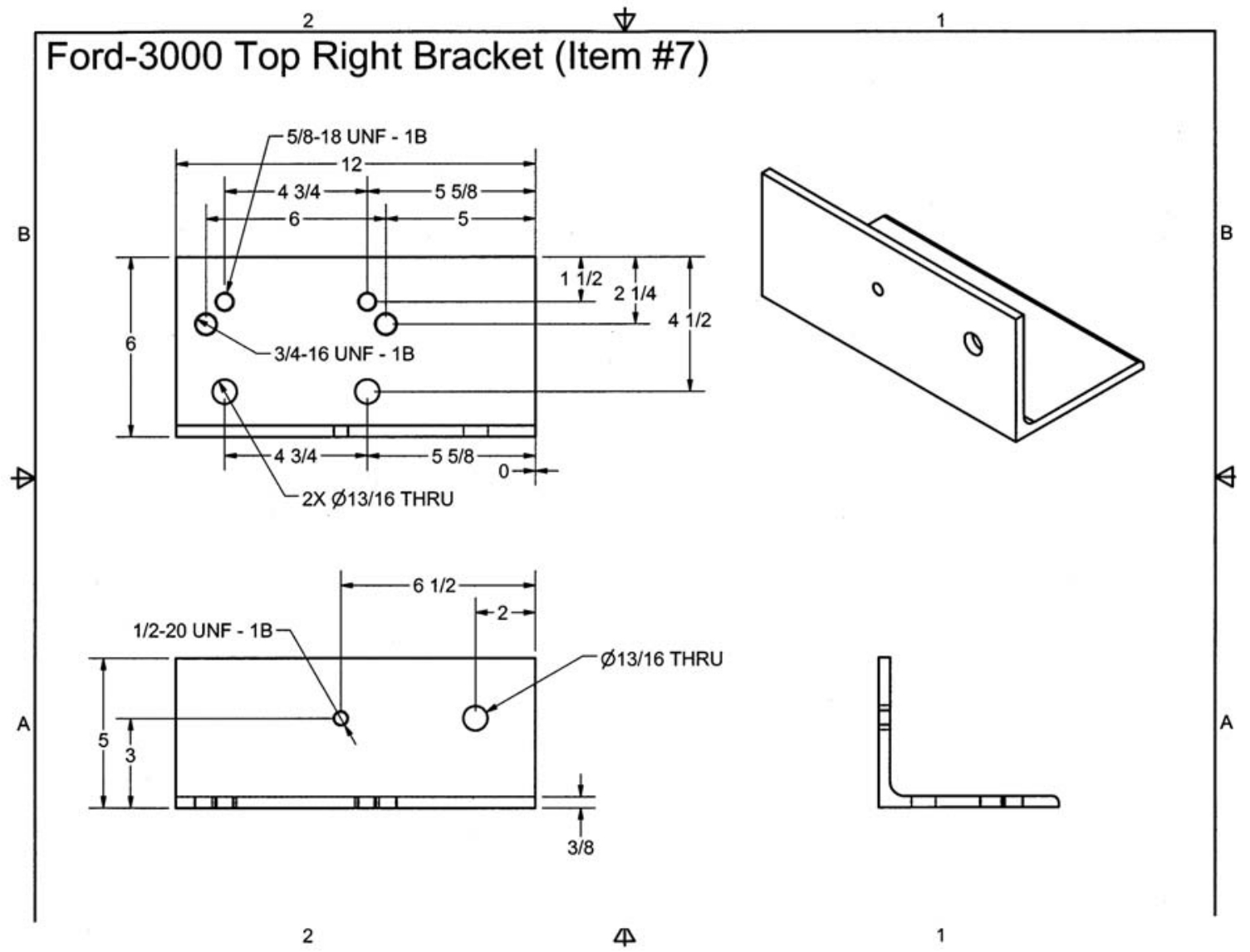




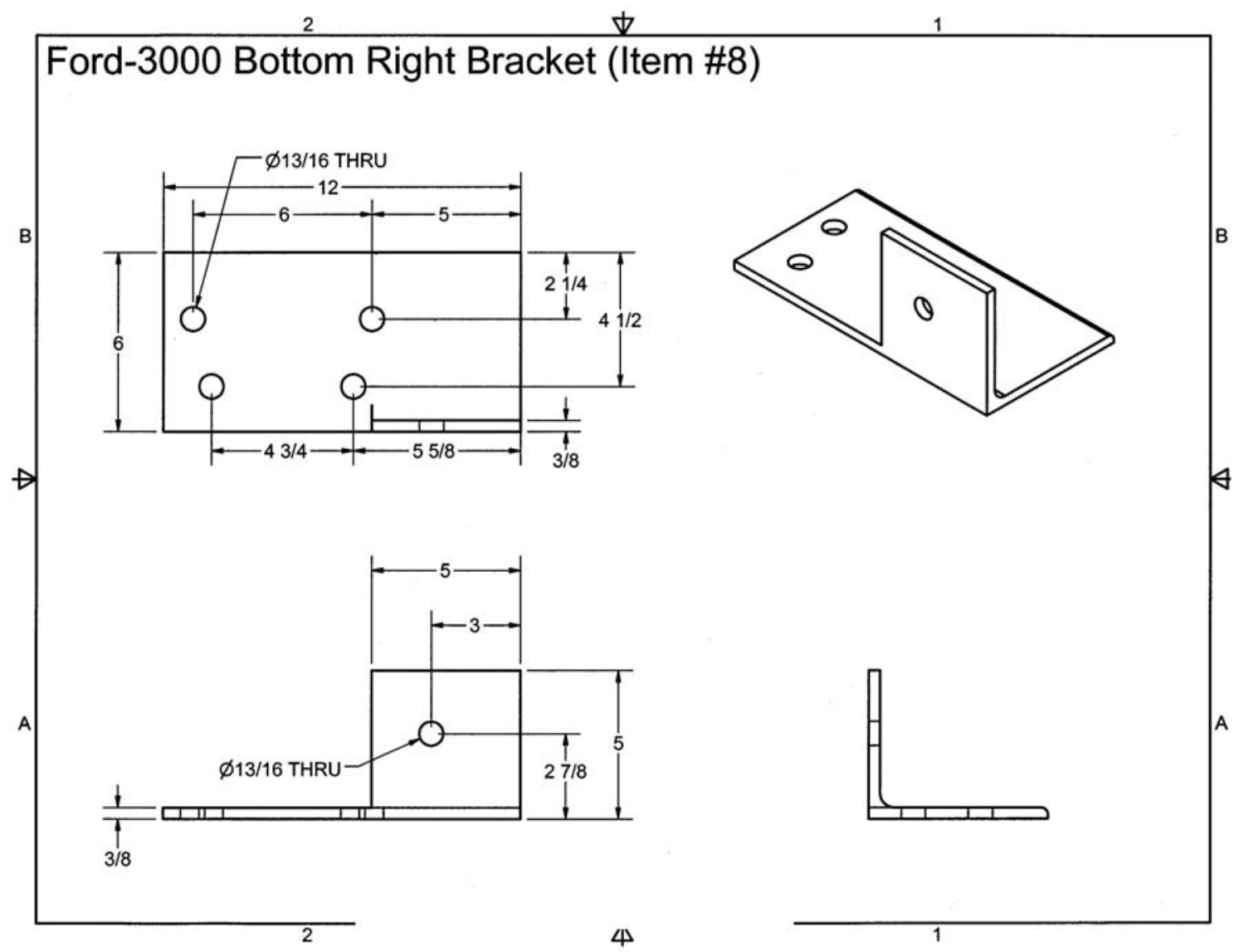




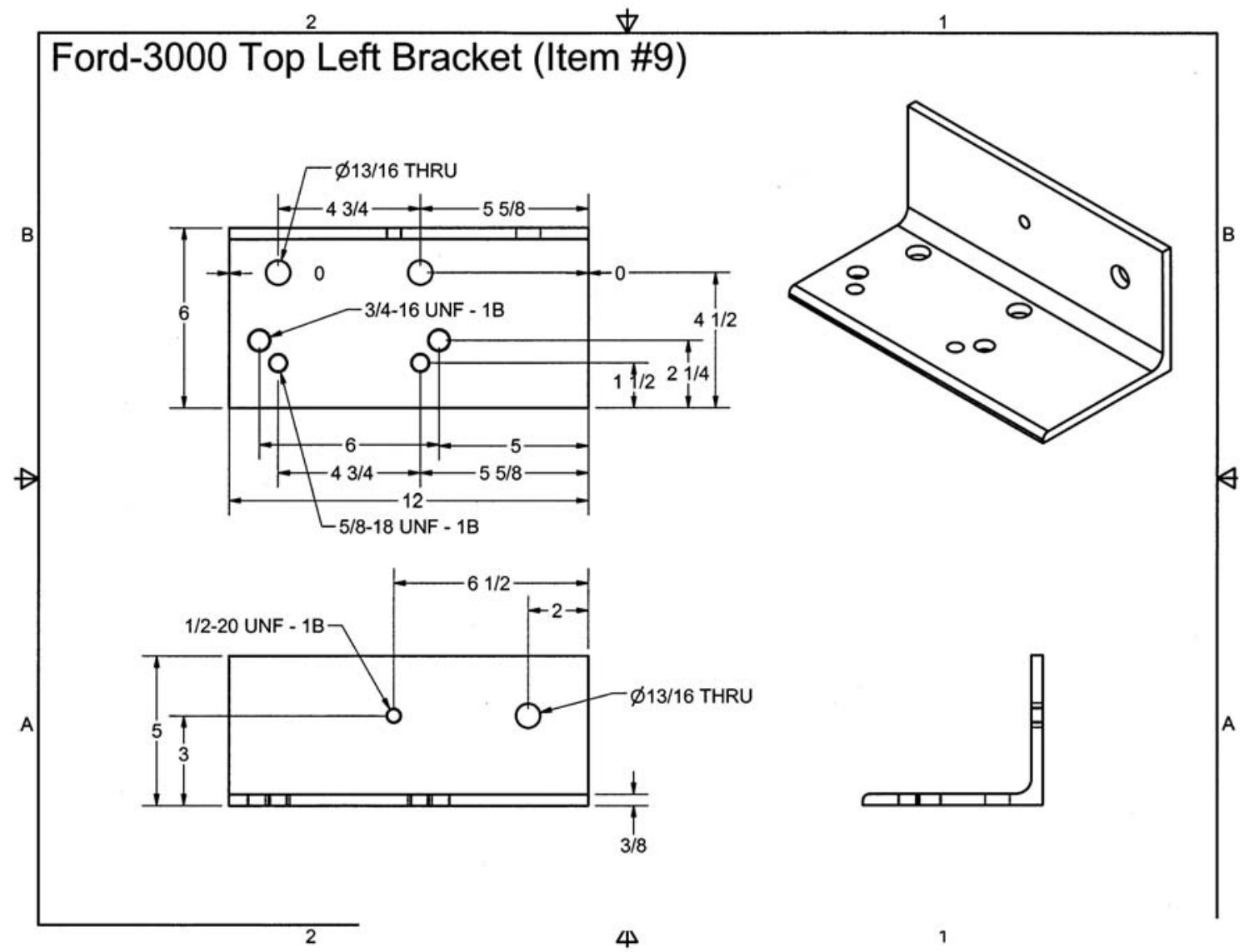




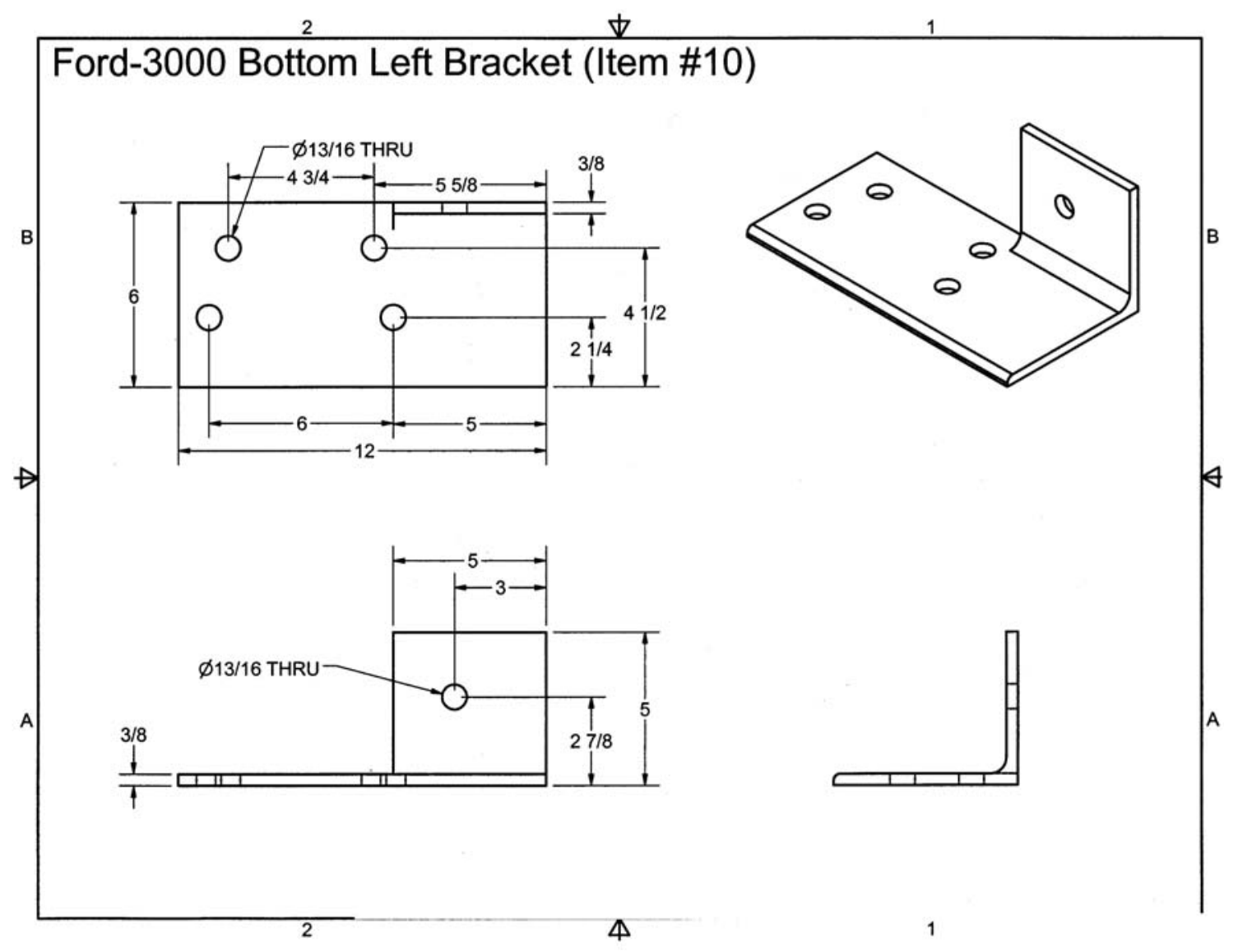




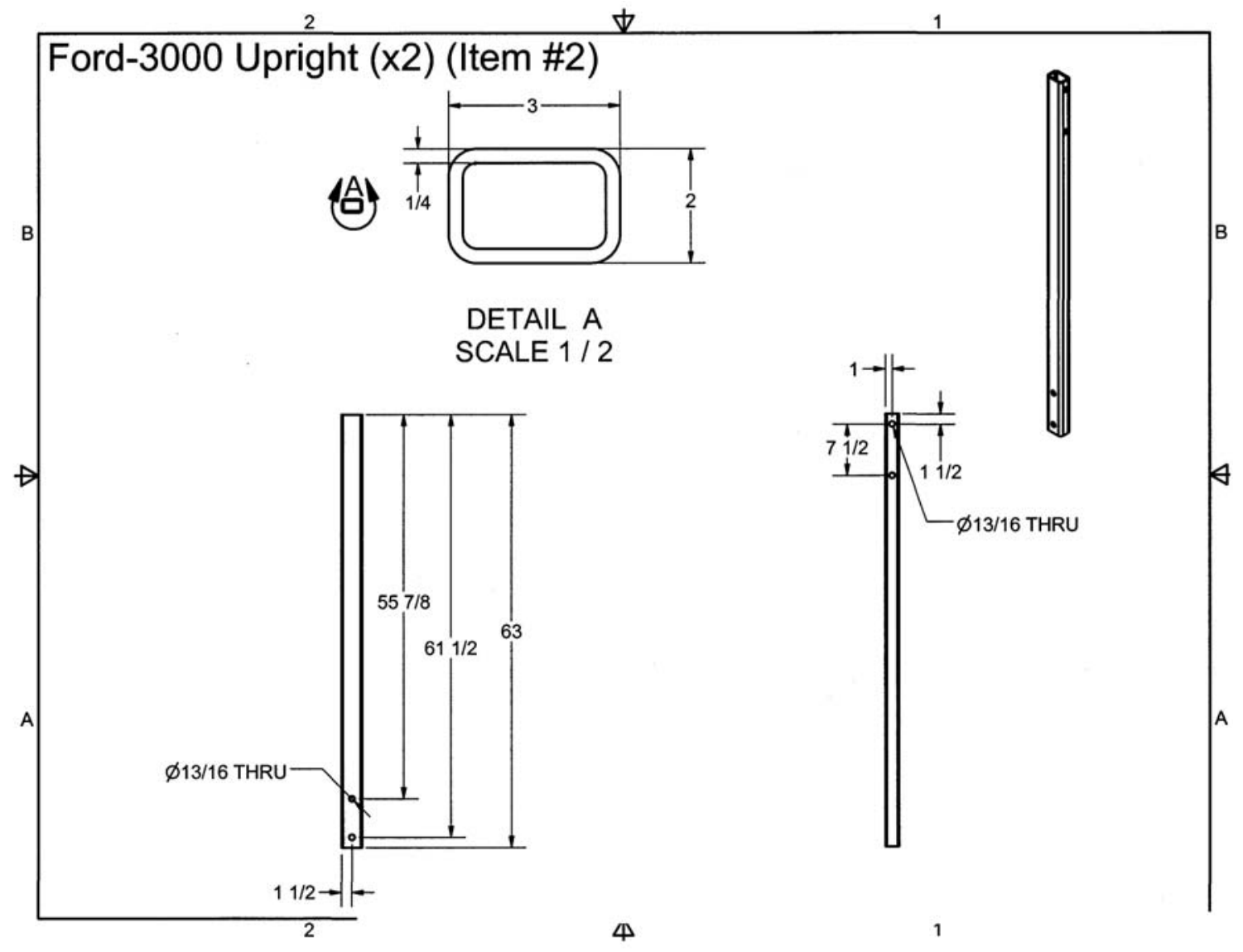




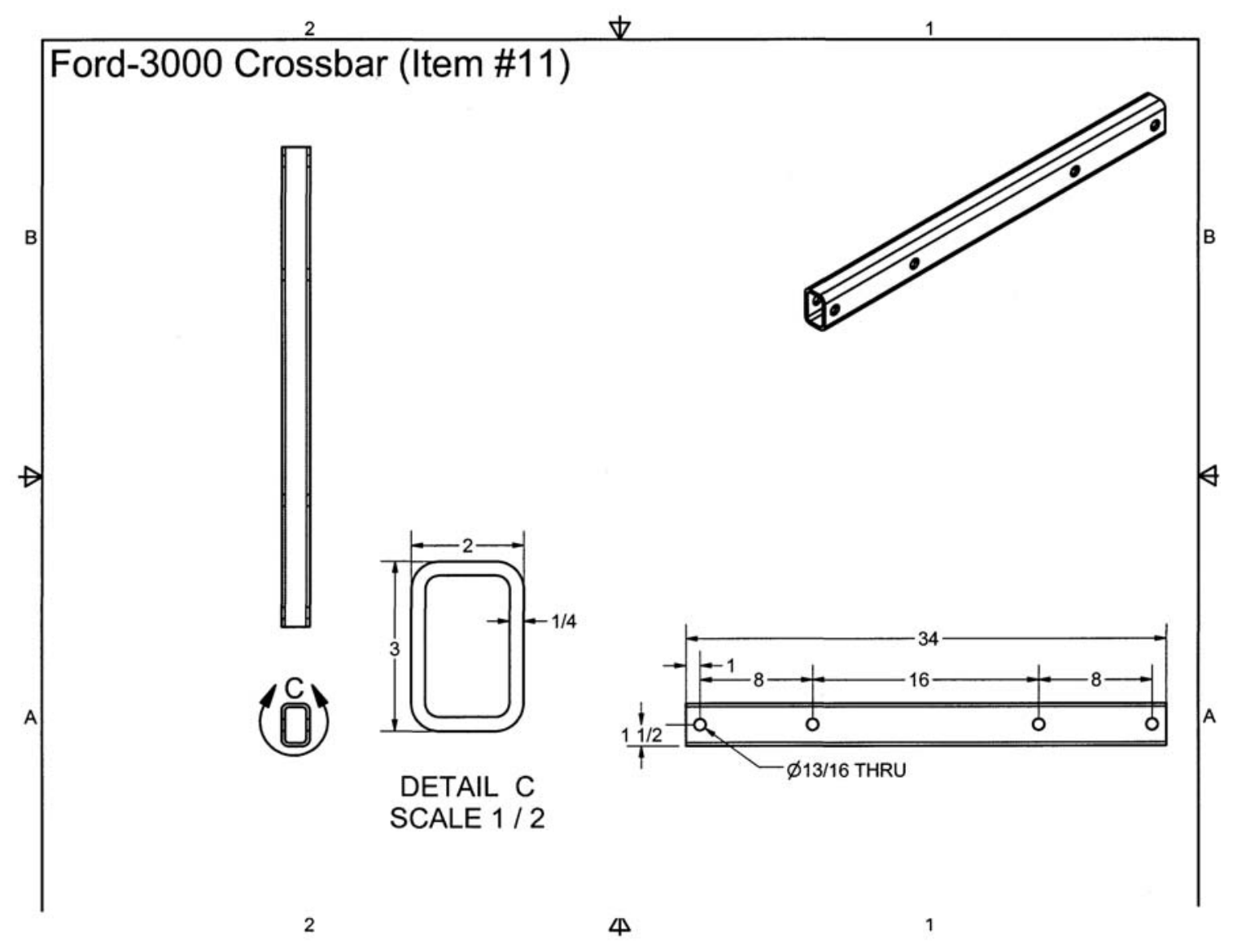

123 


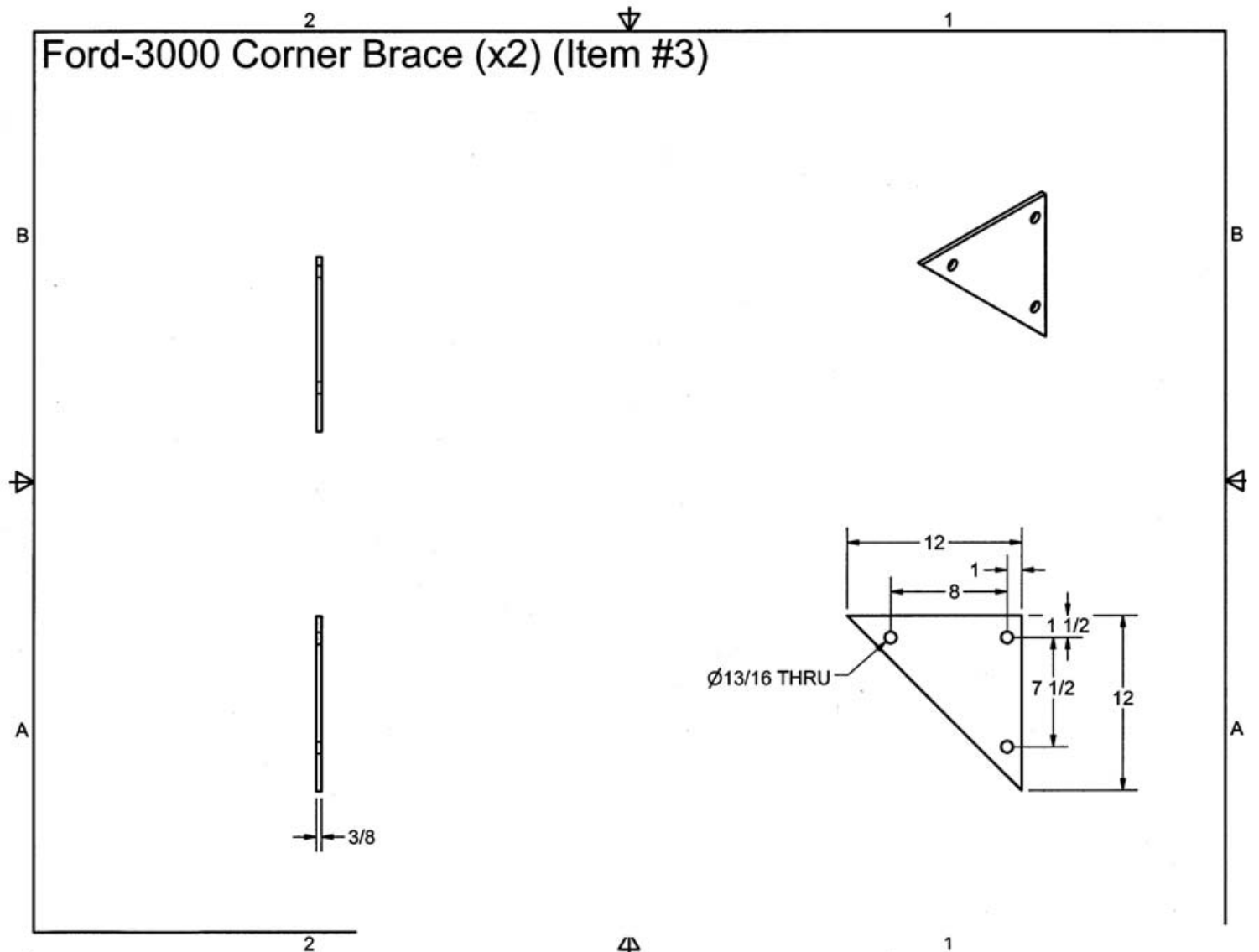




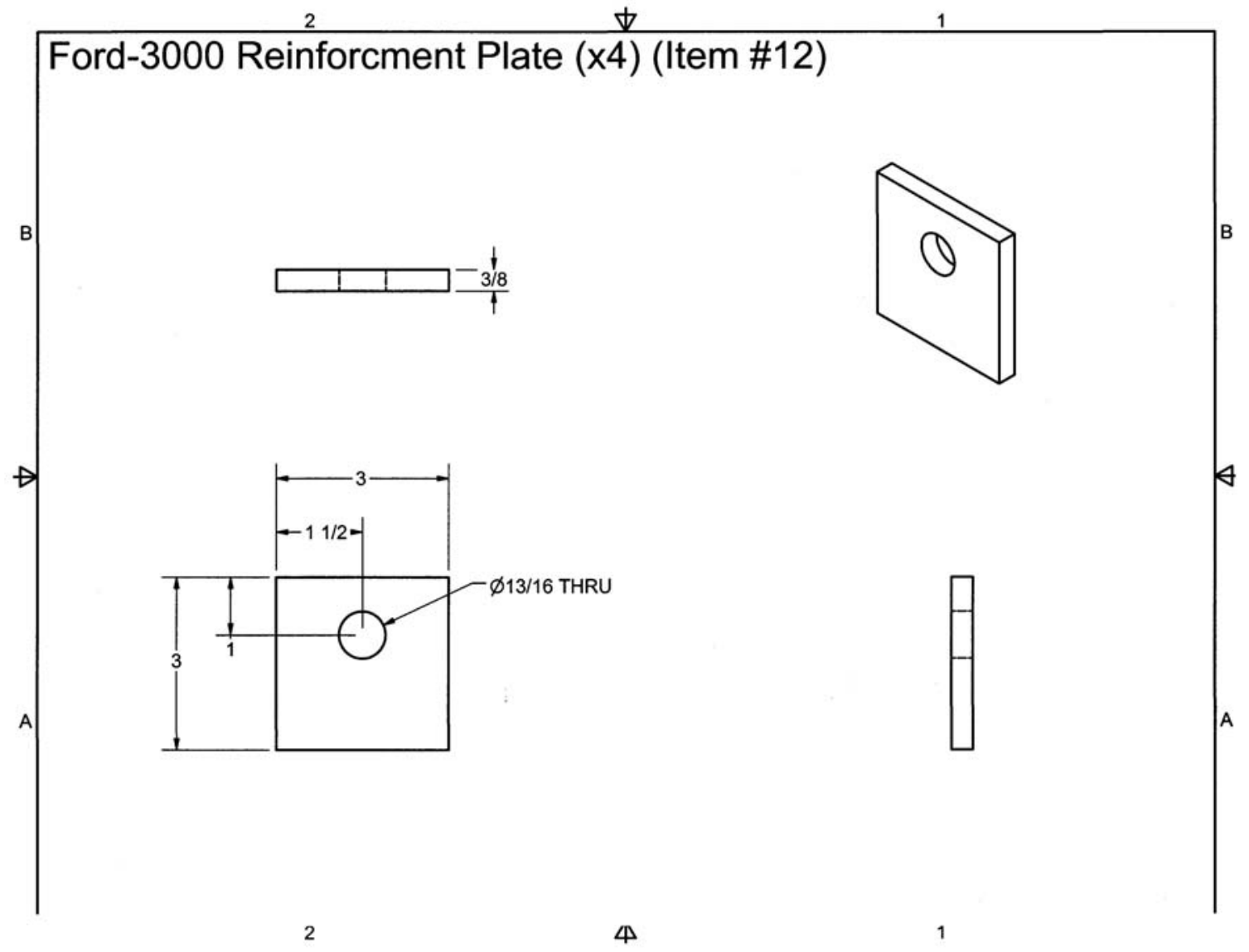




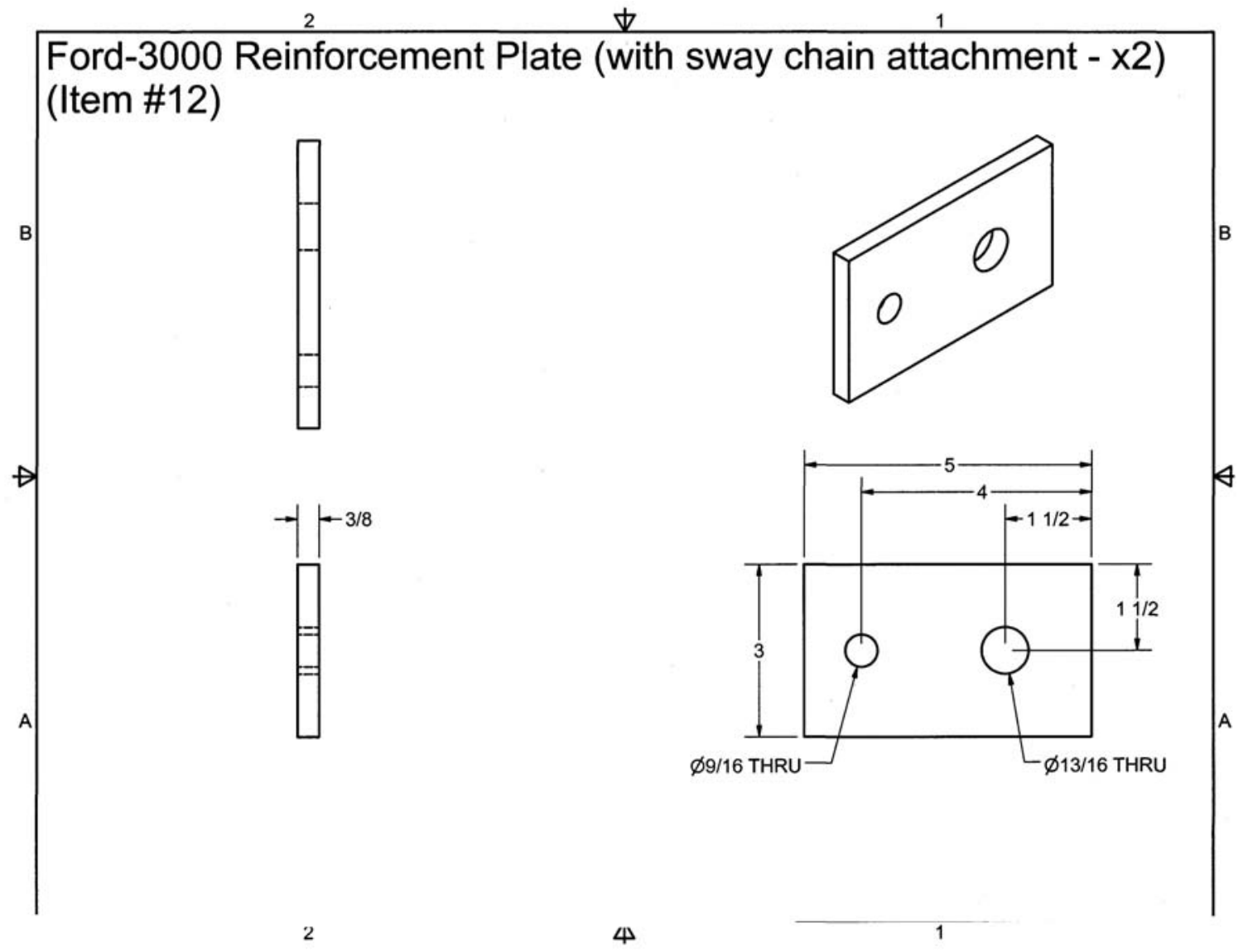




\section{APPENDIX B: Sample FEA (ANSYS) Input Files}




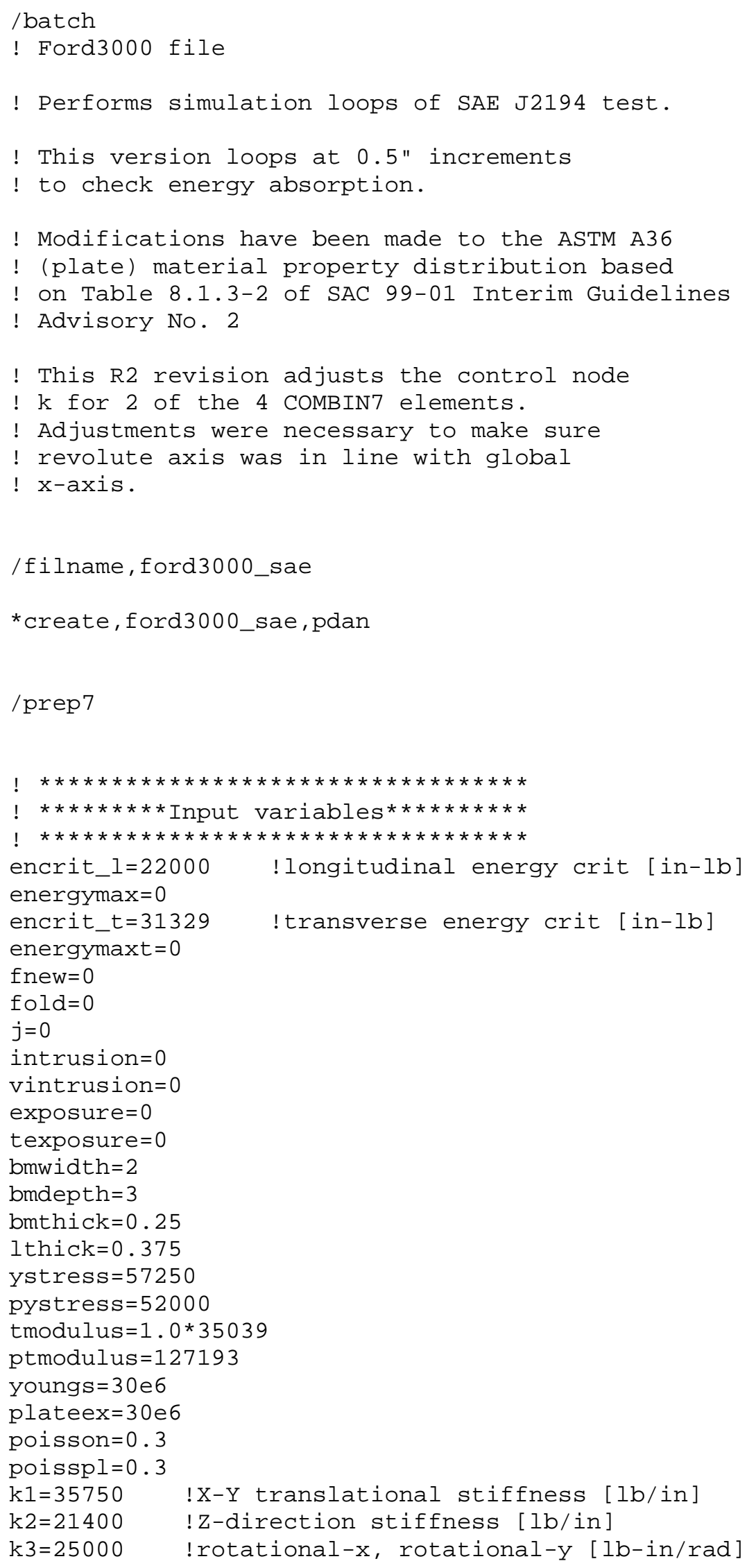



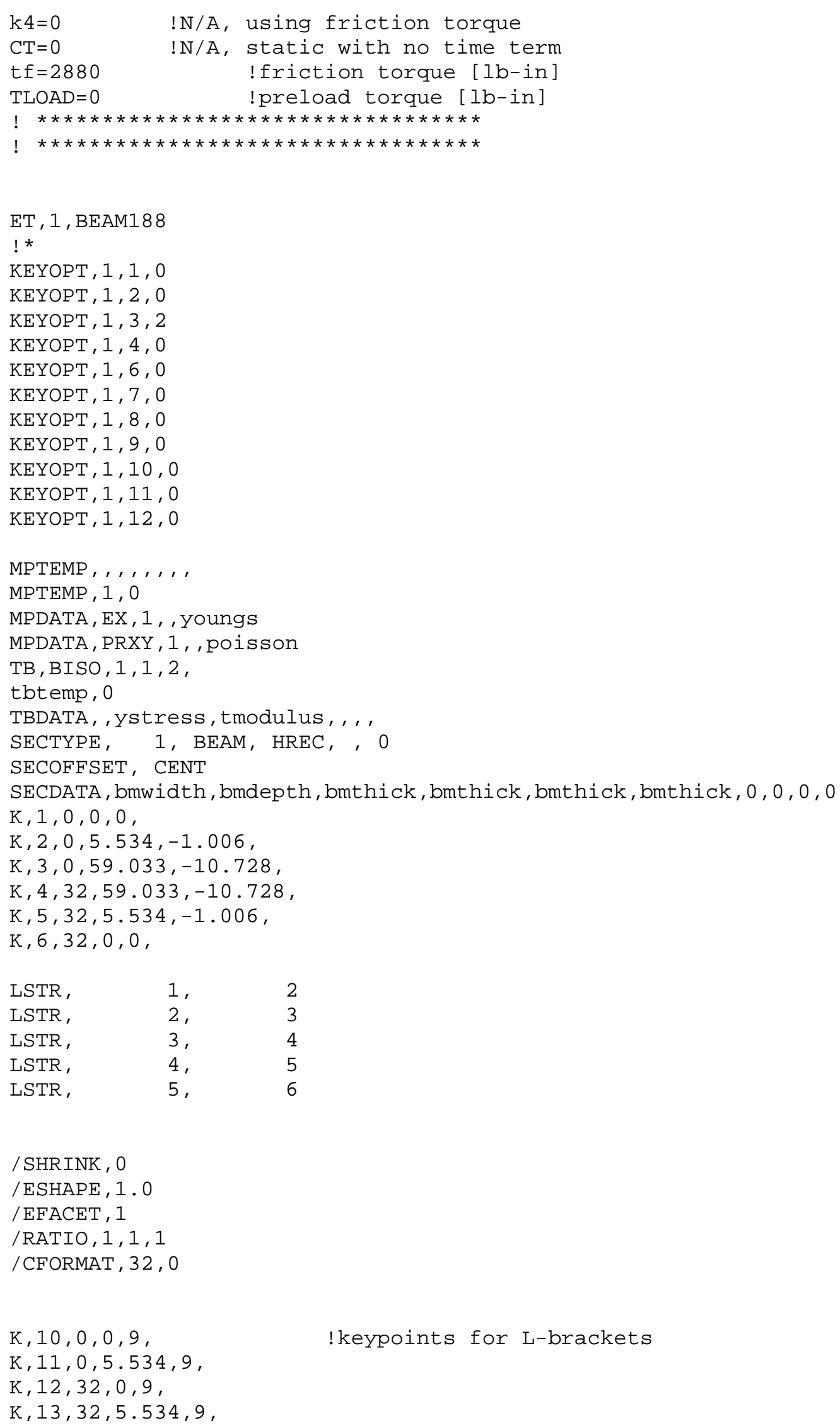


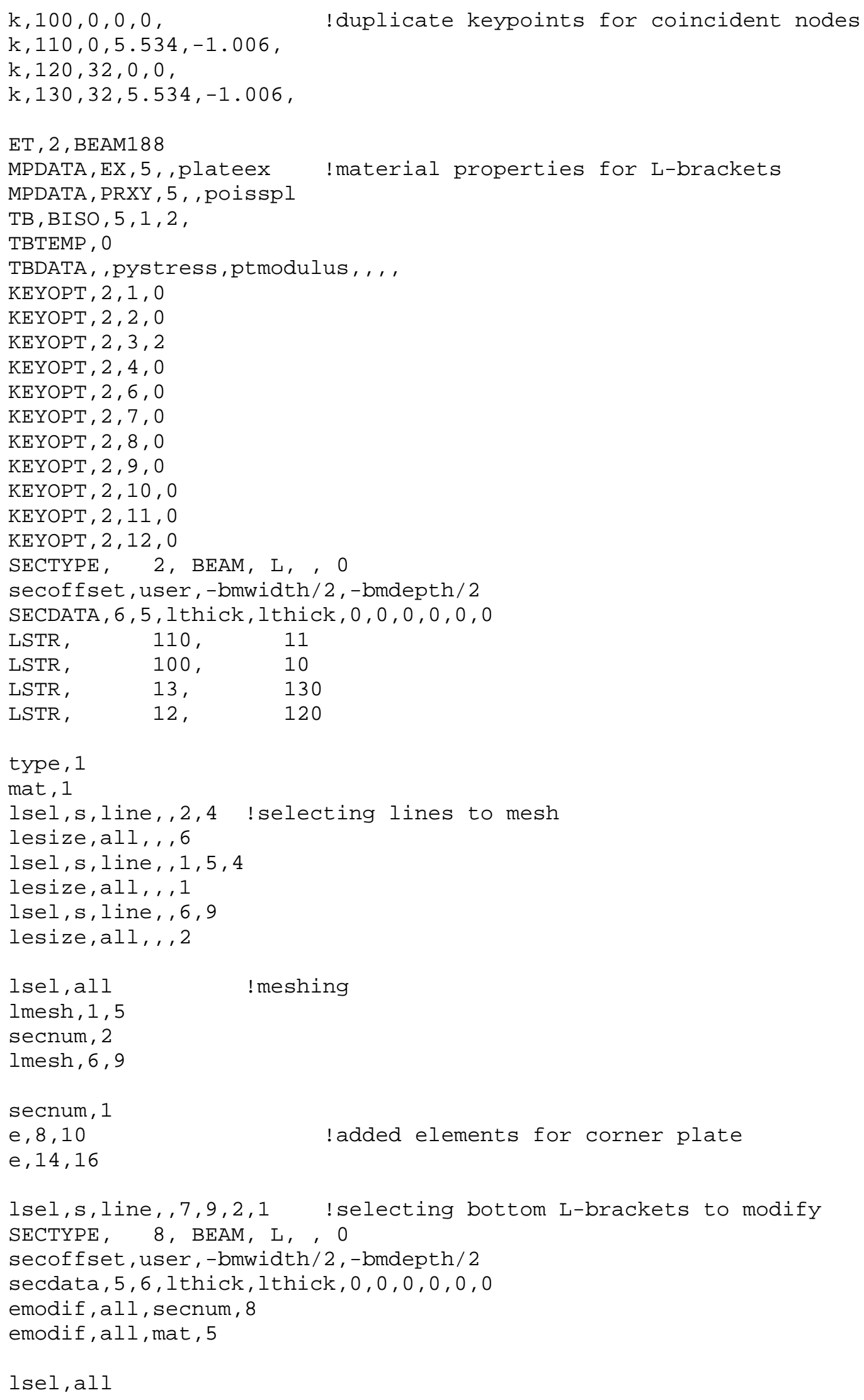




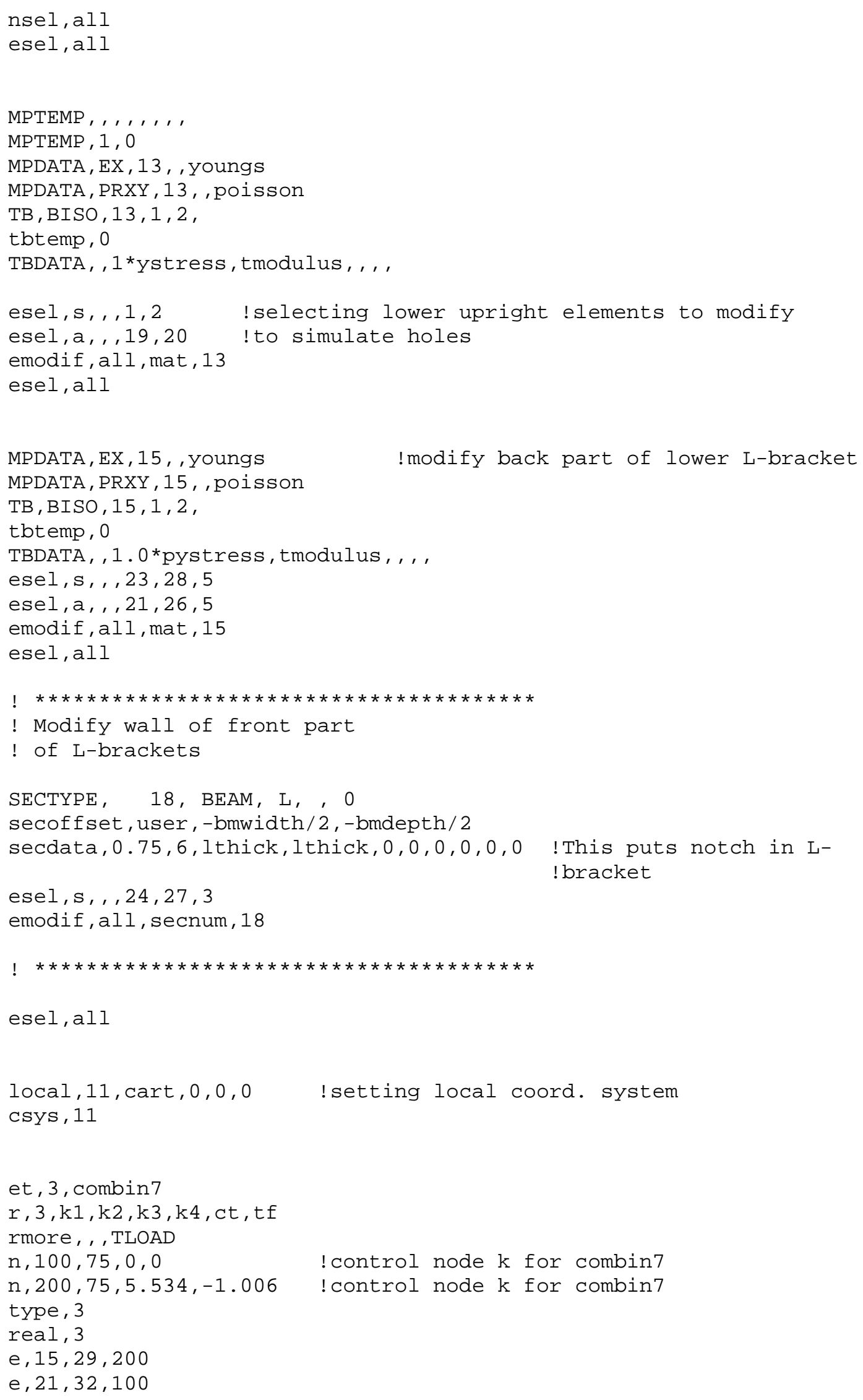




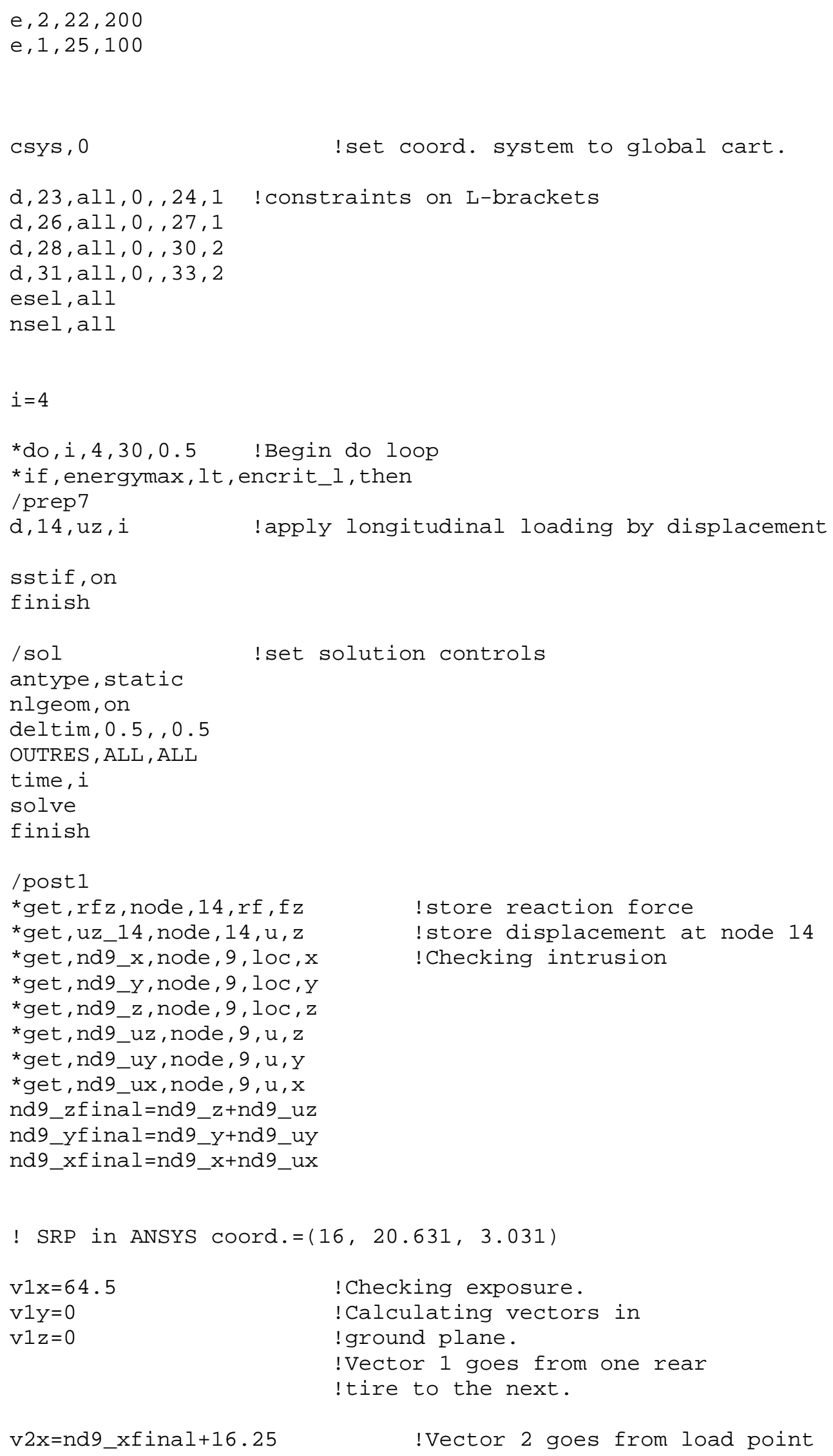




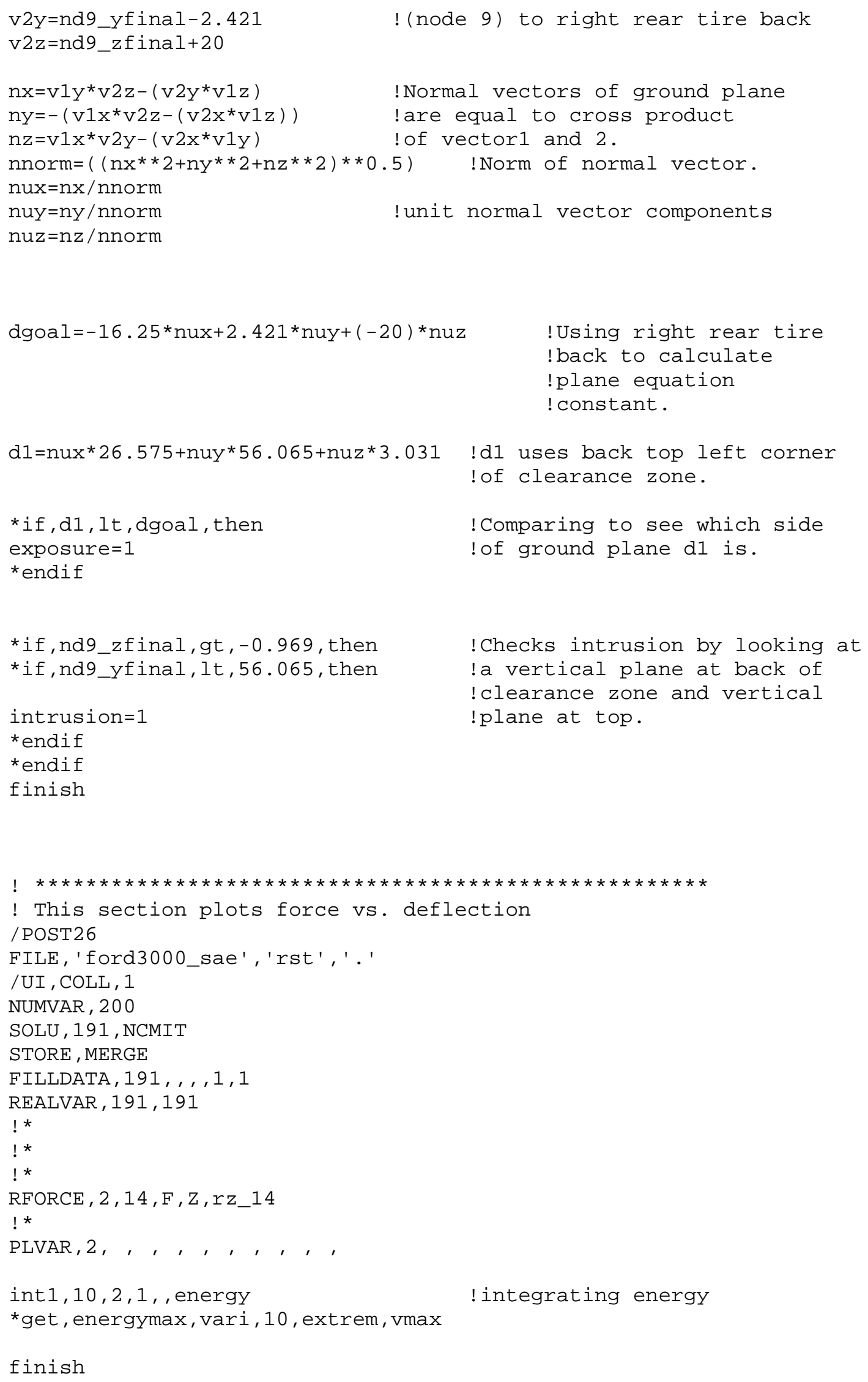




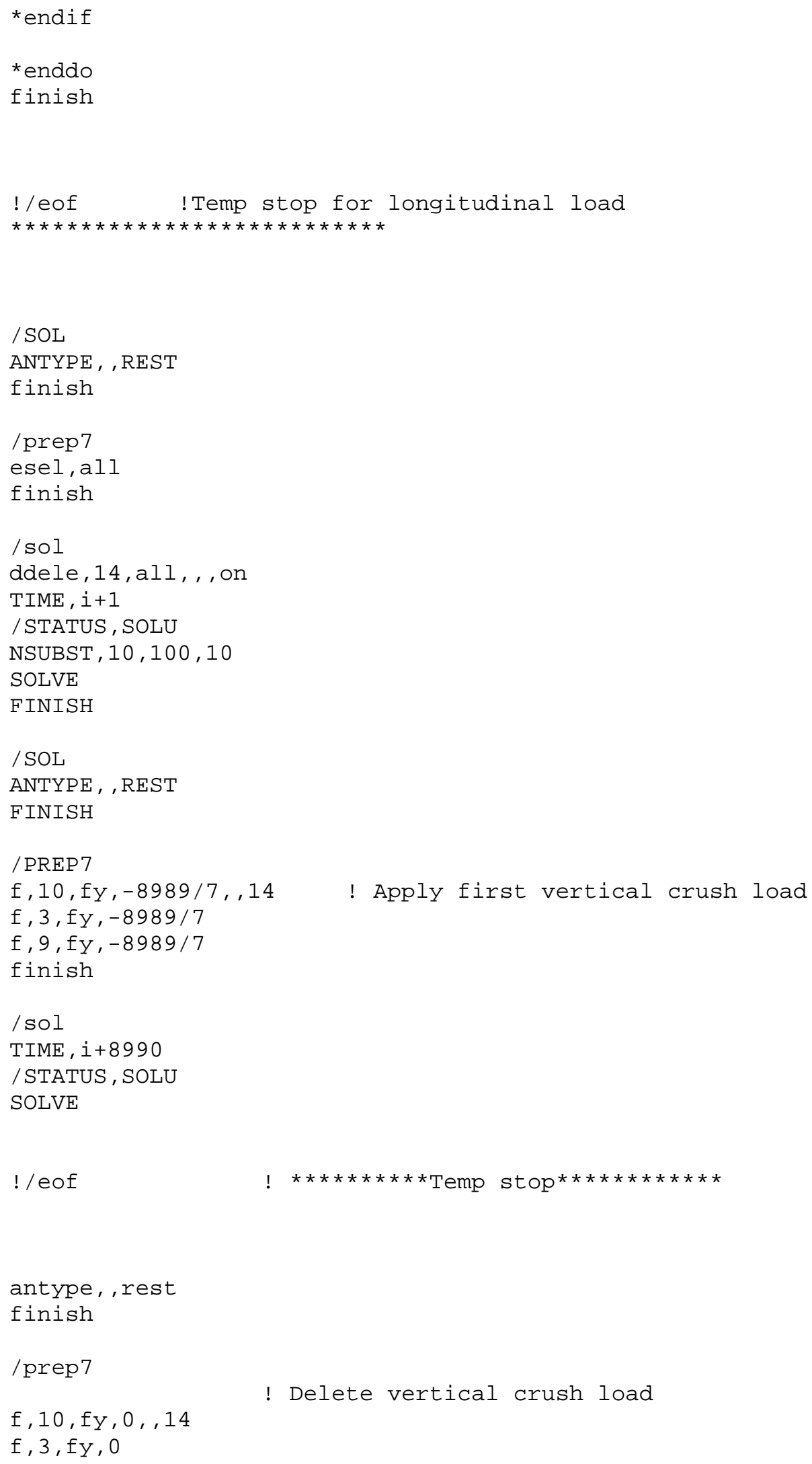




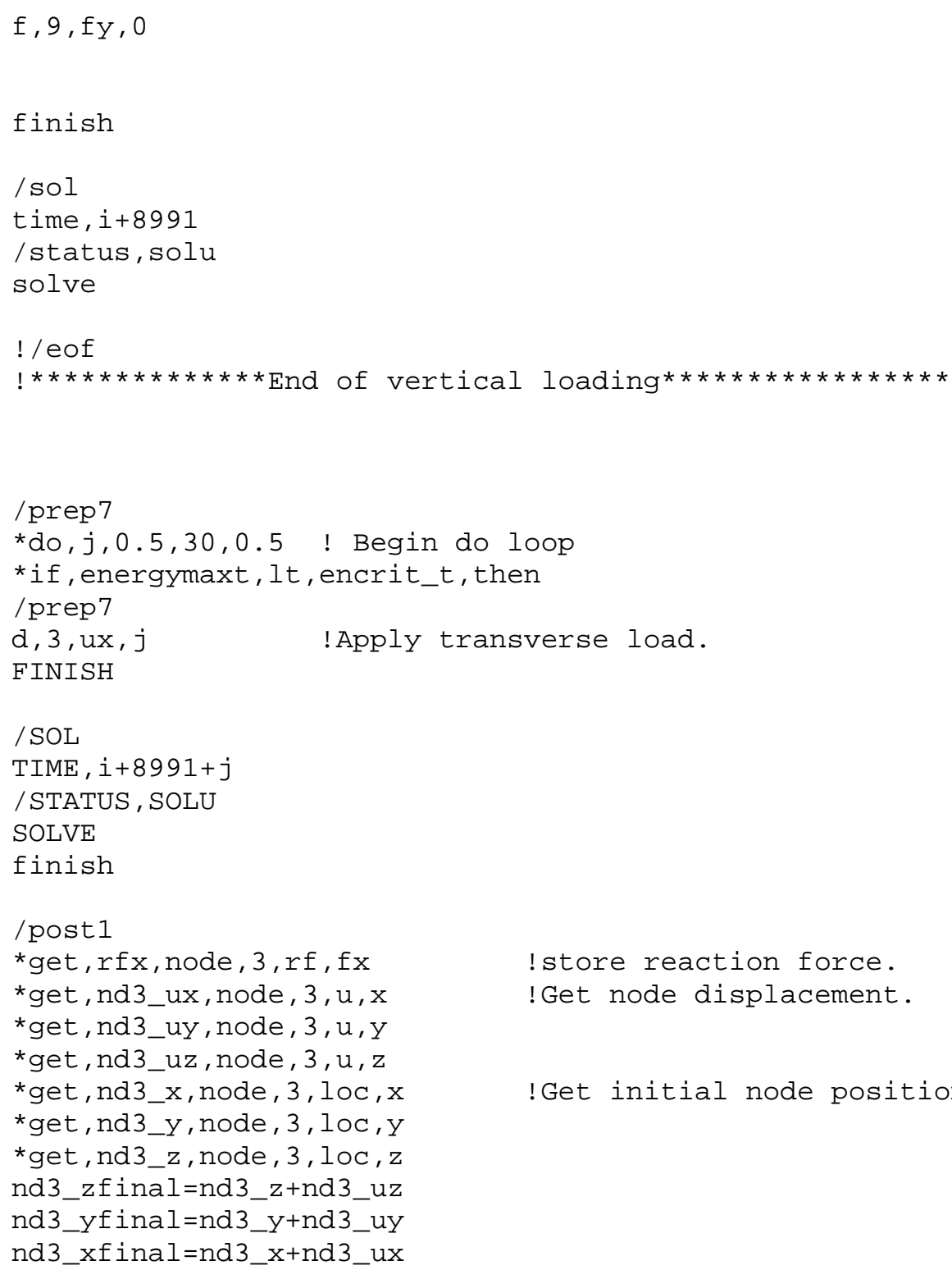




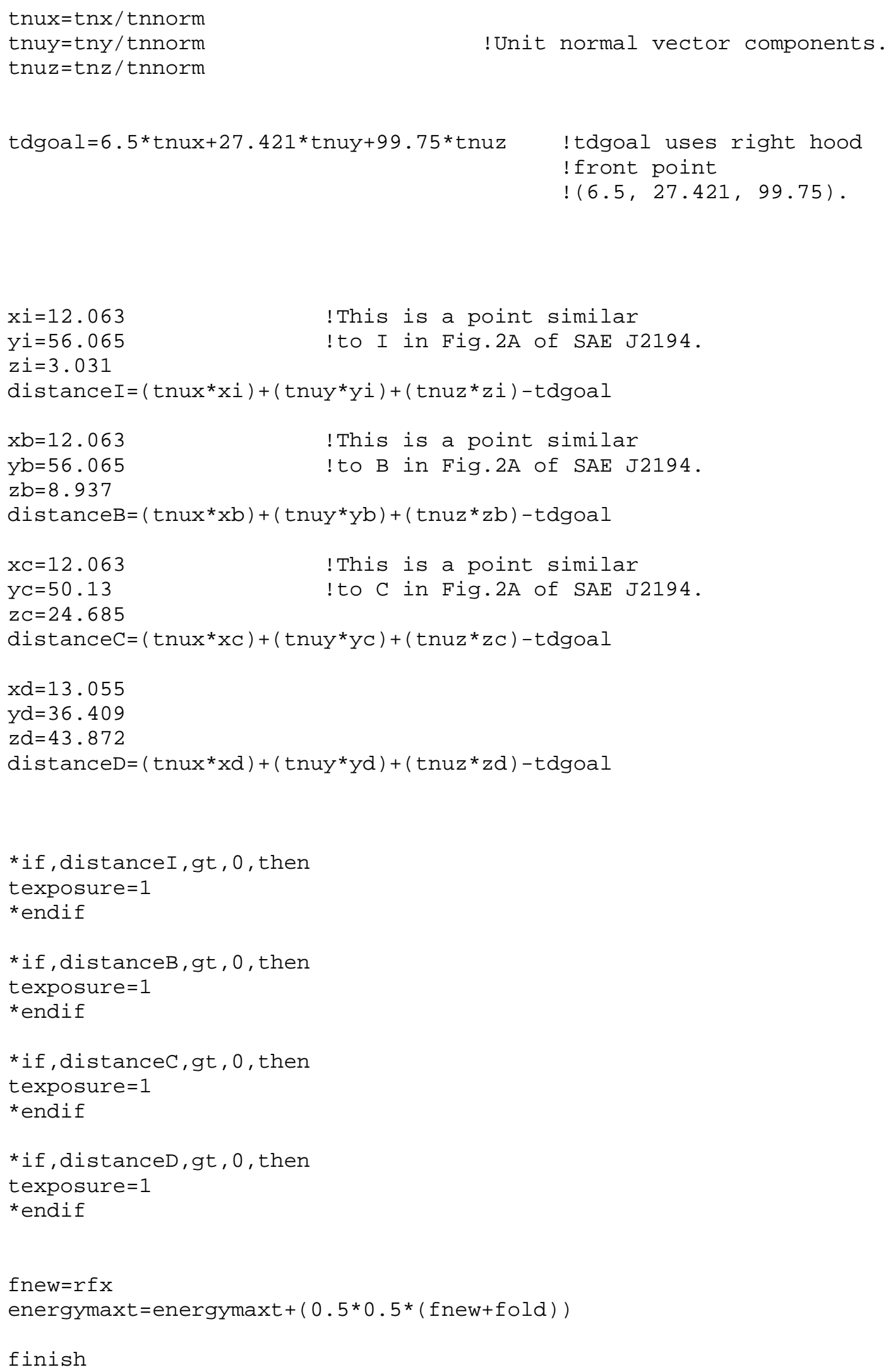




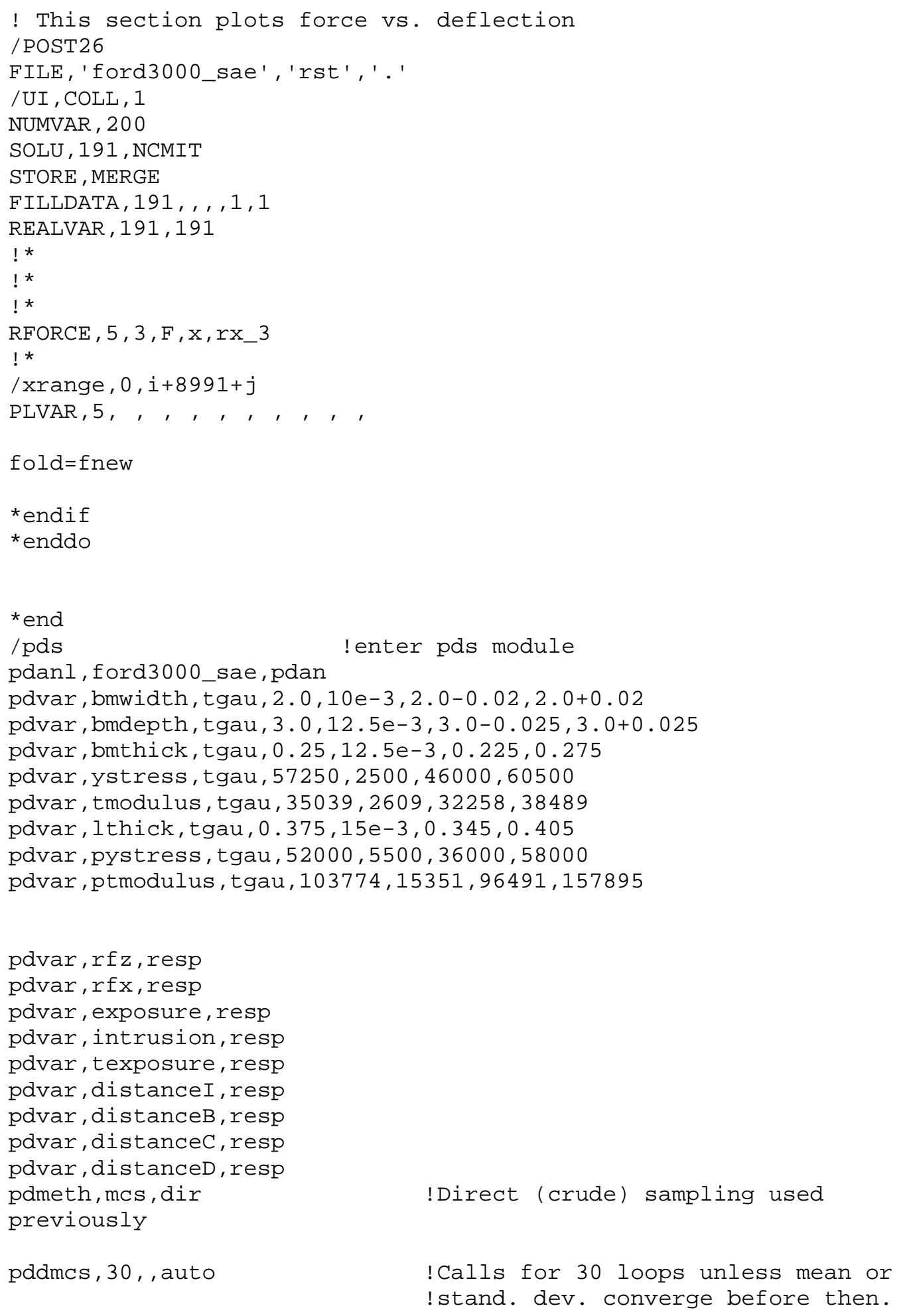




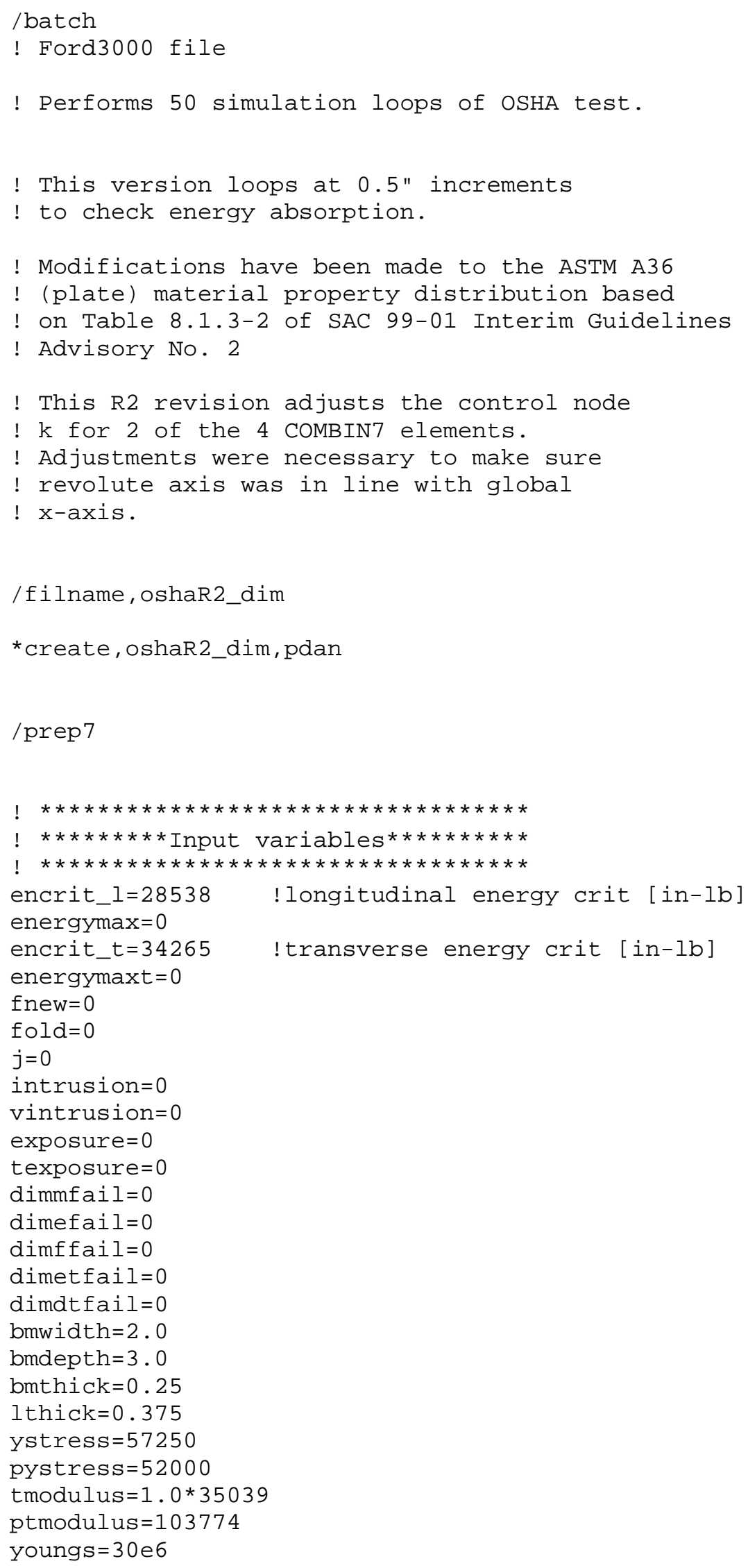




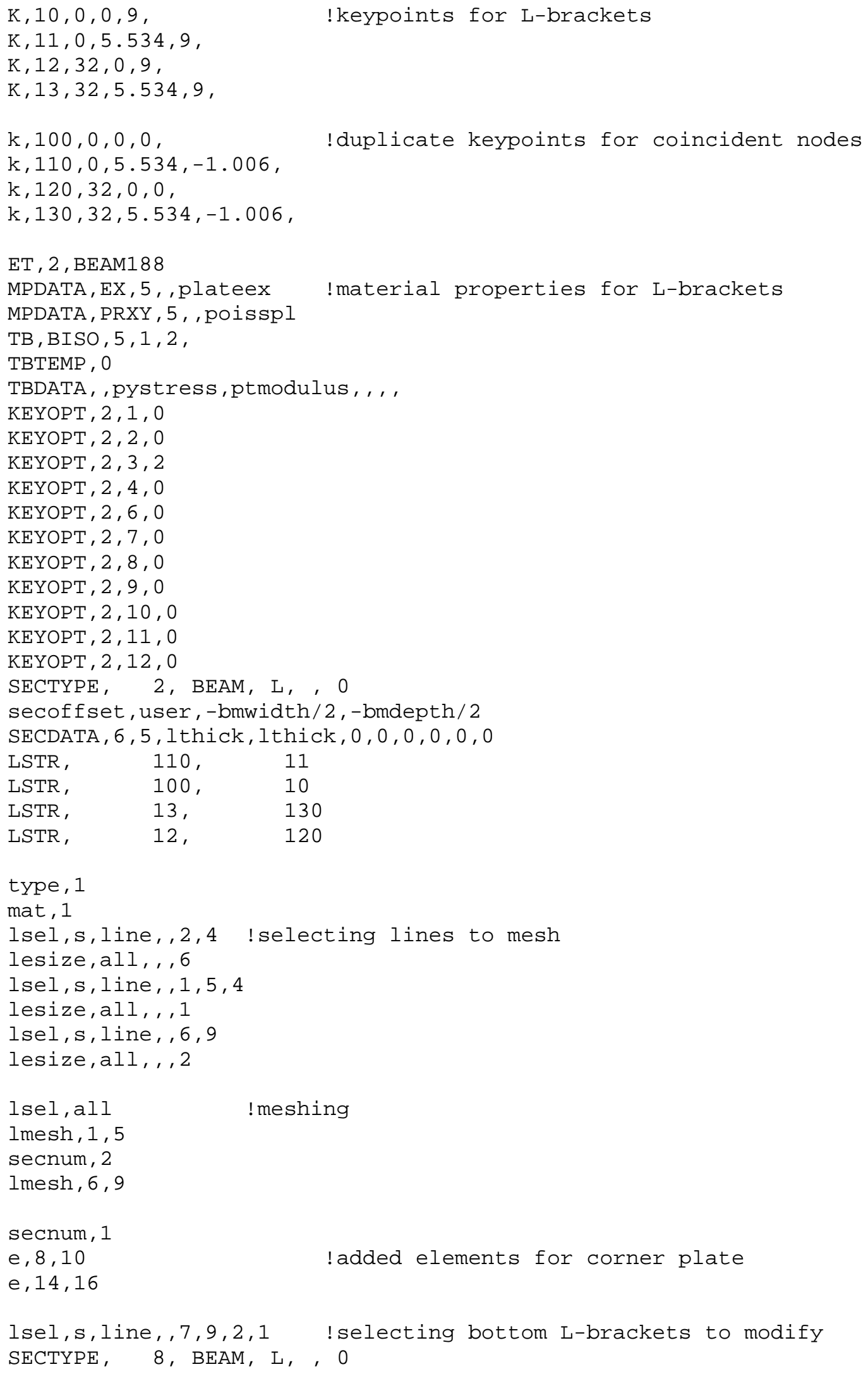




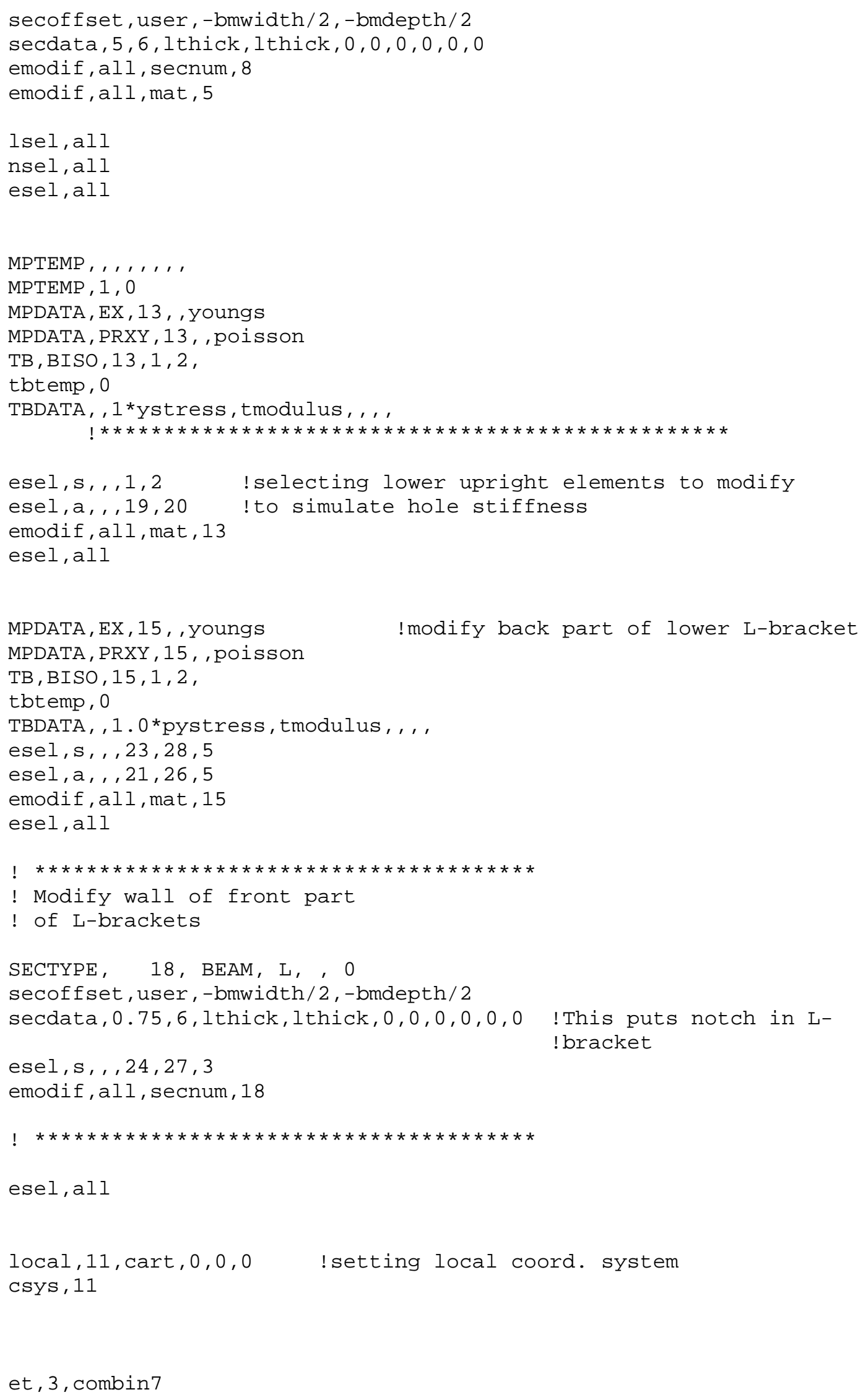




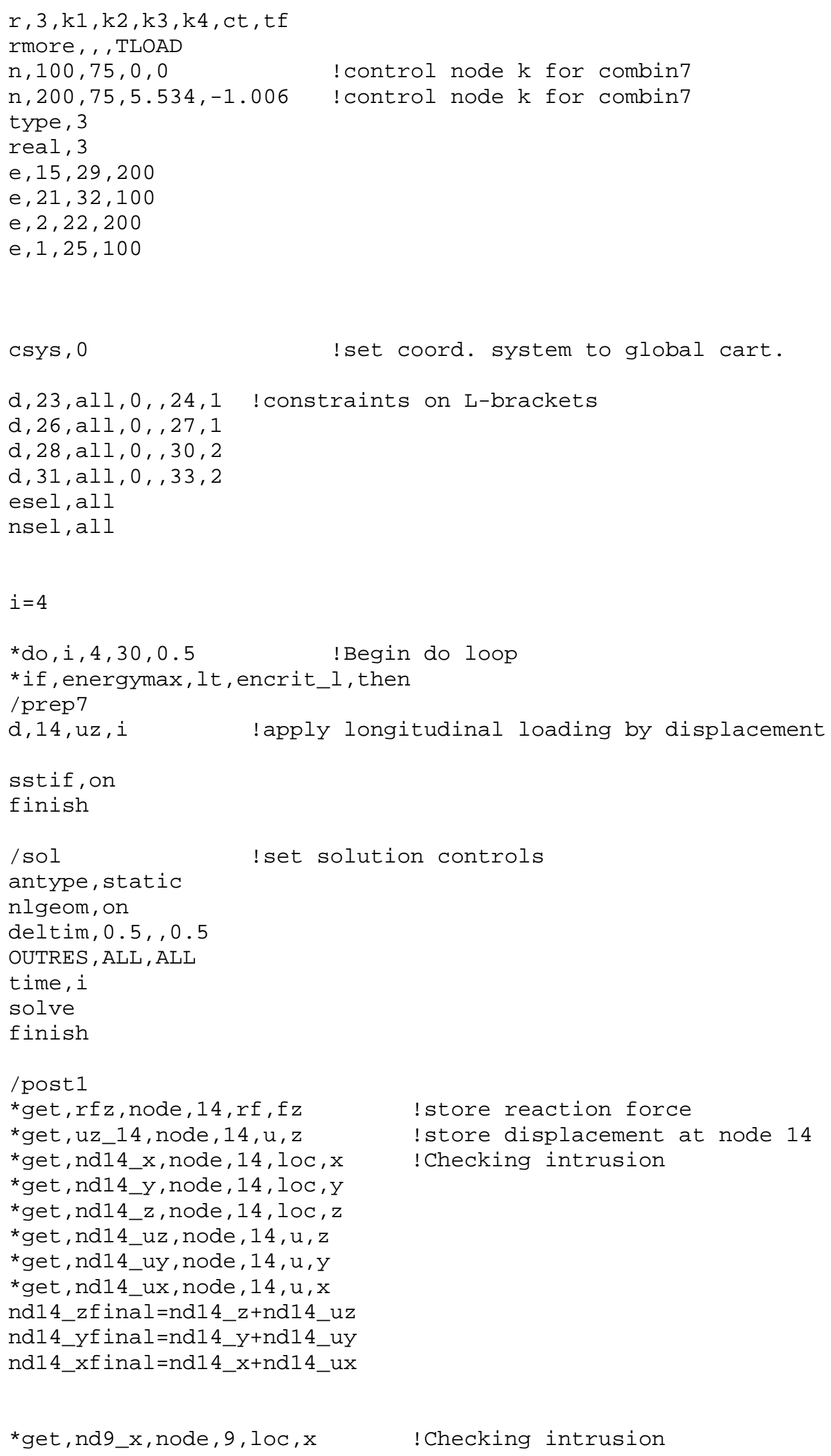




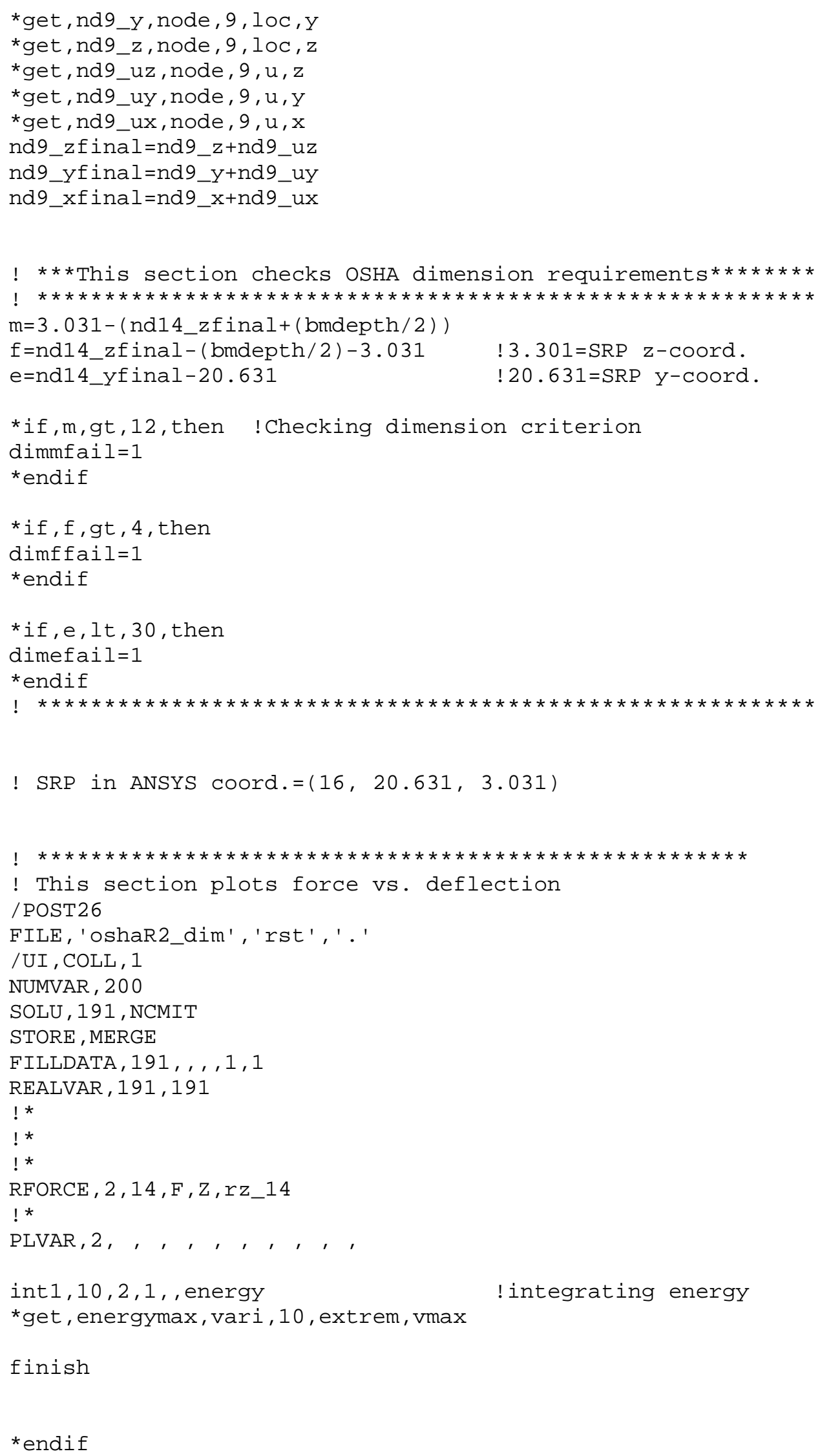


*enddo

finish

!/eof !Temp stop for longitudinal load

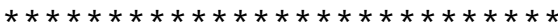

ISOL !Delete longitudinal load

ANTYPE, , REST

finish

/prep7

esel, all

finish

/sol

ddele, 14, all, , on

TIME, $i+1$

/STATUS, SOLU

NSUBST, 10, 100, 10

SOLVE

FINISH

! Transverse load

! $* * * * * * * * * * * * * * * * * * * * * * * * * * * * * * * * * * * * * * * * * * * * *$

/sol

antype, , rest

finish

/prep7

*do, j, $0.5,30,0.5$ ! Begin do loop

*if, energymaxt, lt, encrit_t, then

/prep7

d, 3, ux, j ! Apply transverse load.

FINISH

/SOL

! TIME, $i+8991+j$

time, $i+1+j$

/STATUS, SOLU

deltim, $0.5,0.5$

OUTRES, ALL, ALL

SOLVE

finish

/post1

* get, rfx, node, $3, \mathrm{rf}, \mathrm{fx}$

${ }^{*}$ get, nd3_ux, node, 3, u, x

!store reaction force.

* get, nd3_uy, node, 3, u, y

* get, nd3_uz, node, $3, \mathrm{u}, \mathrm{z}$

* get, nd3_x, node, 3, loc, $x$

! Get node displacement.

!Get initial node position. 


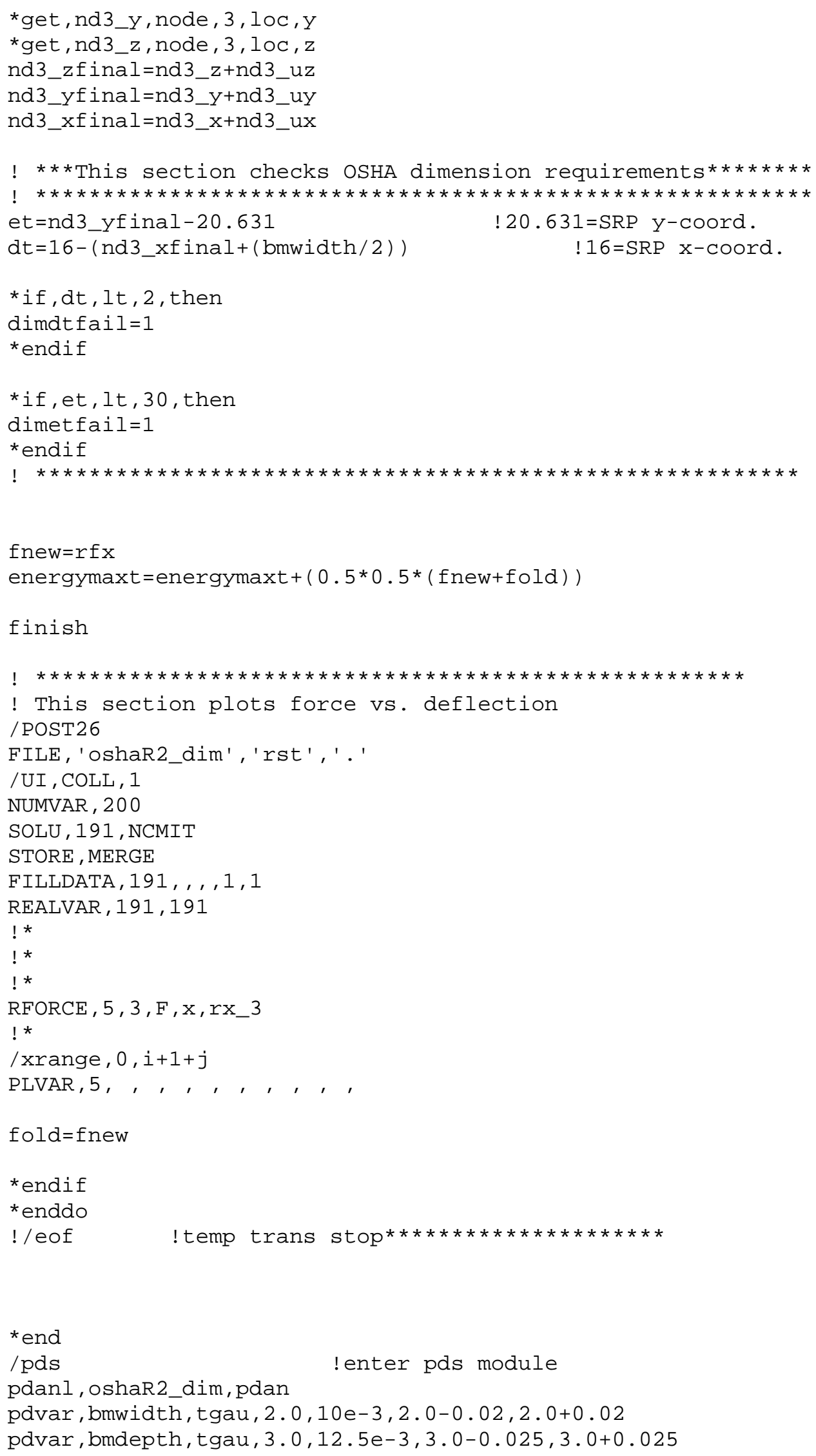


pdvar, bmthick, tgau, $0.25,12.5 e-3,0.225,0.275$

pdvar, ystress, tgau, 57250, 2500, 46000, 60500

pdvar, tmodulus, tgau, 35039, 2609, 32258, 38489

pdvar, lthick, tgau, $0.375,15 \mathrm{e}-3,0.345,0.405$

pdvar, pystress, tgau, $52000,5500,36000,58000$

pdvar, ptmodulus, tgau, 103774, 15351, 96491, 157895

pdvar, rfz, resp

pdvar, rfx, resp

pdvar, exposure, resp

pdvar, intrusion, resp

pdvar, texposure, resp

pdvar, dimmfail, resp

pdvar, dimefail, resp

pdvar, dimffail, resp

pdvar, dimetfail, resp

pdvar, dimdtfail, resp

pdvar, m, resp

pdvar, e, resp

pdvar, f, resp

pdvar, et, resp

pdvar, dt, resp

pdmeth, mcs, dir

!Direct (crude) sampling

pddmcs, 50, , auto

!Calls for 50 loops unless mean or !stand. dev. converge before then

pdexe, , ser , 50, copy, 0SHApts

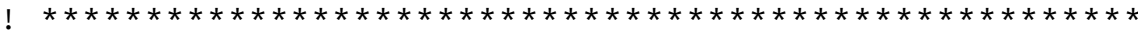

leof ! $* * * * * * * * * * * * * * * * * * * * * * * * * * * * * * * * * * * * * * * * * * * * * * * * * * * * * * * * * * * *$ 


\section{APPENDIX C: Regression Analysis Details for DT Response Surface}




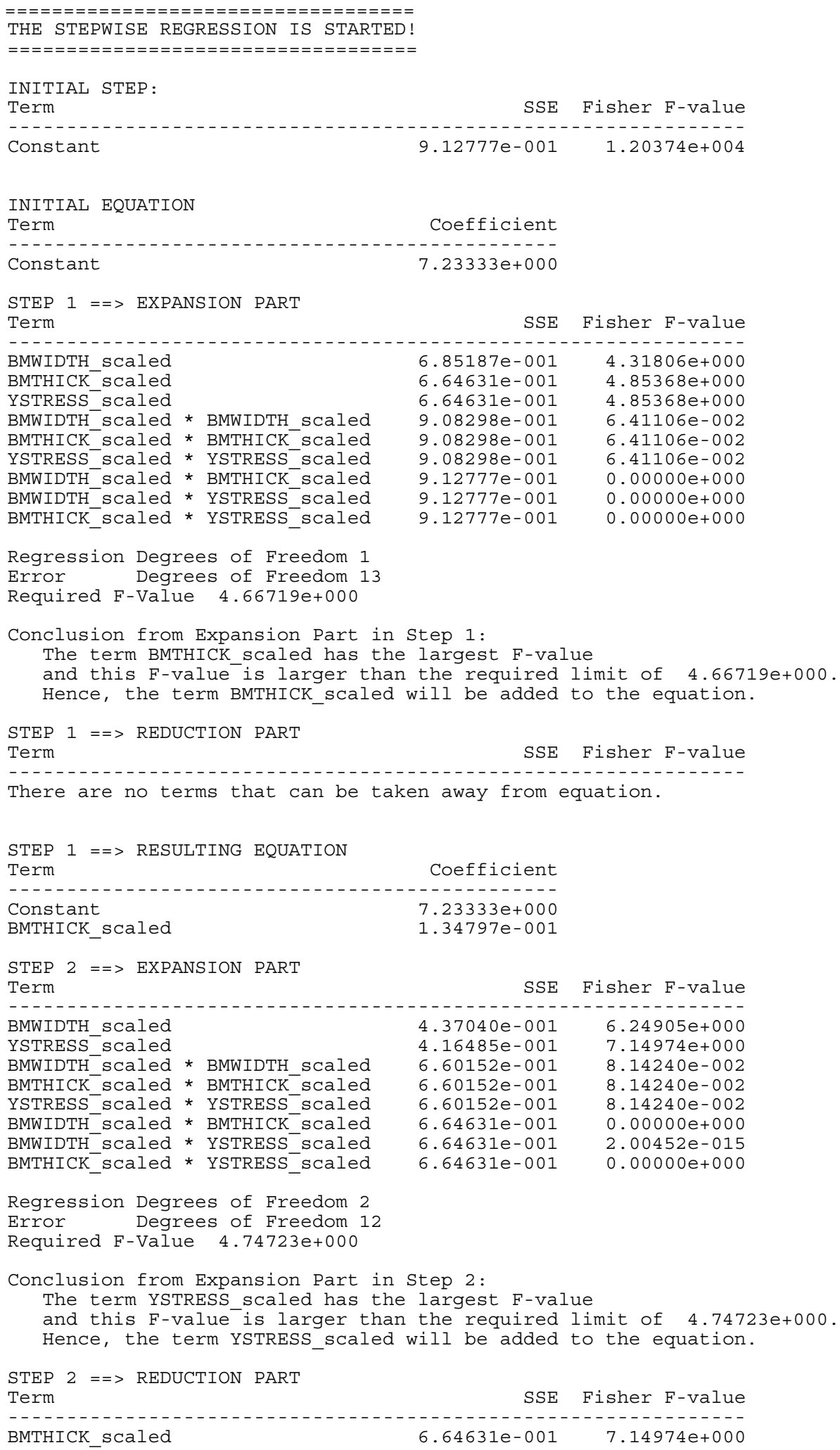




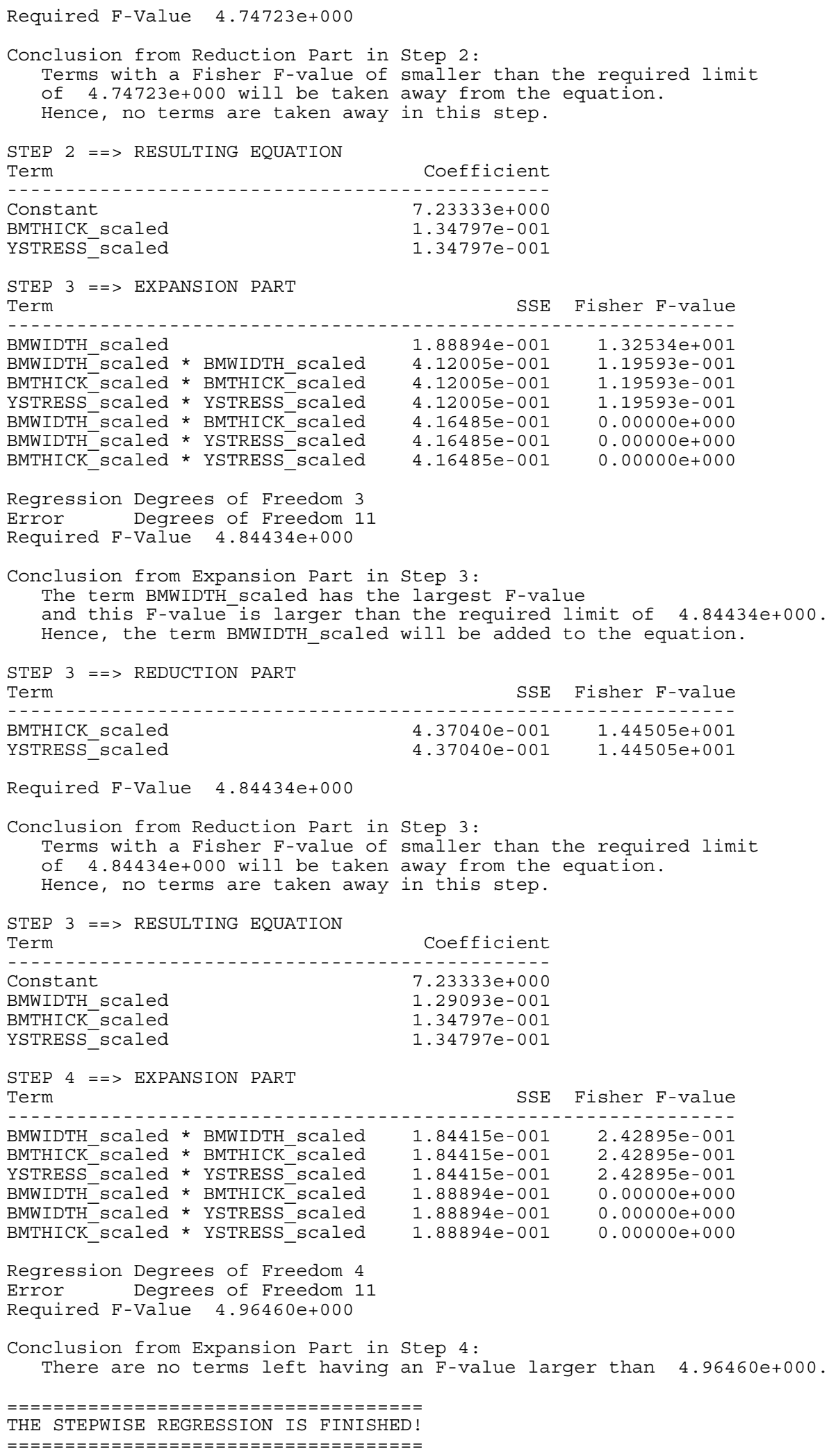




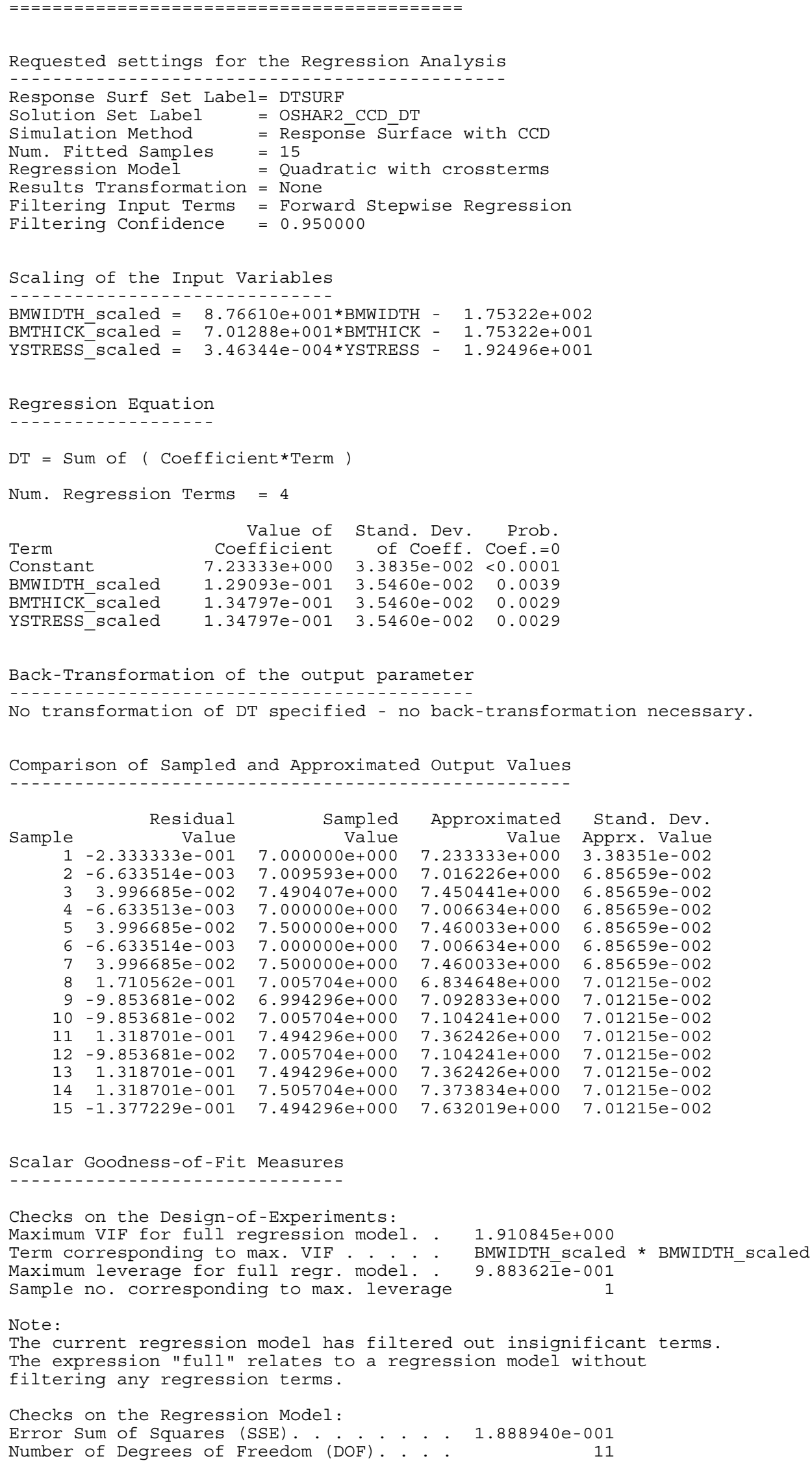


SSE adjusted (SSE over number of DOF's) . 1.717219e-002

Root mean square (sqrt (SSE adjusted)). . 1.310427e-001

Error Variance (SSE-transformed)... . . 1.717219e-002

Coefficient of Determination (R-squared). 7.930557e-001

R-squared adjusted by number of DOF's. 7.366164e-001

Maximum Residual (Absolute) 2.333333e-001

Maximum Residual (Relative)..... . . 3.333333e-002

Maximum studentized residual. . . . . . . . $-1.843086 e+000$

Maximum studentized deleted residual. . . $-2.113743 e+000$

Probability value of max. stud. del. res. 0.06066

Maximum Cook's distance.......... 2.394871e-001

Probability value of max Cook's distance. 0.91011

Anderson-Darling (A.D.) test statistic. . 3.626059e-001

A.D. statistic corrected for normality. . 3.843623e-001

Probability value of A.D. statistic. . . $>0.25000$

t-statistic of constant variance . . - $-2.114010 \mathrm{e}-002$

Probability value of constant variance. 0.98345

Max. probability that regr. coeff. = 0.0. 0.00388 


\section{APPENDIX D: Curriculum Vitae}




\title{
CURRICULUM VITAE
}

\author{
James R. Harris, P.E. \\ Research Safety Engineer \\ Protective Equipment Section \\ Protective Technology Branch \\ Division of Safety Research \\ National Institute for Occupational Safety and Health \\ Morgantown, West Virginia \\ Phone: 304.285 .6120 \\ Fax: 304.285.6047 \\ Email: Jharris@cdc.gov
}

\section{Education:}

B.S. - Mechanical Engineering, West Virginia University, 1993, magna cum laude and Honors Scholar graduate

M.S. - Mechanical Engineering, West Virginia University, 1995

\section{License/Certifications:}

Registered Professional Engineer, \#13749, State of West Virginia, 1998

\section{Work Experience:}

1999-Present, Department of Health and Human Services, PHS, CDC, NIOSH, Division of Safety Research, Protective Technology Branch, Protective Equipment Section

Major project responsibilities and leadership roles:

Commercialization of a Cost-effective ROPS (CROPS) Design, Project Officer. This is a one-year technology transfer project which builds upon previous NIOSH ROPS efforts. Based upon earlier success in demonstrating the technical feasibility of more costeffective ROPS designs, a ROPS manufacturer expressed interest in commercializing our ideas. I proposed the CROPS commercialization project to develop and test designs for additional tractor models. This project has a very strong research to practice ( $\mathrm{r} 2 \mathrm{p}$ ) component and will result in retrofit commercial CROPS designs for five of the most popular non-ROPS tractors. As project officer for this project, I am responsible for managing the project by establishing milestones, developing/tracking budget, and serving as liason with the ROPS manufacturer.

Improved Equipment Design Through Applied Anthropometry, Lead Investigator of Eyewear Study. This is a large, 5-year project which was successfully competed through the rigorous peer-review 
funding process of the National Occupational Research Agenda (NORA). The project is divided into three teams investigating glove, eyewear, and protective tractor equipment design. I conceptualized, developed, proposed, and lead the eyewear study team for this project. I coordinate the activities of this team by establishing project milestones and developing/tracking project budget. Results of this study could affect future versions of the ANSI Z87, protective eyewear, standard as information is shared with this committee via the Eyewear Coverage Taskgroup. In preparation for this project, over 150 papers in the eyewear safety field were reviewed and examined for research gaps. Information from this examination has been provided to interested parties outside of NIOSH and major eyewear manufacturers have sought our expertise in computer-aided analysis of eyewear coverage.

\section{ANSI Z87 Eye and Face Protection Committee, NIOSH Delegate and Member of Eyewear Coverage and Special Editorial}

Taskgroups. This committee is charged with development and maintenance of the ANSI Z87.1 standard, Practice for Occupational and Educational Eye and Face Protection. I was one of only six members of the editorial taskgroup that edited the final version of ANSI Z87.1-200x for committee ballot and subsequent public review. ANSI Z87.1-200x contains substantial changes in impact testing of prescription safety spectacles. I performed a series of tests on multiple fixtures for holding prescription lenses under impact conditions and provided feedback to the ANSI Z87 committee.

\footnotetext{
New Technology to Increase ROPS Use on Tractors, Lead Investigator on Cost-effective Rollover Protective Structure (CROPS) Design Study. This is a four-year project that is divided into four technology-related aspects of increasing ROPS usage on tractors in the United States. I conceptualized, developed, proposed, and now lead the team completing the CROPS Design Study. These leadership duties include establishing the project timeline and milestones as well as tracking project budget. Multiple prototypes have been tested to requirements of the consensus standard for ROPS performance, SAE J2194. Results of this study were presented at a national gathering of farm safety experts in June 2002. In addition I have been asked by other farm safety experts to present a session on tractor stability and rollover hazards to an annual gathering of farmers, researchers, and extension agents from throughout the Ohio Valley. This session will be videotaped for possible re-broadcast to sites nationwide. Follow-up information concerning journal articles I have authored or presentations I have made has been requested from international researchers in India and Italy.
} 
Journal of Agricultural Safety and Health, Associate Editor. As requested by the editor, I coordinate the peer-review process for international manuscripts in my areas of expertise: agricultural safety controls, equipment design, and modeling (finite element analysis).

\section{NIOSH, Division of Safety Research ANSYS Support}

Coordinator. I serve as DSR's in-house finite element analysis (FEA) expert. This includes managing and maintaining DSR's licenses to the FEA package, ANSYS. I provide technical support to those using the finite element analysis (FEA) package and mentor new employees and temporary employees in performing FEA. Scripts and macros I have developed in the ANSYS package over the past nine years continue to be used by others in DSR to facilitate their design work. Results of my FEA work have been presented in both regional and international forums (See presentation list) and published in an FEA trade journal (Analysis Solutions, see publication list).

\section{NIOSH, Division of Safety Research AutoCAD Support}

Coordinator. I serve as DSR's in-house expert for computer-aided design (CAD) using AutoCAD products. I manage and maintain DSR's AutoCAD-related licenses which include AutoCAD, Mechanical Desktop, and Inventor. In addition to developing conceptual drawings and layouts for projects that I am leading, such as the CROPS project, I show other researchers how to implement CAD into his/her project. As an example, I developed a procedure to facilitate data entry and automatic drawing of blind zone spots in AutoCAD for a DSR construction workzone safety project. I have presented some of my work on CAD applications in occupational safety to a national gathering of safety professionals (See presentation list).

\section{National Occupational Research Agenda (NORA) Traumatic} Injury Team. Participation on this team was requested by the team leader based on my experience in applying engineering principles to safety control development for eliminating/minimizing traumatic injury in the workplace. I was an active member of this team which coordinated the national agenda for research in occupational acute traumatic injury.

1995-1999, Department of Health and Human Services, PHS, CDC, NIOSH, Division of Safety Research, Protective Technology Branch, Safety Controls Team

Major project responsibilities and leadership roles:

- $\quad$ Development of an Automatically Deployed ROPS, Coinventor of 
NIOSH AutoROPS (See special achievement list for international patent application information and Alice Hamilton award recognition). Many traditional ROPS are removed from tractors due to overhead clearance issues when operating in orchards or performing work inside of a barn or similar building. The ambitious goal of this project was to develop a ROPS that would normally be in a "lowered" position so as not to pose clearance problems. However, if the tractor began to overturn, the ROPS would automatically deploy to a "raised" position. For this project I developed all conceptual 3-D AutoCAD drawings and provided all FEA of concept performance under load. I served a critical role in conceptualizing and performing initial engineering design and analysis of the structure. This included tasks such as energy transfer analysis during deployment and component sizing for acceptable structural performance under load. Serving as a NIOSH liaison to West Virginia University and guiding the efforts of a graduate student, I completed setup of a ROPS test facility that was used to check performance of the AutoROPS prototype under load. This work included designing and analyzing, via FEA, a test frame to which large ( 20 kip) hydraulic actuators could be attached for SAE J2194 testing. In addition, I developed and customized QuickBASIC computer programs for data acquisition and automated test control of the hydraulic actuators. This test setup has been used multiple times to not only evaluate performance of the NIOSH AutoROPS, but to perform studies on CROPS, new ROPS materials, and traditional ROPS. Results of this work have been presented at national gatherings of the American Society of Agricultural Engineers (See publication list). Information requests on this novel research have been received from multiple foreign countries.

\section{Development of an Automatically Deployed ROPS Overturn}

Sensor. In this project, executed concurrently with the AutoROPS structure project, the sensor was developed which detected a tractor overturn and sent an electrical signal to the AutoROPS structure release mechanism. I mentored another engineer as he adapted earlier FEA scripts I had developed to investigate both the dynamics of both rear and side tractor overturns. I developed additional scripts to automate evaluation of candidate sensor algorithms. These scripts would evaluate whether the sensor algorithm being investigated would work under a variety of tractor speeds and rollover conditions. Designed for efficiency, the FEA scripts would analyze multiple rollover scenarios overnight and summarize the results in simple text files that identified rollover conditions for which the algorithm succeeded or failed. These results were used in determining initial sensor settings before field tests were conducted. During field tests of the complete AutoROPS system, the structure always deployed and provided protection during the rollover event. Due to the potential 
positive impact of the AutoROPS system in preventing future rollover fatalities, this work was recognized with an Alice Hamilton award.

1993-1995, HGO Technology, Inc.

Major project responsibilities:

- Human modeling, CAD integration, and FEA support. I incorporated human modeling and computer-aided design (CAD) software for senior researchers to perform ergonomic evaluations of work environments. Ergonomic simulation work was included in Health Hazard Evaluation HETA 93-0531-2410. In addition, I researched design alternatives and performed preliminary engineering calculations (both traditional and FEA) supporting initial AutoROPS design work.

\section{Research Interests:}

Engineering Controls, Personal Protective Equipment, Incorporating FEA and CAD into Engineering Control Design, Safety Eyewear Performance, Agricultural Safety, Technology Transfer

\section{Memberships:}

American Society of Mechanical Engineers, American Society of Safety Engineers, NIOSH Community Interaction Committee (CIC)

\section{Additional training:}

Ph.D. level coursework: I have completed all coursework towards a Ph.D. in Occupational Safety and Health.

Other: Project Management, Jump-starting High Performing Teams, TQM Team Leader, Project Officer Training, Leadership Skills for NonSupervisors, MS Project 2000, Scientific Ethics, AutoCAD 2000, ANSYS Dynamics

\section{Special Achievements:}

- 2005 Bullard-Sherwood Award for Research2Practice - Honorable Mention, ROPS Technology Transfer Team.

- $\quad$ The Federal Laboratory Consortium Southeast Region, Honorable Mention for Excellence in Technology Transfer, Automatically Deploying Roll-over Protection System (AutoROPS), January 15, 2003.

- 2002 Alice Hamilton Award - Honorable Mention, Engineering \& Physical Sciences Category for paper: Powers JR, Harris JR, Etherton JR, Snyder KA, Ronaghi M, Newbraugh BH. Performance of an automatically deployable ROPS on ASAE tests. Journal of Agricultural Safety and Health 2001;7(1):51-61. 
- $\quad$ CDC Invention Award (April 2001) for Snyder KA, Etherton JR, Harris JR, Powers JR, Ronaghi M, Cutlip RG, Means KH, McKenzie EA, Current RS, inventors; U.S. Government, assignee. Automatically Deploying Roll Over Protective System (AutoROPS). US Patent Cooperation Treaty (PCT) PCT/US01/20282, 2001 June 24.

\section{Publications:}

1. Ronaghi M, Wu JZ, Pan CS, Harris JR, Welcome DE, Chiou SS, Boehler B, Dong RG. Modeling of the static stability of a scissor-lift. [submitted].

2. Harris JR, Struttmann T, Merinar TR. Investigation and implications of a compactor fatality. Proceedings of the 2005 International Mechanical Engineering Congress and Exposition; 2005 November 5-11; Orlando, FL paper \# IMECE2005-80005.

3. McKenzie, Jr. EA, Etherton JR, Harris JR, Cantis DM, Lutz TJ. NIOSH AutoROPS research to practice: Zero turn commercial mowers. Proceedings of the 2005 International Mechanical Engineering Congress and Exposition; 2005 November 5-11; Orlando, FL paper \# IMECE2005-81575.

4. Harris JR, Cantis DM, McKenzie EA, Jr., Etherton JR, Ronaghi M. Commercialization of Cost-Effective rollover protective structures (CROPS). Proceedings of the National Institute for Farm Safety (NIFS) Annual Conference; 2005 June 26-30; Wintergreen, Virginia.

5. McKenzie, Jr. EA, Etherton JR, Harris JR, Cantis DM, Lutz TJ. NIOSH AutoROPS $3^{\text {rd }}$ generation static testing and human interaction element. Proceedings of the 2003 International Mechanical Engineering Congress and Exposition; 2003 November 15-21; Washington, D.C. paper \# IMECE200341330.

6. Harris JR, Whisler R, Ammons DE, Spahr JS, Jackson LL. Assessing PPE protection - Development of a safety eyewear coverage coefficient.

Proceedings of the NORA Symposium 2003; 2003 June 23-25; Washington, D.C. p. 105 (abstract).

7. Harris JR, McKenzie, Jr. EA, Etherton JR, Cantis DM. Designing costeffective rollover protective structures (CROPS) at NIOSH. Proceedings of the National Institute for Farm Safety (NIFS) Annual Conference; 2002 June 23-27; Ponte Vedra, Florida.

8. Etherton JR, Cutlip RG, Harris JR, Ronaghi M, Means KH, Howard S. Dynamic performance of the mechanism of an automatically deployable ROPS. Journal of Agricultural Safety and Health 2002;8(1):113-118. 
9. Etherton JR, Cutlip RG, Harris JR, Ronaghi M, Means KH, Gillispie A. Static load test performance of a telescoping structure for an automatically deployable ROPS. Journal of Agricultural Safety and Health 2002;8(1):119126.

10. Powers JR, Harris JR, Etherton JR, Ronaghi M, Snyder KA, Lutz TJ, Newbraugh BH. Preventing tractor rollover fatalities: performance of the NIOSH AutoROPS. Injury Prevention 2001; 7(Suppl):i54-58.

11. Powers JR, Harris JR, Etherton JR, Snyder KA, Ronaghi M, Newbraugh BH. Performance of an automatically deployable ROPS on ASAE tests. Journal of Agricultural Safety and Health 2001;7(1):51-61.

12. McKenzie E, Powers J, Harris J, Ronaghi M, Etherton J, Current R, Cantis D, Newbraugh B, Lutz T. Continuing developments at NIOSH on ROPS for agricultural tractors. Proceedings of the National Institute for Farm Safety Annual Conference; 2001 June 24-27; Pittsburgh, Pennsylvania.

13. Snyder KA, Etherton JR, Harris JR, Powers JR, Ronaghi M, Cutlip RG, Means KH, McKenzie EA, Current RS, inventors; U.S. Government, assignee. Automatically Deploying Roll Over Protective System (AutoROPS). US Patent Cooperation Treaty (PCT) PCT/US01/20282, 2001 June 24.

14. Harris JR, Mucino VH, Etherton JR, Snyder KA, Means KH. Finite element modeling of ROPS in static testing and rear overturns. Journal of Agricultural Safety and Health 2000;6(3):215-225.

15. Powers JR, Harris JR, Snyder KA, Ronaghi M, Etherton JR, Newbraugh BH. Performance of the NIOSH AutoROPS. National Occupational Injury Research Symposium (NOIRS) 2000; 2000 Oct 17-19; Pittsburgh, Pennsylvania.. p.12 (abstract)

16. Ronaghi M, Harris JR, Powers JR, Snyder KA. Dynamic nonlinear analysis of tractor rollovers. Proceedings of the $9^{\text {th }}$ International ANSYS Conference and Exhibition; 2000 Aug 28-30; Pittsburgh, Pennsylvania.

17. Powers JR, Harris JR, Snyder KA, Ronaghi M, Etherton JR, Newbraugh BH. Performance of a new ROPS on ASAE tests. Proceedings of the $93^{\text {rd }}$ Annual International Meeting of ASAE; 2000 Jul 9-12; Milwaukee, Wisconsin. Paper No. 007005 .

18. Harris JR, Ronaghi M, Snyder KA. Analyzing tractor rollovers using finite element modeling. Analysis Solutions 1998;2(4):24-25. 
19. Etherton JR, Moore P, Harris JR, Zeng S. Safety factors relating to monitored compactor operating parameters. In: Pyatt D, editor. SERA-Vol. 8, Safety Engineering and Risk Analysis - 1998. Proceedings of the ASME Mechanical Engineering Conference and Exposition; 1998 Nov; Anaheim, California. New York: ASME; 1998. p. 49-56.

20. Etherton JR, Harris JR, Ronaghi M. A task-risk approach to selecting a mechanical safeguard design. Proceedings of 1998 System Safety Society Annual Meeting; 1998 Sept; Seattle, Washington. Unionville, VA: SSS; 1998.

21. Harris JR, Mucino V, Etherton JR, Snyder KA, Means KH. Computer simulation of ROPS testing in ASAE S519. National Occupational Injury Research Symposium (NOIRS) 1997; 1997 Oct 15-17; Morgantown, West Virginia. p. 46 (abstract).

22. Etherton JR, Moore P, Harris JR, Zeng S. Factors limiting the use of frame deflection monitoring to predict material jams in baling equipment. National Occupational Injury Research Symposium (NOIRS) 1997; 1997 Oct 15-17; Morgantown, West Virginia. p. 60 (abstract).

23. Harris JR, Ronaghi M, Dotson B. Computer-assisted research for occupational safety. Proceedings of the Computer Applications for the Safety Professional Symposium (sponsored by American Society of Safety Engineers); 1997 June 16; New Orleans, Louisiana. p. 110-115.

24. Harris JR, Ronaghi M. ANSYS applications in agricultural safety research at NIOSH, Division of Safety Research. Proceedings of ANSYS User's Group Conference; 1997 May 13; Research Triangle Park, North Carolina.

25. Harris JR. Finite element modeling of rollover protective structures for analysis of standard ASAE S519 [thesis]. Morgantown (WV): West Virginia Univ.; 1995.

26. Harris JR, Mucino V, Snyder KA, Etherton JR. Computer-assisted analysis of ROPS performance standard ASAE S519. ASME $3^{\text {rd }}$ Annual Great Lakes Region V - Graduate Student Technical Conference; 1995 March 30-April 1; Kalamazoo, Michigan. p. 24-25 (abstract).

\section{Presentations:}

1. Harris JR, Struttmann T, Merinar TR. Investigation and implications of a compactor fatality. Proceedings of the 2005 International Mechanical Engineering Congress and Exposition; 2005 November 5-11; Orlando, FL paper \# IMECE2005-80005. 
2. Harris JR, Whisler R, Ammons DE, Spahr JS, Jackson LL. PPE design: A new technique for assessing safety eyewear coverage with international results. XVIIth World Congress on Safety and Health at Work; 2005 Sept 1822; Orlando, Florida.

3. Harris JR, Cantis DM, McKenzie EA, Jr., Etherton JR, Ronaghi M. Commercialization of cost-effective rollover protective structures (CROPS). National Institute for Farm Safety (NIFS) Annual Conference; 2005 June 2630; Wintergreen, Virginia.

4. Harris JR, Etherton JR, Cantis DM, McKenzie EA, Ronaghi M. Tractor overturns and ROPS performance - Is the SAE standard tough enough? 2004 National Symposium on Agricultural Health and Safety; 2004 June 20-24; Keystone Resort, Colorado.

5. Harris JR, McKenzie EA, Cantis DM, Etherton JR, Ronaghi M. Technology transfer - Putting cost-effective rollover protective structures in the field Poster. 2004 National Symposium on Agricultural Health and Safety; 2004 June 20-24; Keystone Resort, Colorado.

6. Harris JR, Linn HI. NORA Traumatic Injury Team. Safety 2004 (ASSE Professional Development Conference and Exposition); 2004 June 7-10; Las Vegas, NV.

7. Harris JR, Whisler R, Ammons DE, Spahr JS, Jackson LL. Assessing PPE protection - Development of a safety eyewear coverage coefficient. NORA Symposium 2003; 2003 June 23-25; Washington, D.C.

8. Etherton JR, Harris JR. New technology to increase ROPS use on tractors. NIOSH Agricultural Centers Tractor-related Injury and Death Workshop; 2003 February 13-14; Pittsburgh, Pennsylvania.

9. Harris JR. Making research real - ROPS research and why you need a rollbar. Farm Safety Day - The Ohio State University; 2002 November 20; Columbus, Ohio.

10. Harris JR, McKenzie, Jr. EA, Etherton JR, Cantis DM. Designing Costeffective Rollover Protective Structures (CROPS) at NIOSH. National Institute for Farm Safety (NIFS) 2002 Annual Meeting; 2002 June 23-27; Ponte Vedra, Florida.

11. Powers JR, Etherton JR, Harris JR, Ronaghi M, Lutz TJ. The NIOSH AutoROPS for farm tractors: a new technology that increases ROPS usability. NORA Symposium 2001; 2001 June 27; Washington, D.C. (poster) 
12. Ronaghi M, Harris JR, Powers JR, Snyder KA. Dynamic nonlinear analysis of tractor rollovers. Proceedings of the $9^{\text {th }}$ International ANSYS Conference and Exhibition; 2000 Aug 28-30; Pittsburgh, Pennsylvania.

13. Powers JR, Harris JR, Snyder KA, Ronaghi M, Etherton JR, Newbraugh BH. Performance of a new ROPS on ASAE tests. Proceedings of the $93^{\text {rd }}$ Annual International Meeting of ASAE, Paper No. 007005; 2000 July 9-12; Milwaukee, Wisconsin.

14. Harris JR, Mucino V, Etherton JR, Snyder KA, Means KH. Computer simulation of ROPS testing in ASAE S519. National Occupational Injury Research Symposium (NOIRS) 1997; 1997 Oct 15-17; Morgantown, West Virginia.

15. Harris JR, Ronaghi M, Dotson B. Areas of computer-assisted research at NIOSH, Division of Safety Research. ASSE Computer Applications for the Safety Professional Symposium; 1997 June 16; New Orleans, Louisiana.

16. Harris JR, Ronaghi M. ANSYS applications in agricultural safety research at NIOSH, Division of Safety Research. ANSYS User's Group Conference; 1997 May 13; Research Triangle Park, North Carolina.

17. Harris JR, Mucino V, Snyder KA, Etherton JR. Computer-assisted analysis of ROPS performance standard ASAE S519. ASME $3^{\text {rd }}$ Annual Great Lakes Region V - Graduate Student Technical Conference; 1995 March 30-April 1; Kalamazoo, Michigan. 